NBER WORKING PAPER SERIES

\title{
IS THE INTERNATIONAL DIVERSIFICATION POTENTIAL DIMINISHING? FOREIGN EQUITY INSIDE AND OUTSIDE THE US
}

\author{
Karen K. Lewis \\ Working Paper 12697 \\ http://www.nber.org/papers/w12697 \\ NATIONAL BUREAU OF ECONOMIC RESEARCH \\ 1050 Massachusetts Avenue \\ Cambridge, MA 02138 \\ November 2006
}

Wharton School, University of Pennsylvania and NBER. For comments and suggestions, I thank Geert Bekaert, Bernard Dumas, Vihang Errunza, Andrew Karolyi, Magnus Dahlquist, Gangadhar Darbha, Craig MacKinlay, Paolo Soderlind, Jessica Wachter, Frank Warnock, Amir Yaron, and seminar participants at the Wharton Micro-Lunch seminar, the Swedish Institute for Financial Research, and the Kansas City Federal Reserve. I acknowledge funding from the National Science Foundation with thanks. Any errors are my responsibility. The views expressed herein are those of the author(s) and do not necessarily reflect the views of the National Bureau of Economic Research.

(C) 2006 by Karen K. Lewis. All rights reserved. Short sections of text, not to exceed two paragraphs, may be quoted without explicit permission provided that full credit, including $\odot$ notice, is given to the source. 
Is the International Diversification Potential Diminishing? Foreign Equity Inside and Outside the US

Karen K. Lewis

NBER Working Paper No. 12697

November 2006

JEL No. F3,F4,G11,G15

\begin{abstract}
Over the past two decades international markets have become more open, leading to a common perception that global capital markets have become more integrated. In this paper, I ask what this integration and its resulting higher correlation would imply about the diversification potential across countries.

For this purpose, I examine two basic groups of international returns: (1) foreign market indices and (2) foreign stocks that are listed and traded in the US. I examine the first group since this is the standard approach in the international diversification literature, while I study the second group since some have argued that US-listed foreign stocks are the more natural diversification vehicle (Errunza et al (1999)). In order to consider the possibility of shifts in the covariance of returns over time, I extend the break-date estimation approach of Bai and Perron (1998) to test for and estimate possible break dates across returns along with their confidence intervals. I find that the covariances among country stock markets have indeed shifted over time for a majority of the countries. But in contrast to the common perception that markets have become significantly more integrated over time, the covariance between foreign markets and the US market have increased only slightly from the beginning to the end of the last twenty years. At the same time, the foreign stocks in the US markets have become significantly more correlated with the US market. To consider the economic significance of these parameter changes, I use the estimates to examine the implications for a simple portfolio decision model in which a US investor could choose between US and foreign portfolios. When restricted to holding foreign assets in the form of market indices, I find that the optimal allocation in foreign market indices actually increases over time. However, the optimal allocation into foreign stocks decreases when the investor is allowed to hold foreign stocks that are traded in the US. Also, the minimum variance attainable by the foreign portfolios has increased over time. These results suggest that the benefits to diversification have declined both for stocks inside and outside the US.
\end{abstract}

Karen K. Lewis

University of Pennsylvania

Department of Finance, Wharton School

$2300 \mathrm{SHDH}$

Philadelphia, PA 19104-6367

and NBER

lewisk@wharton.upenn.edu 
One of the most enduring puzzles in international macroeconomics and finance is the tendency for investors to disproportionately weight their asset portfolios towards domestic securities and thereby forego gains to international diversification. The puzzle in international macroeconomics has focused upon the tendency for consumers to be underinsured against aggregate shocks that could otherwise have been hedged by holding foreign assets. ${ }^{1}$ In the financial economics literature, the puzzle has been based upon the observation that investor portfolios hold less foreign securities than implied by predictions of standard mean-variance optimization principles. ${ }^{2}$ In both the macroeconomics and financial economics frameworks, the underlying source of diversification arises from the relatively low correlation in asset returns across countries. ${ }^{3}$

A number of explanations have been proposed to explain this phenomenon, including the transactions costs of acquiring and/or holding foreign assets. The transactions may be in the form of outright brokerage type costs or more subtle information costs. ${ }^{4}$ On the other hand, critics have argued that transactions costs cannot be very high for stocks of foreign companies that trade in the United States on exchanges. ${ }^{5}$ Furthermore, Errunza et al (1999) argue that domestically traded stocks can span the risks of foreign markets. These stocks are no more expensive to acquire than domestic stocks. The foreign stocks traded on the New York Stock Exchange (NYSE) must also go through the same disclosure requirements as domestic companies, including provision of the US-based accounting and financial statements. It therefore seems unlikely that the information costs are significantly higher for these stocks. If so, domestic investors need not go to foreign capital markets to diversify internationally and they may do so with essentially no difference in costs.

These international gains from diversification depend critically on low correlations between foreign and domestic stock returns. The growing impression in recent years, however, is that the returns from international securities have become more correlated over time due to a general integration of markets. If true, the rising international correlations would suggest that gains from diversification have declined. This raises the question: Do the international diversification opportunities remain in this new integrated financial environment?

\footnotetext{
${ }^{1}$ See for example Backus, Kehoe and Kydland (1991), Baxter and Crucini (1995), Cole and Obstfeld (1991), Stockman and Tesar (1995), and Pesenti and van Wincoop (2002).

${ }^{2}$ See for example the frameworks in French and Poterba (1991) and Pastor (2000).

${ }^{3}$ Lewis (1999) describes the relationship between these two approaches in the context of domestic investor's diversification into foreign assets.

4 See Gehrig (1993).

5 Tesar and Werner (1995) also show that the aggregate turnover of foreign stocks is higher than domestic stocks, suggesting that the transactions costs for purchasing and selling foreign stocks are not higher than domestic stocks.
} 
This paper re-examines the asset pricing relationships upon which the diversification argument rests and asks what the potentially changing nature of these relationships say about diversifying into foreign markets. I begin by examining the standard foreign market diversification relationship in foreign market indices. I then study the set of foreign companies traded in the United States. For both sets of foreign returns, I allow for the possibility that the relationship between US and foreign markets have changed over time. I then analyze the effects of potential asset pricing changes in aggregates and cross-listed firms to consider the implications for home bias.

An extensive literature has analyzed international asset pricing relationships, including the possibility that those relationships have changed over time. Papers investigating the potential for changing asset pricing relationships have generally either put structure on the dynamic process for parameters or the dates at which relationships are presumed to change. ${ }^{6}$ Of course, these approaches are entirely appropriate for the purposes of estimating parameters given a dynamic adjustment process as in the former case, or testing for changes in parameters conditioned on dates as in the latter case.

My goal in this paper is different, however. I intend to provide a longitudinal picture of basic international equity returns over time, for individual stocks as well as market indices, from the perspective of a US investor. For this purpose, I need an approach that will minimize the structure on the dynamic process of changing parameters and of their potential change dates. By doing so, the resulting estimated processes may be stable or they may change over time in a minimally parameterized manner. Moreover, no a priori information about change dates is imposed.

To achieve this goal, I estimate a standard factor model for each foreign equity return together with the US market and then test for shifts in the relationship. In practice, tests for structural breaks pick up parameter shifts that can be either discrete or time-varying with variation changes that are sufficiently significant. ${ }^{7}$ To test for when these parameter distribution shifts occur, I use the endogenous break point estimation approach of Bai and Perron (1998) to generate the series of covariation parameters over time. I build up these estimates to provide yearly asset pricing parameters of countries and of foreign companies traded in the United States.

To consider the economic significance of these parameter changes, I use the estimates to examine the implications for a simple portfolio decision model in which a US investor could choose

\footnotetext{
${ }^{6}$ For example, Bekaert and Harvey (1995) and Baele (2005) estimate a time-varying Markov switching process in international equity return relationships. Studies that examine the effects of specific event dates such as market liberalizations, foreign speculators, or equity cross-listings include Bekaert and Harvey (1997,2000), Bekaert, Harvey and Lumbsdaine (2002), Foerster and Karolyi (1999), and Henry (2000).

${ }^{7}$ Stock (1994) describes the difficulties between testing for structural breaks versus parametric changes that would suggest non-stationarity. As Bai and Perron (2003a) show, the algorithm for the model to be estimated below can be extended to threshold switching models.
} 
between US and foreign portfolios. When restricted to holding foreign assets in the form of market indices, I find that the optimal allocation in foreign market indices actually increases over time. However, the optimal allocation into foreign stocks decreases when the investor is allowed to hold foreign stocks that are traded in the US. Also, the lowest variance attainable by diversifying into foreign portfolios has increased over time. These results suggest that the benefits to diversification have declined both for stocks inside and outside the US.

The paper also makes two other contributions. First, while the estimation in Bai and Perron (1998) was developed for single equations, this paper extends the empirical analysis to multiple equations and provides a framework for examining the cross-section of the parameters.

The second contribution concerns a test for the independence of the world market effect in a standard international two factor equity model. In particular, international returns are often modeled as a function of a world market and local market factors. ${ }^{8}$ However, since local markets depend upon the world market, a shift in the relationship between foreign market indices would also confound the relationship between an individual foreign stock trading in the US and the US market. In this paper, I show that the two factor model can be written as a nested relationship between foreign stocks and the home market, and the home and foreign markets in turn. I propose a test for whether shifts in the relationship between foreign stocks and the US are a result of changes at the macro level or at the individual stock level.

The paper proceeds as follows. Section 1 provides estimates for the foreign markets. Section 2 gives the results including the foreign stocks in the United States. Section 3 examines the overall implications for the portfolio potential for foreign stocks inside and outside the US. Concluding remarks follow.

\section{Section 1: What is Happening to Diversification in Foreign Markets?}

The standard diversification puzzle has typically been examined with stock market indices in foreign markets. I follow this approach first before examining the effects of individual foreign company returns in the next section.

\section{1a. Empirical Framework and Motivation}

To consider the conventional approach in the literature, I start with a standard factor pricing relationship:

$$
\mathrm{r}_{\mathrm{t}}^{\ell}=\alpha^{\ell}+\beta^{\ell} \cdot \mathrm{f}_{\mathrm{t}}^{\ell}+\mathrm{u}_{\mathrm{t}}^{\ell}
$$

\footnotetext{
${ }^{8}$ See for example Ferson and Harvey (1993) and Dumas and Solnik (1995).
} 
Where $\mathrm{r}_{\mathrm{t}}^{\ell}$ is the nominal excess return on the equity market of country $\ell$ at date $t, \mathrm{f}_{\mathrm{t}}^{\ell}$ is a vector of factors at time $t$ that affect the return on the equity market of country $\ell, \beta^{\ell}$ is a vector of factor intensity parameters, $\alpha^{\ell}$ is a constant parameter and $u_{\mathrm{t}}^{\ell}$ is a residual. This pricing relationship can be motivated in various ways. From a general equilibrium viewpoint, when markets are complete, $\mathrm{f}_{\mathrm{t}}^{\ell}$ is a scalar latent variable proportional to the stochastic discount rate. ${ }^{9}$ Alternatively, $\mathrm{f}_{\mathrm{t}}^{\ell}$ may represent a common component across countries, but also include additional hedge factors arising from local risks. For example, if real returns differ across countries due to deviations from purchasing power parity, $\beta^{\ell}$ ' $\mathrm{f}^{\ell}$ can represent the pricing to reflect the risk premia on portfolios that bear this risk, in addition to the common pricing component across countries. ${ }^{10}$

A benchmark model that has often been used to examine international equity market index returns especially in the context of the gains to international diversification is: ${ }^{11}$ $\mathrm{r}_{\mathrm{t}}^{\ell}=\alpha^{\ell}+\beta^{\ell} \mathrm{r}_{\mathrm{t}}^{\mathrm{w}}+\mathrm{u}_{\mathrm{t}}^{\ell}$

The model is a single factor model where the benchmark depends on $\mathrm{r}^{\mathrm{w}}{ }_{\mathrm{t}}$, the return on a global world equity portfolio. In this section, I use this framework to examine the potential portfolio allocation changes in equity market indices. In the following section, I examine individual company stock returns and include local factors described above as well.

The connections between international equity markets appear to be increasing over time. Due to crises and political changes, international pricing relationships have often experienced shifting patterns in their co-movements. In addition, the pricing relationship between emerging market country returns and the world market returns often appear to change around the time of opening in markets. ${ }^{12}$ While specific events may herald a significant change in asset pricing relationships between countries, a more gradual integration process may achieve the same effect.

As stated at the outset, my goal is to minimize the structure on whether and how the factor loadings, as in equation (2), change. By doing so, I allow the estimates to capture the cross-section and time-series variation in international asset pricing relationships without preconditioning on liberalization events or any presumption about whether international markets have become more integrated. As such, I

\footnotetext{
${ }^{9}$ See for example the discussion in Bekaert and Hodrick (1992).

${ }^{10}$ Adler and Dumas (1983) developed the classic model on this relationship. Dumas and Solnik (1995) and Vassalou (2000) provide some empirical evidence showing that real PPP deviations are priced in the international market.

${ }^{11}$ See for example, Obstfeld (1994) and Henry (2003).

${ }^{12}$ For an early paper examining equity market liberalization, see Bonser-Neal, et al (1990). More recently, Henry (2000) and Chari and Henry (2004) have studied the effect of market liberalization on market indices. Bekaert, Harvey and Lumsdaine (2002) use the joint behavior of international returns in order to date implicit liberalization from integration.
} 
use the data on equity returns across countries to ask whether and how these pricing relationships have changed over time.

For this purpose, I follow three steps. First, I test for breaks in the relationship between local equity market returns and the world market. Second, for equity returns in the countries that reject the hypothesis of no breaks, I implement the approach derived by Bai and Perron (1998, 2003a) to estimate the break points in the relationship and provide confidence intervals for the breakpoints for each country. Third, I use the parameter estimates to form hypothetical tangency and minimum variance portfolios to see how the changes in asset pricing relationships would affect international allocation. In the next section, I repeat this analysis for foreign firms that cross-list in the United States in order to determine whether domestic investors achieve the same diversification.

\section{1b. Econometric Analysis}

The estimator developed by Bai and Perron (1998) considers a single equation time series regression equation with a given number of breaks in the parameters. I first describe the basic B-P framework before explaining below how I extend this analysis to allow for multiple equations. In the following section, I show how any possible shifts in the parameters in equation (2) can be used to examine individual stock pricing relationships in a nested equation setting.

Single-Equation Estimation: To examine potential breaks in the basic asset pricing relationship in equation (2), I follow B-P in allowing for the possibility of up to a given number, m, breaks in the parameters. I begin by considering the estimation for a specific country, $\ell$.

$$
\mathrm{r}_{\mathrm{t}}^{\ell}=\mathrm{I}\left(\mathrm{T}_{\tau}\right)\left[\alpha_{\tau}^{\ell}+\beta_{\tau}^{\ell} \mathrm{r}_{t}^{\mathrm{w}}+\mathrm{u}_{\tau, \mathrm{t}}^{\ell}\right], \quad \text { for } \tau=1, \ldots, \mathrm{m}+1 ; \quad \mathrm{t}=1, \ldots, \mathrm{T}
$$

where $I\left(T_{\tau}\right)$ is a function that indicates whether time is within a set of time intervals $T_{\tau}$ for $\tau=1, \ldots$, $\mathrm{m}+1$. Without loss of generality, the time intervals are arrayed so that:

$$
\begin{aligned}
I\left(T_{\tau}\right) & =1 \text { if } \mathrm{t} \in\left\{\mathrm{T}_{(\tau-1)}+1, \ldots, \mathrm{T}_{\tau}\right\} \\
& =0 \text { otherwise }
\end{aligned}
$$

So that:

$$
\begin{aligned}
\mathrm{t} & =\left\{1, \ldots, \mathrm{T}_{1}, \mathrm{~T}_{1+1}, \ldots, \mathrm{T}_{2}, \mathrm{~T}_{2+1}, \ldots, \mathrm{T}_{3}, \ldots, \mathrm{T}_{\mathrm{m}, \ldots, \mathrm{T}\}}\right. \\
& =\left\{\mathrm{I}^{-1}\left(\mathrm{~T}_{1}\right), \mathrm{I}^{-1}\left(\mathrm{~T}_{2}\right), \ldots, \mathrm{I}^{-1}\left(\mathrm{~T}_{m+1}\right)\right\}
\end{aligned}
$$

Where $\mathrm{I}^{-1}\left(\mathrm{~T}_{j}\right)$ is the inverse function of $\mathrm{I}\left(\mathrm{T}_{\mathrm{j}}\right)$, and $\mathrm{T}_{0}=0$ and $\mathrm{T}_{\mathrm{m}+1}=\mathrm{T}$.

To economize on notation for developing the estimator which will also be used in the next section, I subsume the country index $\ell$ and rewrite the general factor model in (1) as:

$\mathrm{r}_{\mathrm{t}}=\delta \cdot \mathrm{f}_{\mathrm{t}}+\mathrm{u}_{\mathrm{t}}$ 
where $r_{t}$ is the asset return series, $u_{t}$ is the residual, and $\delta$ is the parameter vector $\delta=\{\alpha, \beta\}$ ' and where $f_{t}$ is rewritten to include a constant as the first factor. Using this notation together with the model in (3) and (4) implies that:

$\mathrm{r}_{\mathrm{t}}=\delta_{\tau} \cdot \mathrm{f}_{\mathrm{t}}+\mathrm{u}_{\mathrm{t}}$

where $\delta_{\tau}$ is a fixed parameter vector for each period $\tau, \tau=1, \ldots, \mathrm{m}+1$ on the intervals $\mathrm{I}^{-1}\left(\mathrm{~T}_{1}\right), \mathrm{I}^{-1}\left(\mathrm{~T}_{2}\right) \ldots$, $\mathrm{I}^{-1}\left(\mathrm{~T}_{\mathrm{m}+1}\right)$. In general, the breakpoints $\mathrm{T}_{1}, \mathrm{~T}_{2}, \ldots, \mathrm{T}_{\mathrm{m}}$ are unknowns. Bai and Perron (1998) show that the breakpoints can be estimated consistently by minimizing over the sum of squared residuals for all possible partitions of the data into $\mathrm{m}+1$ different intervals. In other words, $\mathrm{T}_{1}, \mathrm{~T}_{2}, \ldots, \mathrm{T}_{\mathrm{m}}$ can be consistently estimated by solving the following minimization:

$$
\left\{\hat{\mathrm{T}}_{1}, \hat{\mathrm{T}}_{2}, \ldots, \hat{\mathrm{T}}_{\mathrm{m}}\right\}=\underset{T_{1}, T_{2}, \ldots, T_{m}}{\arg \min }\left[\sum_{\tau=1}^{m+1}\left(\sum_{t \in\left\{T_{(\tau-1)}+1, \ldots, T_{\tau}\right\}}\left[r_{t}-\delta_{\tau}^{\prime} \mathrm{f}_{\mathrm{t}}\right]^{2}\right)\right]
$$

Bai and Perron (1998) also derive the limiting distribution of these break point estimates which provide confidence intervals on the breakpoint estimates.

Multi-Equation Estimation: The Bai-Perron estimator described above was developed for an individual time series. Since my goal is to develop a cross-sectional as well as time-series picture of the covariation pattern in foreign relative to domestic returns, I extend this framework to multiple equations.

Specifically, I examine the effects of each country index separately to build up a set for each return of: (a) number of breaks; (b) break date estimates and their associated confidence intervals; and (c) parameters per subperiod interval. Later I will use this panel of estimates to demonstrate the implications for this distribution of returns on international portfolio choice.

I first test for the number of breaks, $m^{\ell}$, for each country market index. I then estimate the set of break dates: $\left(\hat{\mathrm{T}}_{1}^{\ell}, \hat{\mathrm{T}}_{2}^{\ell}, \ldots, \hat{\mathrm{T}}_{\mathrm{m}^{\ell}}^{\ell}\right)$ and $\delta_{\tau} \forall \tau=1, \ldots, \mathrm{m}^{\ell}+1$. In other words, rewriting equation (3) as a set of equation over countries $\ell$ implies:

$$
\mathrm{r}_{\mathrm{t}}^{\ell}=\mathrm{I}\left(\mathrm{T}_{\tau}\right)\left[\alpha_{\tau}^{\ell}+\beta_{\tau}^{\ell} \mathrm{r}_{t}^{\mathrm{w}}+\mathrm{u}_{\tau, \mathrm{t}}^{\ell}\right], \quad \text { for } \ell=1, \ldots, \mathrm{L}, \quad \tau=1, \ldots, m^{\ell}+1
$$

Note that the number of parameter shifts, $m$, differ by country $\ell$. Moreover, no restrictions are placed on the variance of the residual, $\mathrm{u}_{\tau, \mathrm{t}}^{\ell}$, over subperiods. Indeed, the variance will generally change over subperiods, $\mathrm{T}_{\tau}$, and across countries, $\ell$. In the empirical estimates below, the standard errors are also corrected for a general conditional heteroskedasticity as in White (1980).

\section{1c. Country-Level Data}


The goal of this paper is to look at the effects of potential changes in foreign asset pricing relationships relative to the US market. I take the approach from a US perspective for two main reasons. First, a great deal of research has focused upon diversification from the point of view of a US investor, including some of the earliest research on home bias. It therefore seems natural to focus upon this benchmark case. Second, the US market has the biggest market cap of any country in standard world indexes. While I will use the US market as the measure of the "world" index below, estimation using the Morgan Stanley World Index instead gives qualitatively similar results.

For data analysis on the country indices, I use the Morgan Stanley Capitalization Weighted indices for major countries. ${ }^{13}$ To compare these market indices with foreign stocks in the United States, I examine only the foreign countries with foreign stocks on the New York Stock Exchange in 2004. This partition yields the 40 foreign countries listed in Appendix Table 1. Weekly returns are constructed for each of these indices reconverted into US dollars from 1970, or the earliest available, until April 2004. The returns are transformed into excess returns by subtracting the stock returns from the weekly T-bill rate obtained from Ken French's website. As explained above, the US market was used to proxy for the "world" index. This equity market series was taken to be the S\&P 500. More information about these series is provided in Appendix 1.

\section{1d. Break Tests}

Table 1 provides evidence for breaks in the asset pricing relationship in equation (3). Each country's equation is first tested for the number of breaks using the supF test described in Bai and Perron (2003a). For each series, a sequential procedure estimates each break one at a time, and estimation stops when the $\operatorname{supF}(\tau+1 \mid \tau)$ test is no longer significant at the given marginal significance level. For this analysis, I allow for up to four subperiods. ${ }^{14}$

Panel A of Table 1 reports summary evidence for the "supF test" given by marginal significance level (MSL) of 10\%, 5\%, and 2.5\%. The second column of Panel A reports the proportion of the countries that rejected the hypothesis of zero breaks. In a naturally occurring distribution with no breaks, one would expect to reject the hypothesis of breaks about the same percent of the time as given by the MSL. However, the proportion of the countries that reject no breaks ranges from about $64 \%$ for $2.5 \%$ and $5 \%$ MSL to $72 \%$ for $10 \%$ MSL. Since the estimated proportion is considerably higher than the MSL, these results suggest that the relationships are shifting over time by more than would occur by chance.

\footnotetext{
${ }^{13}$ The index includes reinvested dividends converted into US dollars.

${ }^{14}$ As will be shown below, the country returns show little evidence of more than two breaks anyway, so this seems like a fairly conservative assumption for the maximum number of breaks, $\mathrm{m}$.
} 
The last three columns of Panel A report the proportion of countries that show evidence of one break, two breaks and three breaks, respectively. Countries with one break make up the majority of the cases ranging from $69 \%$ at $10 \%$ MSL to $78 \%$ at $2.5 \%$ MSL. On the other hand, the number of countries with evidence of 3 breaks is quite small at only 4 to $7 \%$. This evidence suggests that assuming the number of breaks to be less than four is not overly restrictive.

\section{1e. Breakpoint Statistics}

Given the number of breaks by country, I estimate the break date equations for each country return series. Defining $\hat{m}_{\ell}$ as the estimated number of parameter breaks for country $\ell$, the result is a set of $\hat{\mathrm{m}}_{\ell}$ break date estimates for $\ell=1, \ldots, \mathrm{L}$ for given by

$\left(\hat{\mathrm{T}}_{1}^{\ell}, \hat{\mathrm{T}}_{2}^{\ell}, \ldots, \hat{\mathrm{T}}_{\hat{\mathrm{m}}_{\ell}^{\ell}}\right)$

and parameter estimates for each interval $\tau=1, \ldots, \hat{\mathrm{m}}_{\ell}+1$ for country $\ell$ given by $\left\{\hat{\alpha}_{\tau}^{\ell}, \hat{\beta}_{\tau}^{\ell}, \hat{\mathrm{u}}_{\tau}^{\ell}\right\}$

Where the residual is normally distributed with possibly differing variance across intervals, $u_{\tau, t}^{\ell} \sim N\left(0, \sigma_{\tau}^{\ell 2}\right)$

Thus, I estimate a set of parameters by subperiod along with break points and confidence intervals around each estimate of the breakpoint and parameters.

As equation (6) shows, the estimation of the break dates (7a) requires minimizing the sum of squared residuals for all possible $\mathrm{m}$ partitions of the data. In practice, the estimator can have poor properties when the partition becomes too small as Bai and Perron (2003b) show. They propose imposing a constraint on the minimal length of a segment for calculating the sum of squares in the argmin calculation in (6). This minimum is given as a percentage of the total number of observations for a series so that the percentage "trimming" constraint $\varepsilon$ is used to construct a minimal length of a segment: $\mathrm{h}=\varepsilon \mathrm{T}$. Bai and Perron (2003b) show that the size of this trimming factor depends upon the number of breaks, $\mathrm{m}$, and derive critical values based on this statistic. I chose $\varepsilon=.15$ as a conservative constraint on the minimal sample length. ${ }^{15}$

Panel B of Table 1 reports the mean and standard deviation of the break point estimates $\mathrm{T}_{1}$ and $\mathrm{T}_{2}$ across the countries. ${ }^{16}$ Under "Full Sample by Break," I give the mean and standard deviation for all first and second breaks. As the evidence shows, the mean of the first break is in November 1992 while the

\footnotetext{
${ }^{15}$ In Monte Carlo simulations, Bai and Perron find that the maximal value of $\mathrm{m}$ for $\varepsilon=0.15$ is 5 . Since $\mathrm{m}$ is 4 or less in all the analysis in this paper, this appears relatively conservative.

${ }^{16}$ There were insufficient data points to estimate the mean and standard deviation for the third break point.
} 
mean of the second break is November 1997. When the breaks are grouped by single break versus double break countries, the evidence looks similar. The countries that appear to shift parameters only once are on average centered on May 1993 while the countries with evidence of two breaks have their first break centered at March 1991. Overall, the mean breaks occur in the early and late 1990s.

The standard errors around the break dates give a sense of how tightly the break dates are estimated. Panel B of Table 1 also reports the mean of the standard error of the break point estimates across countries. The standard error means range from 5 months for the second break estimates to 12 months for the first break estimate when all first breaks are grouped together. To get a better picture of the break-points, Figure 1a plots the break-point estimates for each year by country along with its $95 \%$ standard error bounds for the 5\% marginal significance case. As the figure shows, most of the countries have only one break but a few have two break points. For example, Belgium experiences a break relative to the US in the late 1970s and then again in the late 1990s. The figure also shows that many of the breaks in the Latin American and Asian country returns occur in the late 1990s.

One way to look at how many breaks occur in different periods is to depict the frequency of breaks in five year intervals. Figure $1 \mathrm{~b}$ shows the frequency of breaks by the number of countries with break points decomposed into the first break, second break and total. Figure 1c shows the same information plotted by the percentage of total breaks over the period. As the figure clearly demonstrates, most of the country breaks occur in the late 1990s.

\section{1f. Parameter Estimates}

While the results above show evidence that the relationship between US and foreign equity markets shifted over time, they do not indicate how those relationships have changed. These changes can be seen in the parameter estimates themselves. Table 2 reports descriptive statistics for the set of estimates of the beta parameter in (7b) for the MSL of $5 \%{ }^{17}$. These statistics are reported for different groupings of portfolios and across pseudo-periods between breaks. Note that these pseudo-subperiods are not actual time periods. Rather, they correspond to a thought experiment in which the countries with no breaks have parameters $\delta_{1}^{\ell}$ for the whole sample, countries with one break create a new subperiod with estimates $\delta_{2}^{\ell}$ at the same time, etc. This hypothetical period decomposition allows me to examine the properties of the parameter distribution within breaks. Below I report the effects of parameters aligned over time by year as well.

More precisely, the pseudo-periods are formed by allocating the estimates for each country into the maximum number of periods. In other words, defining this maximum as

\footnotetext{
${ }^{17}$ For the MSLs of $2.5 \%$ and $10 \%$ the estimates are virtually identical.
} 
$\hat{m} \equiv \underset{\ell=1, . . L}{\operatorname{Max}}\left\{\hat{m}^{1}, \ldots, \hat{m}^{L}\right\}$,

the parameter estimates by pseudo-periods are given by:

$\delta^{\ell}=\left\{\delta_{1}^{\ell}, \delta_{2}^{\ell}, \ldots, \delta_{m+1}^{\ell}\right\}$

for $\ell=1, \ldots, \mathrm{L}$

Where $\delta_{\tau}^{\ell}=\delta_{\tau}^{\ell}$

if $\tau \leq \widehat{m}_{\ell}+1$

$$
=\delta_{\bar{m}_{\ell}}^{\ell}
$$

if $\tau>\widehat{m}_{\ell}+1$

This assignment creates coefficient estimates for each country $\ell$ over each of the $m+1$ pseudosubperiods. Since we estimate the maximum number of breaks for any country to be 2 , the number of pseudo-periods is 3 .

Table 2 reports the breakdown by pseudo period and by market portfolio. ${ }^{18}$ Panel A shows the Market Weighted Portfolios by totals and broken down by quartile from bottom to top. ${ }^{19}$ The mean size of beta rises from 0.386 to 0.588 , which could be interpreted as a general increase in covariation between local markets and the US market. The break-down by market value quartile portfolios shows a similar relationship in all but the lowest $\left(1^{\text {st }}\right)$ Quartile. Panel A also reports the mean of the standard errors across countries to be about 0.05 . The table also reports the cross-sectional standard deviation of the market weighted betas at around 0.003 for the total portfolio and about 0.05 for the quartiles.

Panel B shows similar results for a market-weighted breakdown of developed countries versus emerging markets. While the mean of the standard errors is higher for emerging markets, the general tendency for mean beta to rise over time can be seen in both portfolios.

Panel C details the breakdown of portfolios by region. The general tendency for country portfolio betas to increase over time can be seen in all regions except for Latin America and Oceania.

To see whether these estimates are sensitive to the choice of marginal significance level, Figure 2 depicts the mean of betas and their standard deviation for three different levels. As the figure shows, the parameter estimates are virtually identical across MSLs. Figure A1 in the appendix shows the same relationship for alphas.

\section{1g. Parameters over time}

The results in Table 2 and Figure 2 are based upon pseudo-periods in which the parameters are treated as though they coincide with distinct periods. However, since breaks occur at different times for each country, they do not correspond to changes in calendar time.

\footnotetext{
${ }^{18}$ Since there is little evidence for 3 breaks, the results for Period 4 are virtually identical to Period 3 and are therefore not reported.

19 To ensure the countries remain in the same portfolios over time in this table, the market weights are taken at April 2004 values. Below, I examine a time-varying market weight of portfolios in which weights are updated annually.
} 
To consider how the parameters change over time, I next take each return's estimated parameter vector and array them over time to form a time series of the parameters. That is, I form the set of parameter vectors for each country and time period:

$$
\hat{\delta}^{\ell}(t)=\left\{\hat{\delta}_{1}^{\ell}(1), \hat{\delta}_{1}^{\ell}(2), \ldots, \hat{\delta}_{1}^{\ell}\left(\hat{\mathrm{T}}_{1}^{\ell}\right), \hat{\delta}_{2}^{\ell}\left(\hat{\mathrm{T}}_{1}^{\ell}+1\right), \ldots, \hat{\delta}_{m^{\ell}}^{\ell}\left(\hat{\mathrm{T}}_{\mathrm{m}^{\ell}}^{\ell}\right), \ldots, \hat{\delta}_{m^{\ell}}^{\ell}(\mathrm{T})\right\} \quad \forall \ell=1, \ldots, \mathrm{L} ; \mathrm{t}=1, \ldots, \mathrm{T}(9)
$$

Below, I consider the foreign portfolio distribution from the point of view of a US investor at a yearly basis. For this purpose, I examine a subset of the parameter vectors in equation (9), by taking the estimates at the end of each year.

I report the plot of the time series and cross section of these estimates in Figures 3 below.

Figure 3 a reports the estimates of $\beta^{\ell}(t)$ for an MSL of $5 \%$. As the cross-section indicates, the betas of local markets on the US market tended to increase over time, particularly in the late 1990s. Figure $3 b$ reports the same results for an MSL of $10 \%$ with almost the same results as for MSL of 5\%. The exception is that there are more breaks with a higher MSL so that some of the emerging markets register negative betas in the late 1990s after the Asian crisis. In what follows, I will use the parameter results for MSL 5\%, although the overall results are robust to choices of MSL $2.5 \%$ and MSL $10 \%$.

\section{1h. Break Point Confidence Intervals}

The estimation provides confidence intervals for when breaks occur. Thus for each of the estimates of break points in (7a) $\left(\hat{\mathrm{T}}_{1}^{\ell}, \hat{\mathrm{T}}_{2}^{\ell}, \ldots, \hat{\mathrm{T}}_{\mathrm{m}^{\ell}}^{\ell}\right), \forall \mathrm{L}, \mathrm{I}$ estimate $90 \%$ and $95 \%$ confidence intervals around the break points. This provides upper and lower bounds for which the break points occur with $90 \%$ or $95 \%$ probability. Defining L(Break) as the number of countries with evidence of breaks, this

estimation gives a set of $\sum_{\ell=1}^{L(B r e a k)} \hat{m}^{\ell}$ upper confidence interval bounds and lower confidence interval bounds. Figure 4a depicts the total proportion of countries with upper bounds and lower bounds of breaks in a given year. As the figure shows, lower bounds for breaks appear in three main groups: the late 1970s to early 1980s; the early 1990s; and following the Asian crisis of 1997. A finer break-down of the confidence intervals is given in Figure $4 \mathrm{~b}$ where the proportions are decomposed into countries with evidence of one break versus countries with two breaks. As this figure suggests, countries with two breaks generally have the second one either during the 1991 to 1994 period or else the late 1990s.

\section{1i. Economic Significance: Foreign Portfolio Choice}

Up to this point, I have explored the data from a statistical viewpoint to look at the changing picture of a standard international asset pricing relationship. I now begin to look at the economic significance of these changes. For this purpose, I ask how a US investor would allocate his portfolio 
between domestic and foreign equity markets, given the betas and alphas estimated above. The optimization gives a portfolio allocation based upon the distribution of returns from the portfolio as $r_{t}^{p}$ :

$r_{t}^{p}=\sum_{k=1}^{K} \omega_{t}^{k} r_{t}^{k}$

where $\mathrm{K}$ is the number of assets and where $\omega_{t}^{k}$ is the portfolio weight from asset $\mathrm{k}$.

Below, I consider two different forms of this portfolio allocation decision. First, since diversification has been the focus of much of the international home bias puzzle literature, I use the estimates to consider the minimum variance portfolio attainable from the estimates. This portfolio allocation estimate is useful because it provides a measure of how much the variance of the domestic equity portfolio investment can be reduced by holding foreign stocks. Under the assumption that returns are exogenous and iid, a standard assumption for CAPM versions of equation (1), it is wellknown that the weights on the minimum variance portfolio are given by: ${ }^{20}$

$\omega_{t}^{\text {MinVar }}=\left(\frac{V^{-1} \iota}{\iota^{\prime} V^{-1} \iota}\right)$

where $\boldsymbol{\omega}_{\mathrm{t}}$ is the $\mathrm{K} \times 1$ vector of optimal portfolio shares, $\mathrm{t}$ is a $\mathrm{K}$ dimensional vector of ones, and $\mathrm{V}$ is the variance-covariance matrix of returns.

The second portfolio allocation decision I consider is based upon differing expected returns across countries. In this case, standard portfolio theory shows that the optimal allocation lies on a tangency line determined by the risk-free rate and the efficient frontier given by:

$\bar{\omega}_{t}=\left(\frac{V^{-1} E(\boldsymbol{r})}{\iota^{\prime} V^{-1} E(\boldsymbol{r})}\right)$

where $\mathrm{E}(\mathbf{r})$ is the vector of expected equity returns.

To focus upon the relationship between the US and foreign markets, I form a market-weighted portfolio of the foreign markets, $r_{t}^{F}=\sum_{\ell=1}^{L} x_{t}^{\ell} r_{t}^{\ell}$, and use the US return as the residual portfolio. Then, using the mapping from parameter estimates to time series in equation (9), the mean vector $\mathrm{E}$ and the variance-covariance matrix of returns $\mathrm{V}$ are computed. Appendix 2 details these computations.

Figures 5 show the effects of the parameter estimates on the allocation into foreign markets based upon the portfolios above. In Figure 5a, I first report the foreign portfolio allocation implied by the parameter estimates for the minimum variance portfolio. The figure shows the allocation into foreign stocks over time along with the confidence interval arising from the standard error of the

\footnotetext{
${ }^{20}$ For example, the solution to the minimum variance and the tangency portfolio described below are given in Campbell, Lo, and MacKinlay (1996), Chapter 5.
} 
portfolio of $\beta^{\ell}$. The standard error calculations are explained in Appendix 2. The figure shows that the optimal holding of the portfolio increases modestly from $60 \%$ in 1973 to $70 \%$ by 2003 . More dramatically, the allocation dips down from 1974 to 1987, but then follows a generally increasing trend since 1987.

This result may seem surprising given that the estimates of beta suggested that the covariance of the US with the rest of the world should be increasing over time. Focusing on this relationship would lead to the conclusion that allocation into foreign markets should decrease, not increase. To explore this relationship more closely, I report the portfolio beta in Figure 6a. The beta of the foreign returns does indeed increase. Figure $6 \mathrm{~b}$ shows the resulting components in the foreign return variance and the covariance of foreign returns to US returns. The green line shows that the covariance of the foreign and US returns increase over the time period, albeit slowly. At the same time, however, the residual non-diversifiable variance in foreign returns declines fairly quickly. Since 1987, this standard deviation has declined dramatically, from about 5 basis points per week to 2 basis points per week. As a result, allocation into foreign stocks becomes more desirable even though the covariance has also increased. Figure $6 \mathrm{c}$ depicts the implied correlation of the domestic and foreign portfolios.

The estimates show that the covariance of the US market with the rest of the world has increased over time. This result would suggest that the optimal allocation into foreign markets should decline. By contrast, a model of foreign portfolio allocation based upon the estimates shows an increase in optimal portfolio diversification into foreign stocks. The reason is that even though the covariance between markets has declined, the systematic idiosyncratic risk in foreign markets has declined.

Figure $5 \mathrm{~b}$ depicts the constructed tangency portfolio using country mean estimates to measure differences in expected returns. In this case, the swings in the portfolio allocation become more exaggerated over time. When the diversification potential of foreign markets declines in 1987, it coincides with a period when mean returns become negative. As a result, a US investor would want to short the foreign equity portfolio.

\section{Section 2: What is Happening to Diversification into Foreign Stocks in US Markets?}

While the integration of international markets has coincided with higher covariation between markets, it has also provided better ways to hedge foreign idiosyncratic risk. That is, the hedge properties of foreign stocks relative to domestic stocks have declined but the non-diversifiable component of risk in foreign markets has also declined. Based upon the parameter estimates above, the net effect of these two opposing forces is that the diversification potential of foreign markets increases. 
The inability for diminishing diversification to provide an explanation for home bias suggests a re-consideration of more conventional explanations such as transaction costs and information costs. Since the early 1990s, a growing number of foreign stocks have begun to trade in the United States. These foreign stocks trade on US exchanges with the same transactions costs as do domestic stocks. On the NYSE, the companies must go through the same disclosure requirements as US companies. These requirements include SEC registration and financial reporting according to US GAAP accounting standards. Errunza et al (1999) emphasized the importance of domestically traded foreign stocks as a potential way to circumvent transaction costs while reaping the same foreign portfolio diversification. ${ }^{21}$ They found that domestically traded securities span the foreign market indices.

If the asset pricing characteristics of foreign market indices can be duplicated by domesticallytraded assets, then the implications for home bias in light of the results above become even more dramatic. Domestically traded assets can be acquired at comparable transactions costs and, yet, financial integration has on net improved the portfolio diversification from holding foreign stocks.

To examine whether these results hold up in light of the shifts in asset pricing relationships found above, I reconsider the asset pricing relationships of domestically traded foreign stocks. Some researchers have found that the behavior of foreign stocks change when they are listed in the United States in that their betas with respect to the US market get closer to one. ${ }^{22}$ If so, the shift in betas could result from a change in the relationship between the local market index and the US market as found above, or it could be due to a foreign company-specific shift in its relationship to the US market. ${ }^{23}$ The implications for the diversification potential of domestically-traded foreign stocks depend critically on this distinction, however. If the shift is general to the entire foreign market, then the individual foreign stocks are replicating the foreign market behavior found above. On the other hand, if the shift is specific to the company, then the foreign stocks trading in the US market may represent a somewhat different asset class than the rest of their local market.

To examine these relationships, I first look at the empirical asset pricing relationships in foreign firm equities that traded in the United States as of 2004. That is, I ask whether the presence of foreign stocks in the US would change the desirability of investing in the foreign markets. As above, the decision is made from the point of view of a US investor, but here I allow the investor to also allocate the portfolio into domestically traded foreign stocks. For this purpose, I first test for

\footnotetext{
${ }^{21}$ Errunza et al (1999) also include a portfolio of domestic multinational corporations.

${ }^{22}$ See for example, Foerster and Karolyi (1999) who examine the impact upon local and world betas of foreign stocks after cross-listing in the US.

${ }^{23}$ Lewis and Darbha (2004) examine the time of changes in the betas and compare them to listing dates finding that the change in betas generally occurs after the listing date.
} 
changes in the asset pricing relationships and then use these estimates to examine the effects on a simple portfolio allocation model.

\section{(2a) Data on Foreign Companies}

In order to examine the diversification potential of foreign companies in the US, I collected the available time series for local market returns on all foreign companies listed on the NYSE in May 2004. By doing so, my analysis focuses upon the foreign companies that end up being listed in the US. This approach allows me to consider the portfolio decision of a US investor who wishes to consider only domestically available foreign stocks. ${ }^{24}$

Foreign stocks trade on a variety of exchanges in the US, including the over the counter market (OTC) and institutional investor-only markets (RADR, 144A). In this paper, I restrict the analysis to foreign stocks on the public exchanges for two main reasons. First, my goal in this paper is to consider diversification and, indirectly, home bias, from the viewpoint of a representative small US investor. I therefore exclude foreign stocks that are only available to large institutional investors. Second, OTC stocks do not require the same level of disclosure requirements as do domestic and foreign stocks on the public exchanges. As such, domestic investors may consider these foreign stocks to have higher costs associated with acquiring information.

Exchange-traded foreign companies in the US primarily trade on the NYSE and NASDAQ. ${ }^{25} \mathrm{I}$ exclude NASDAQ stocks since recent research suggests that the "Tech Bubble" of the late 1999s may have made the sources of risk in foreign stocks difficult to interpret. ${ }^{26}$ In this study, I use weekly stock returns in foreign markets for parent non-US companies that have stocks trading on the New York Stock Exchange. The time period is from January 1970 or the earliest date of availability to May 2004. All return series are measured in US dollars.

The data for this paper were collected in the following steps for non-Canadian companies. Step (1) A data set of all foreign companies with stocks listed on the New York Stock Exchange in the US were obtained from the Bank of New York, the primary custodian bank for ADRs in this country. This set was cross-checked with listings from the NYSE itself and JP Morgan, another ADR custodian bank. All together there were 351 ADRs for 337 parent companies across 41 foreign countries. Step (2) For

\footnotetext{
${ }^{24}$ An alternative would be to examine available stocks on the US in each year and incorporate the possibility of de-listing. I leave this analysis for future research.

${ }^{25}$ Currently, two foreign companies also trade on the AMEX.

${ }^{26}$ See the discussion on the sources of risk in Carrieri, Errunza, and Sarkissian (2006), Brooks and Del Negro (2005), and Bekaert, Hodrick, and Zhang (2005). In 2004, the market value of foreign stocks on the NYSE and NASDAQ together comprised $98 \%$ of the total market value across public exchanges. At the 2000 peak of NASDAQ, the foreign companies hit a max of $27 \%$ of this total. Thus, the companies listed on NYSE comprise most of the foreign market cap in the US.
} 
each of these companies, stock returns in the home market and market values for full available history were collected from Datastream. ${ }^{27}$

Canadian companies trade directly on US exchanges without ADR registration. As such, these companies are not listed on custodian bank ADR directories. Andrew Karolyi kindly provided the handcollected names and identifying mneumonic codes for the Canadian companies listed in the US. ${ }^{28}$ Appendix Table A2 lists the total set of companies on the NYSE and their home countries.

\section{(2b) Empirical Framework and Motivation}

Examining the individual stock returns requires an extension of the standard factor model in (1). For each individual foreign company $i$, the returns are given by loading on a factor model for the local and US markets:

$\mathrm{r}_{\mathrm{t}}^{\mathrm{i} \ell}=\alpha^{i \ell}+\beta^{\mathrm{i} \ell^{\prime}} \mathrm{f}_{\mathrm{t}}^{\ell}+\mathrm{e}_{\mathrm{t}}^{\mathrm{i} \ell} \quad i=1, \ldots, \mathrm{N} ; \ell=1, \ldots, \mathrm{L}$

where $\mathrm{r}^{\mathrm{i} \ell}$ is the return on company $i$ which is located in country $\ell$. These returns depend upon a set of factors that affect companies in country $\ell$. A standard model often used to characterize company returns internationally is one in which $\mathrm{f}_{\mathrm{t}}^{\ell}=\left\{\mathrm{r}_{\mathrm{t}}, \mathrm{r}^{\mathrm{w}} \mathrm{t}\right\}$. According to this approach, the domestic market captures local risk factors that are not measured in the world return. Thus, the model would be written as:

$\mathrm{r}_{\mathrm{t}}^{\mathrm{i} \ell}=\alpha^{\mathrm{i} \ell}+\beta^{\mathrm{i} \ell} \mathrm{r}_{\mathrm{t}}^{\ell}+\beta^{\mathrm{iw}} \mathrm{r}_{\mathrm{t}}^{\mathrm{w}}+\mathrm{e}_{\mathrm{t}}^{\mathrm{i} \ell}$

However, as we have noted above, the joint distribution of $\left\{r_{t}^{\ell}, r_{t}^{w}\right\}$ has been unstable over the sample period. If local stocks have a stable relationship with their local market over time but the local markets experience shifts against the US markets, the local stocks will appear to have an unstable relationship with the US market. This instability would just be a reflection of the overall local market relationship with the US noted above. These country level breaks will then contaminate estimates about the relationship between foreign stocks trading in the US and their relationship with the US market.

To see this relationship, substitute the shifting country return process $r_{t}^{\ell}$ from (3') into the company return in $\left(12^{\prime}\right)$. This implies:

$$
\begin{aligned}
\mathrm{r}_{\mathrm{t}}^{\mathrm{i} \ell} & =\alpha^{\mathrm{i} \ell}+\beta^{\mathrm{i} \ell} \mathrm{I}\left(\mathrm{T}_{\tau}\right)\left[\alpha_{\tau}^{\ell}+\beta_{\tau}^{\ell} \mathrm{r}_{t}^{\mathrm{w}}+\mathrm{u}_{\tau, \mathrm{t}}^{\ell}\right]+\beta^{\mathrm{iw}} \mathrm{r}_{\mathrm{t}}^{w}+\mathrm{e}_{\mathrm{t}}^{\mathrm{i} \ell} \\
& =\mathrm{I}\left(\mathrm{T}_{\tau}\right)\left[\alpha^{\mathrm{i} \ell}+\beta^{\mathrm{i} \ell} \alpha_{\tau}^{\ell}+\left(\beta^{\mathrm{i} \ell} \beta_{\tau}^{\ell}+\beta^{\mathrm{iw}}\right) \mathrm{r}_{t}^{\mathrm{w}}+\beta^{\mathrm{i} \ell} \mathrm{u}_{\tau, \mathrm{t}}^{\ell}\right]+\mathrm{e}_{\mathrm{t}}^{\mathrm{i} \ell} \\
& =\mathrm{a}_{t}^{i \ell}+b_{t}^{i \ell} \mathrm{r}_{t}^{\mathrm{w}}+\varepsilon_{\mathrm{t}}^{i \ell}
\end{aligned}
$$

Where

\footnotetext{
${ }^{27}$ I also collected the price in the US. Since this price moved very closely with the local return through arbitrage, I focus upon the longer local market series.

${ }^{28}$ These data were used in Doidge, Karolyi, and Stulz $(2004,2005)$.
} 
$\mathrm{a}_{t}^{\mathrm{i} \ell} \equiv \alpha^{\mathrm{i} \ell}+\beta^{\mathrm{i} \ell} \alpha_{\tau}^{\ell}$

$b_{t}^{i \ell} \equiv \beta^{\mathrm{il}} \beta_{\tau}^{\ell}+\beta^{\mathrm{iw}}$

$\varepsilon_{\mathrm{t}}^{i \ell} \equiv \beta^{\mathrm{i} \ell} \mathrm{u}_{\tau, \mathrm{t}}^{\ell}+\mathrm{e}_{\mathrm{t}}^{\mathrm{i} \ell}$

And where, as above, $\tau$ indexes the subinterval in which foreign market indices are stable against the US market return. Equation (13) shows that even if the factor loadings of the foreign stocks on the local and world market, $\alpha^{\mathrm{i} \ell}, \beta^{\mathrm{i} \ell}$, are not time-varying, an estimate of these parameters would be since the factor loadings of the local market on the world, $\alpha_{\tau}^{\ell}, \beta_{\tau}^{\ell}$, are shifting.

At the same time, there may be different reasons for the relationship between foreign stocks and the US market to change relative to the overall local market. Using event studies, a vast literature on international cross-listings has found that a company's cost of capital tends to fall after cross-listing. Moreover, the betas of the foreign stock increase against the US. ${ }^{29}$ Others such as Baruch and Saar (forthcoming) have argued that the decision to list on an exchange arises from the perception that the company is more similar to other stocks on a given exchange. Therefore, if there are shifts in individual foreign stock returns as a result of listing in the US market, it is not clear when these shifts would occur.

To maintain the agnostic approach taken above, I begin by asking whether foreign stocks listed on US exchanges have a stable relationship with the US market once accounting for the breaks against their local markets. For this purpose, note that equation (13) can be written as a set of restrictions on the foreign stock return factor pricing equations:

$\mathrm{r}_{\mathrm{t}}^{\mathrm{i} \ell}=\mathrm{I}\left(\mathrm{T}_{\tau}\right)\left[\alpha_{\tau}^{i \ell}+\beta_{\tau}^{i \ell} \alpha_{\tau}^{\ell}+\left(\beta_{\tau}^{i \ell} \beta_{\tau}^{\ell}+\beta_{\tau}^{i w}\right) \mathrm{r}_{t}^{\mathrm{w}}+\beta_{\tau}^{i \ell} \mathrm{u}_{\tau, \mathrm{t}}^{\ell}\right]+\mathrm{e}_{\mathrm{t}}^{\mathrm{i} \ell}$

where

$\alpha_{\tau}^{i \ell}=\alpha_{q}^{i \ell}$

$\beta_{\tau}^{i \ell}=\beta_{q}^{i \ell}$

$\beta_{\tau}^{i w}=\beta_{q}^{i w}$

$\forall \tau \neq \mathrm{q}, \quad \tau, \mathrm{q}=1, \ldots, \mathrm{m}^{\ell}$

I therefore begin by estimating (13') and testing restrictions (13a) and (13b) for each foreign stock. Since some studies have focused upon ADRs alone and thereby excluded Canadian stocks, Table 3 reports the results for the non-Canadian firms. Panel A gives a summary of the number and proportion of firms that come from countries with No Breaks $(m=0)$, One Break $(m=1)$, and Two Breaks $(m=2)$, respectively. Roughly $40 \%$ of the firms come from countries that did not show evidence of a change in

${ }^{29}$ See for example, Foerster and Karolyi (1999). Karolyi (2006) surveys the literature on international cross-listings. 
asset pricing relationships with the US. Another $42 \%$ come from countries with one break, while only $18 \%$ of the firms come from countries that show evidence of two breaks.

Table 3 Panel B reports the results of testing zero restrictions on the stock level world parameters, broken down by country breaks and combined in the last column under "All." $40 \%$ of the foreign stocks reject the joint restriction that: $\alpha^{i \ell}=0=\beta^{i \ell}$. However, when the restrictions are decomposed into the parameters separately, only about $5 \%$ of the stocks can reject the hypothesis that $\alpha^{i \ell}=0$ at the $5 \%$ MSL, which is comparable to the number that one would reject in a random sample. This proportion falls even lower to $3 \%$ when the tests are conditioned on the breaks from the home country: Ho : $I\left(T_{\tau}\right) \alpha^{i \ell}=0$. These results show that there is no evidence of excess returns of foreign companies in the US once conditioned on local company returns.

The results for $\beta^{i w}$ are more mixed. About $45 \%$ of the foreign stocks in the US reject the hypothesis that the direct coefficient of the foreign stock on the US is different from zero. Note that this can also be seen as a test that of the null hypothesis that the foreign stock depends upon the US market only through the effect of the local market on the US: $\beta^{i \ell} \beta_{\tau}^{\ell}$. Interestingly, while this restriction is rejected for approximately $45 \%$ of the foreign companies, this means that the returns over $50 \%$ of the companies cannot reject this restriction.

Table 3 Panel $\mathrm{C}$ reports the proportion of firms that reject the restrictions given in (13a-c). The first column reports the proportion rejecting the hypothesis that given in (13a) that alphas are constant over time. Since very few stocks had evidence that these parameters were different from zero, it is not surprisingly that only about $6 \%$ of the stocks rejected this hypothesis. Tests for constancy of $\beta^{i \ell}$ and $\beta^{i w}$ reject more often at $16 \%$ and $13 \%$, respectively. I will further analyze these companies below.

To understand the power of these tests, Table 3 Panel D gives summary information about cross-sectional and time series numbers of observations for the foreign companies. The first entry in each cell gives the summary statistics for all but the non-Canadian companies, while the second entry gives the summary for all the foreign companies. The cross-sectional number of firms is 363 and these break down into the number of breaks in the home company as described above. The table also reports summary statistics for the number of time series observations per firm. These range from a minimum of 62 to a maximum of 1670 observations. The mean and median of number of time series observations are 800 and 634, respectively, for all of the foreign companies. Generally, the number of observations of individual stocks is fewer than their home country indices, leading to the question of whether there are enough observations within each country subperiod to have sufficient power for the 
tests in Panel C. To examine this issue, the right hand columns report the number of observations decomposed by number of observations within the subperiods implied by the shifts in local markets against the world. The minimum ranges from 62 for stocks for pseudo-subperiod 1 to 266 for stocks during pseudo-subperiod 3. Similarly, the median number of observations per company range from 406 for $\tau=1$ to 266 for $\tau=3$. . Finally, the last row gives information about the total number of observations as approximately 580,000 for the total sample, 335,000 for stocks from subperiod 1, 128,000 for stocks from subperiod 2, and 17,632 for stocks from subperiod 3 . The number of observations when Canadian companies are excluded is smaller, yet remains large. The number of observations therefore suggests there should be sufficient power to detect shifts in parameters across home country subperiods.

Given the evidence for parameter instability across these subperiods for about $40 \%$ of the foreign stocks, I next examine the behavior of returns for these individual stocks more closely. For each of these companies, I estimate the following nested model:

$$
\begin{array}{lr}
\mathrm{r}_{\mathrm{t}}^{\mathrm{i} \ell}=\Xi\left(\kappa_{\varsigma}\right)\left[\alpha_{\varsigma}^{\mathrm{i} \ell}+\beta_{\varsigma}^{i \ell} \mathrm{r}_{\mathrm{t}}^{\ell}+\beta_{\varsigma}^{i w} \mathrm{r}_{\mathrm{t}}^{\mathrm{w}}+\mathrm{e}_{\varsigma, \mathrm{t}}^{\mathrm{i} \ell}\right], & \text { for } \mathrm{i}=1, \ldots, \mathrm{N} ; \varsigma=1, \ldots, \mathrm{n}^{\mathrm{i}}+1 \\
\mathrm{r}_{\mathrm{t}}^{\ell}=\mathrm{I}\left(\mathrm{T}_{\tau}\right)\left[\alpha_{\tau}^{\ell}+\beta_{\tau}^{\ell} \mathrm{r}_{t}^{\mathrm{w}}+\mathrm{u}_{\tau, \mathrm{t}}^{\ell}\right], & \text { for } \ell=1, \ldots, \mathrm{L}, \tau=1, \ldots, m^{\ell}+1
\end{array}
$$

Equation (14) takes the two-factor international stock equation given in (13) but allows for the possibility of shifts in the company level returns that differ from the home country shifts estimated earlier and repeated here as $\left(3^{\prime}\right) . \Xi\left(\kappa_{\varsigma}\right)$ is an indicator function similar to the indicator function $I\left(T_{\tau}\right)$ in foreign markets. In particular, $\Xi\left(\kappa_{\varsigma}\right)$ maps the subperiods over which firm level parameters are constant into the time domain the subperiods. Note that since the estimation is conducted by firm, the intervals should be specified as dependent upon the firm i. Subsuming these superscripts on the time intervals $\kappa$ without loss of generality, the mapping analogous to equation (4) is:

$\Xi\left(\kappa_{\varsigma}\right)=1$ if $\mathrm{t} \in\left\{\kappa_{(\zeta-1)}+1, \ldots, \kappa_{\zeta}\right\}$ for $\kappa_{\zeta} \in\left\{\kappa_{1}, \kappa_{2}, \ldots, \kappa_{\mathrm{n}}\right\}$

where the estimates of $\kappa_{\zeta}$ are:

$$
\left\{\hat{\kappa}_{1}, \hat{\kappa}_{2}, \ldots, \hat{\kappa}_{n^{i}}\right\}=\underset{\kappa_{1}, \kappa_{2}, \ldots, \kappa_{n^{i}}}{\arg \min }\left[\sum_{\varsigma=1}^{n^{i}+1}\left(\sum_{t \in\left\{\kappa_{(\zeta-1)}+1, \ldots, \kappa_{\varsigma}\right\}}\left[r_{t}^{i \ell}-\delta_{\varsigma}^{i} ' \mathrm{f}_{\mathrm{t}}^{\ell}\right]^{2}\right)\right]
$$


where $\kappa_{o}=0, \kappa_{n^{j}+1}=T$. The equations in (15) contain both local home country returns and US market returns. In turn, these variables are jointly unstable as documented above. For this reason, it is important the condition the firm level estimation in (15) on these macro breaks. I describe this estimation next.

\section{2c. Company Break Tests Statistics}

The cross-subinterval tests above found evidence for company-specific return instability. In order to estimate the subperiods of relative stability in equation (15), I begin by testing for the number of breaks in the equity pricing relationship, as above. Note that $f_{t}^{\ell}=\left\{r_{t}^{\ell}, r_{t}^{w}\right\}$ and that equation (3') describes the relationship between the elements in this vector. Consistent estimates for this relationship are given in Section 1. Constraining the factor process by these estimates, I first test for the number of breaks in each company returns, $\mathrm{n}^{\mathrm{i}}$, for the set of companies, $\mathrm{i}=1, \ldots, \mathrm{N}$.

Results for the break date estimates are given in Table 4. At an MSL of 10\%, 164 companies reject the hypothesis of no breaks, with the numbers declining to 111 companies at an MSL of $2.5 \%$. As with the foreign markets, most of the foreign firms only reject the hypothesis that there is not more than one break. Only one firm rejects the hypothesis at 2 or more breaks at the 5\% MSL.

The table also reports the mean of the break-point estimate and of the standard errors of the estimates. The statistics for the break points are provided by marginal significance level of the number of breaks. The first break has a mean in 1996, the second break in 1998 to 1999. There are insufficient numbers of firms with three breaks to make inferences.

There are greater differences when the companies are sorted into whether they show evidence of single, double, or triple breaks. The single break companies have a mean break in 1997. The double break companies generally show a first shift in the early 1990s with a second mean shift in 1999 . The triple break companies show a similar pattern but with an early break in the late 1970s and early 1980s. The mean of the standard error of these estimates range from four to nine months.

Figure 7A gives a plot of the breakdates of the foreign companies, arrayed by home country. The first break in the relationship between individual company returns against the US and on the home market is by Kubota, a Japanese firm in 1977, while the last break is by Cunoc, a Hong Kong firm. Figure 7B gives a plot of the number of initial breaks, second breaks and total breaks, while Figure 7C shows the same information as a proportion of the companies that show instability. Clearly, most of the companies show instability during the late 1990s and early 2000 s.

While the predominance of changes appears in the latter part of the sample, it should be emphasized that most of the companies do not show any evidence of instability. At the peak period, only 
60 companies demonstrated a first or second break, out of a total of 363 companies or about $16 \%$ of the total possible companies.

\section{2e. Parameter Estimates}

The evidence above gives evidence of instability in the asset pricing relationships, but it does not tell us about the pattern in the parameter relationships. For this purpose, Tables 5 and 6 report cross-sectional statistics on the parameter estimates for various portfolios of foreign stocks, grouped into the 4 break pseudo-periods described above.

Local Market Betas: Panel A shows the results for the coefficient of the $i$-th stock return on the local

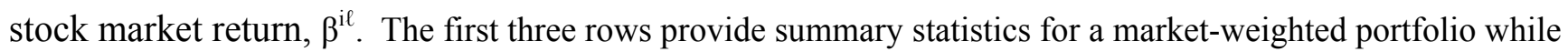
the second set of rows do the same for an equally-weighted portfolio. In all cases, the mean of the local beta is quite close to one. The mean of the standard error as well as the standard deviation of beta is quite small for the market-weighted portfolio, although the equally weighted portfolio shows a great deal more variation. The rest of the panel shows the results broken down into quartile portfolios. The mean of the top quartile is very close to one, while the bottom quartile is lower at around .83 for the first subperiod. The top quartile has quite small standard error means at less than 0.09 , while the bottom quarter shows greater standard error means, but still less than 0.14 . The pattern suggests that the betas of the individual stocks on the local markets are quite close to 1 and these relationships have not changed much over time.

Panel B shows the same statistics grouped into regional portfolios. While the means are very close to one for Europe and Oceania, the means are somewhat lower for Africa \& the Middle East and, for the first subperiod, Latin America and Asia. These results suggest that there may be differences for emerging versus developed markets.

Panel $\mathrm{C}$ addresses this possibility where the results are reported for market weighted portfolios. The mean of the local beta for emerging markets is closer to 0.85 for the first sub-period but increases to close to one for the subsequent periods. In all of the sub-cases considered, the betas are relatively close to one and do not decrease over time. This suggests that companies that list in the US move closely with their local markets. Despite general shifts in international markets, the co-variation of the foreign stocks with their own country indices has not changed much over time.

US Market Betas: Table 6 shows the same statistics for the cross-section of betas on the US market. The means are all quite close to zero. This result is consistent with the zero restriction hypothesis tests in Table 3 that found approximately $60 \%$ of the stocks could not reject the hypothesis that these estimates are equal to zero.

Most estimates in the literature find that direct estimates of foreign cross-listed stocks on the US market are significantly greater than zero. It is therefore important to note that the estimates here are the conditional direct effects of the stocks on the US market. To see this point, note that the standard 
coefficient of foreign stocks on the US market return in equation (13) is comprised of three different parameters: $\mathrm{b}^{\mathrm{iw}} \equiv\left(\beta^{\mathrm{i} \ell} \beta^{\ell}+\beta^{\mathrm{iw}}\right)$ where $\mathrm{b}^{\mathrm{iw}}$ is the composite coefficient. In this way, $\beta^{\mathrm{i} \ell}$ can be seen as the standard CAPM beta of foreign stock returns on their local market return while $\beta^{\ell}$ is the world CAPM beta of the local market on the US market. As the country level estimates in Table 2 suggest, $\beta^{\ell}$ are significantly positive and the market weighted estimates range from about 0.4 to 0.6 . Table 5 reports that estimates of the stock level betas on their own markets, $\beta^{\mathrm{i} \ell}$, are also generally significantly positive and quite close to one. The product of these two betas, $\beta^{\mathrm{i} \ell} \beta^{\ell}$, then measures the implied effect of the foreign stocks on the US market that would be implied by standard CAPM relationships. As such, the parameter $\beta^{\text {iw }}$ can be viewed as the marginal relationship between foreign stocks and the US market that is not implied by these standard relationships. Not surprisingly, then, this direct effect is equal to zero in many cases.

In Panel A of Table 6, the mean of the parameter estimate for the market weighted portfolio increases from 0.06 in Periods 1 and 2 to 0.08 in Periods 3 and 4. When this result is broken into quartile-based portfolios, no overall relationship emerges. These differences combined with the fact that developed country firms have more market weight than the emerging markets suggest that there may be differences across regions. Panel B of Table 6 shows the break-down into regional portfolios. Indeed, Europe, Asia and Oceania show a trend toward increasing betas on the US market, while the Latin American and the Africa/Middle East portfolios show the opposite trend.

Since Asia and Europe include some emerging market countries, Panel $\mathrm{C}$ breaks the firms into developed versus emerging market portfolios. Both portfolios show a general decrease in mean between the first pseudo-subperiod to the later subperiods.

In summary, the marginal effect of foreign stocks on the US market is small and close to zero. When broken into market-weighted developed and emerging market portfolios, these marginal effects become smaller over time. This result may suggest that the foreign stocks listed in the US have become more integrated with the US market over time.

\section{(2g) Foreign Portfolio Allocation}

The analysis above describes how the parameters have changed over time, but do not give a sense of the economic significance of the relationships. For this purpose, I use a similar mean-variance optimization model as I did in the country indices above. However, I now allow the investors to hold a portfolio of foreign stocks in the United States. The investor has a choice of combinations arising from three different portfolios: (a) the domestic market; (b) a capitalization weighted average of foreign 
market indices; and (c) a capitalization weighted average of foreign markets listed in the United States. As such, I take a similar optimization as considered in Section 1 but now include a new portfolio formed from the market-weighted returns on the domestic-listed foreign stocks:

$r_{t}^{S}=\sum_{i=1}^{N} z_{t}^{i} r_{t}^{i, \ell}$

where $\mathrm{z}_{\mathrm{t}}^{\mathrm{i}}$ is the market cap weight from company $i$ in the total portfolio of foreign companies listed on the NYSE. The tangency portfolio weights of the domestic market, portfolio of foreign markets, and portfolio of foreign stocks listed in the domestic market are given by equation (11), repeated here for convenience:

$\boldsymbol{\omega}_{\mathrm{t}}=\mathrm{V}_{\mathrm{t}}^{-1} \mathrm{E}\left(\mathbf{r}_{\mathbf{t}}\right) / \mathrm{t}^{\prime} \mathrm{V}_{\mathrm{t}}^{-1} \mathrm{E}\left(\mathbf{r}_{\mathbf{t}}\right)$

where now $\mathbf{r}_{\mathbf{t}} \equiv\left[r_{t}^{s}, r_{t}^{F}, r_{t}^{w}\right]^{\prime}$ so the optimal portfolio is given by (11) and:

$\mathrm{E}\left(\mathbf{r}_{\mathbf{t}}\right)=\left[\Xi\left(\kappa_{\varsigma}\right)\left[\alpha_{\varsigma}^{i \ell}+\beta_{\varsigma}^{i w} E\left(r_{t}^{w}\right)\right], I\left(T_{\tau}\right)\left[\alpha_{\tau}^{\ell}+\beta_{\tau}^{\ell} E\left(r_{t}^{w}\right)\right], E\left(r_{t}^{w}\right)\right]$

$\mathrm{V}_{\mathrm{t}}=\mathrm{E}_{\mathrm{t}}\left[\left(\mathbf{r}_{\mathrm{t}}-\mathrm{E}_{\mathrm{t}} \mathbf{r}_{\mathrm{t}}\right)\left(\mathbf{r}_{\mathrm{t}}-\mathrm{E}_{\mathrm{t}} \mathbf{r}_{\mathrm{t}}\right)^{\prime}\right]$

Figures 8 show the effects of the parameter estimates on the allocation into both the foreign markets and the US listed foreign stocks. The figures depict the allocation into foreign stocks over time in two different portfolios: the foreign markets and the domestically-listed foreign stocks. In order to get a sense of the variability of these allocations, I used Monte Carlo simulations to obtain 95\% confidence intervals as follows.

First, the parameters: $\beta^{\ell}, \beta^{\mathrm{i} \ell}, \beta^{\text {iw }}$ were drawn using the variance-covariance matrix from their estimated joint distribution in each year. Second, these estimates together with their standard errors were used to calculate the tangency portfolio for that run of the distribution. Third, after 10,000 generations of the tangency portfolio, the $95 \%$ confidence intervals were generated for each year. Fourth, the first three steps were followed for each subsequent year up until 2004.

I first report the minimum variance portfolio in Figure 8a. Thus, the allocation decision between foreign and US stocks is made purely of changes in variance. Up until about 1994, the results support the notion that there is under-investment in foreign assets. For most of this period, the diversification benefits suggest that the US investor should be holding from $50 \%$ to $80 \%$ of his portfolio in foreign assets. During 1992, the estimates even suggest that the domestic investor should short the domestic market and go long a combination of foreign markets and foreign stocks listed in the US. After 1994, this relationship changes dramatically. By the end of the sample, the parameter estimates indicate that only about $20 \%$ of the US investor's portfolio should be held in foreign assets in order to achieve the minimum variance portfolio. 
Figure 8a also shows the optimal relationship between holdings in foreign stocks in the US and foreign stocks in foreign market indices. From 1974 to 1987, foreign stocks in the US outperform the diversification of the foreign markets. The optimal holdings of the foreign stocks range around $40 \%$ of the portfolio while optimal holdings of foreign market indices range around $25 \%$. This relationship reverses during 1987 to 1990, but after 1994, the optimal holdings of foreign markets and foreign stocks in the US are approximately the same at around $10 \%$.

Figure $8 \mathrm{~b}$ repeats this analysis for the tangency portfolio where the mean returns are allowed to differ using the estimates from Section 1 above. The figure shows a similar time pattern between portfolio investment in the US and the foreign markets as the minimum variance portfolio. During the 1970s and 1980s, the lower return in the US market means that a US investor would hold very little of the domestic asset. This relationship switches dramatically in the late 1980s, before exhibiting the same optimal short position during 1990-1993 as found in the minimum variance case. The high mean in foreign mean during the period following 1994 attenuates the tendency to allocate portfolio to the US market.

When comparing the three asset results in Figures 8 with the two asset framework in Figures 5, the results are strikingly different. As shown in Figures 5 when the only source of foreign diversification is to hold the foreign market indices, the optimal allocation into foreign stocks increases over time. As we saw above, even though the correlation across markets increased, the allocation into foreign markets increased because of the decline in systematic risk in the foreign portfolio. By contrast, when the investment set is expanded to include a portfolio of foreign stocks listed in the US, the optimal allocation into foreign assets in total decline. I investigate the sources of this difference in the next section.

\section{Foreign Stocks Inside or Outside of the US?}

The portfolio allocations considered above are clearly just an alternative way to view the distribution of the parameter estimates. Therefore, to understand the difference in results, I take a closer look at this distribution over time and across stocks.

\section{(3a) Parameters Behind the Decisions}

To understand the parameters that determine these patterns, Figures 9 show the parameters and standard errors for the market weighted portfolios of foreign market indices and foreign companies that are listed in the US. Figure 10a shows that the estimate of the foreign market on the US, $\beta^{\ell}$, is relatively stable over time, consistent with the country beta estimates in Figure 6a. On the other hand, the estimate of the coefficient of the foreign stocks with their own markets, $\beta^{i, \ell}$, has increased from 
1982, peaking at above 1 in 2001 . At the same time, the beta of the stocks on their own local markets, $\beta^{i, w}$, varied near zero. The aggregate measure of the relationship between foreign stocks and the US market, $\mathrm{b}^{\mathrm{iw}} \equiv\left(\beta^{\mathrm{i} \ell} \beta^{\ell}+\beta^{\mathrm{iw}}\right)$, shows some variation, but generally rises faster than the local country on the US market due to the increase in $\beta^{\mathrm{i} \ell}$.

These parameters together with the variance estimates of the components generate the portfolio combinations. To understand the variance component for the portfolios, note that these components as derived in Appendix 2 are given by:

$$
\begin{aligned}
& \operatorname{Cov}\left(r_{t}^{s}, r_{t}^{f}\right)=\sigma_{w}^{2} \mathbf{Z}_{t}{ }^{\prime} \mathbf{b}_{t}^{w} \boldsymbol{\beta}_{t}^{\ell} \mathbf{X}_{t}+\mathbf{Z}_{t}{ }^{\prime} \boldsymbol{\beta}_{t}^{i} \mathbf{U}_{t} \mathbf{X}_{t} \\
& \operatorname{Cov}\left(r_{t}^{s}, r_{t}^{w}\right)=\sigma_{w}^{2} \mathbf{Z}_{t}^{\prime} \mathbf{b}_{t}^{w} \\
& \operatorname{Cov}\left(r_{t}^{f}, r_{t}^{w}\right)=\sigma_{w}^{2} \mathbf{X}_{t}{ }^{\prime} \boldsymbol{\beta}_{t}^{\ell}
\end{aligned}
$$

Where $\mathbf{U}_{t} \equiv E_{t}\left(\mathbf{u}_{t} \mathbf{u}_{t}{ }^{\prime}\right)$ for $\mathbf{u}_{t} \equiv\left[\mathrm{u}_{\mathrm{t}}^{1}, \ldots, \mathrm{u}_{\mathrm{t}}^{\mathrm{L}}\right]^{\prime}$, the cross-country variance-covariance matrix; $\sigma_{w}^{2} \equiv E\left(u_{t}^{w 2}\right) ; \mathbf{Z}_{\mathbf{t}}$ and $\mathbf{X}_{t}$ are, respectively, the $\mathrm{N} \mathrm{x} 1$ vector of the market weights of the foreign stocks in the foreign stock portfolio and the Lx1 vector of market weights in the foreign stocks in the US at time t; and where $\mathbf{b}_{t}^{w}, \boldsymbol{\beta}_{t}^{\ell}$ are the vectors of portfolio parameters with typical element, $\mathrm{b}_{t}^{i w}, \beta_{t}^{\ell}$.

The covariances are depicted in Figure 9b. The covariance between foreign markets and the US market return move quite closely with the covariance between foreign stocks in the US and the US market return. This is not surprising since these covariances are both driven by similar movements in coefficients and changes in market values. By contrast the covariance between foreign markets and the foreign stocks in the US has increased dramatically since 1994 when they were actually negative. Note that part of the changes in covariances between the two terms may arise from changes in the crosscountry variance-covariance matrix $\mathrm{U}$.

To examine these relationships, Figure 9c shows the time varying pattern of variance estimates of these portfolios. Appendix 2 shows that the variances of the foreign portfolios is given by:

$$
\operatorname{Var}\left(r_{t}^{F}\right)=\sigma_{w}^{2} \mathbf{X}_{t}{ }^{\prime} \boldsymbol{\beta}_{t}^{\ell} \boldsymbol{\beta}_{t}^{\ell}{ }^{\prime} \mathbf{X}_{t}+\mathbf{X}_{t}{ }^{\prime} \mathbf{U}_{t} \mathbf{X}_{t}
$$

The variance of the foreign portfolio return, $r_{t}^{f}$, depends upon two terms. The first term evolves according to variation in market weights of the foreign market indices, $\mathrm{X}$, and the risk-loading of the country indices on the world market, $\boldsymbol{\beta}_{t}^{\ell}$. This term captures the variation in the foreign return arising from its dependence on the world return. The second term measures the effects of return variation from comovements in returns across countries. In a standard CAPM framework, this would represent the idiosyncratic risk that would be minimized in large portfolios. 
Figure 9c shows the evolution of this estimate over time. The foreign portfolio variance shows a marked increase following the 1987 stock market crash, but then generally declines afterward with a slight elevation in the early 1990s. The figure also shows the contribution to this variance from the residual covariance among countries, $\mathbf{X}_{t}{ }^{\prime} \mathbf{U}_{t} \mathbf{X}_{t}$. As the figure shows, the systematic variance in this country portfolio comprises a majority of the overall variance in the beginning in 1974. After 1987, though, the contribution of this residual variance to the overall variance declines until about half by 2004 .

Similarly, the variance of the foreign stocks in the US is:

$$
\operatorname{Var}\left(r_{t}^{s}\right)=\sigma_{w}^{2} \mathbf{Z}_{t}{ }^{\prime} \mathbf{b}_{t}^{w} \mathbf{b}_{t}^{w}{ }^{\prime} \mathbf{Z}_{t}+\mathbf{Z}_{t}{ }^{\prime} \boldsymbol{\beta}_{t}^{i} \mathbf{U}_{t} \boldsymbol{\beta}_{t}^{i} \mathbf{Z}_{t}+\mathbf{Z}_{t}{ }^{\prime} \Omega_{t} \mathbf{Z}_{t}
$$

The first two terms on the right hand side mirror the components found in the variance of foreign market indices. That is, the first and second terms capture the risk arising from dependence of these stocks on the US market and the systematic world comovement captured by $U_{t}$. By contrast, the last component, $\mathbf{Z}_{t}{ }^{\prime} \Omega_{t} \mathbf{Z}_{t}$, is the residual variation in foreign stocks after the effects of variation in US market and foreign market risks have been taken out.

Figure 9c shows this measure over time. The residual variance is small for most of the period except for the period from 1987 to 1992 . By the end of the sample, the contribution of this term to overall variance is essentially zero. The overall variance of the foreign stocks in the US follows the movement of the foreign market, but with more exaggerated swings.

\section{(3b) Interpreting the Portfolio Allocation}

Given the variance and covariance estimates over time, the portfolio allocations in Figure 8 become transparent. Following 1987, the systematic risk increases for foreign stocks both inside and outside the US. As a result, the US investor would choose to hold more domestic stocks and less foreign stocks, particularly those that are listed in the US. However, from 1990 onward, the variance of the foreign stocks decline. Since there is a negative covariance between foreign stocks inside and outside the US from 1991 to 1994, the US investor gets an extra diversification boost from holding onto both types of foreign stocks and even shorts the domestic stock market in 1992. Subsequently, the covariance between the two portfolios of foreign stocks increase and the US investor cannot achieve the same diversification benefit.

One way to see this relationship is to examine the attainable minimum variance portfolio over time. This is depicted in Figure10a along with the St Dev of holding the US portfolio alone. Another view at the same relationship is given in Figure $10 \mathrm{~b}$ which shows the percentage reduction in standard deviation at the minimum variance point for the US investor. This is given by: [StDev(US Return) StDev(MinVar)]/StDev(US Return). The figure compares the minimum variance point for portfolios 
using market indices as in Section 1 with the portfolio results using both sets of foreign stocks as in Section 2.

Figure 10b shows that the diversification gains decline between 1974 and 2004 for both sets of stocks. However, there is a sharp increase in risk reduction in the early 1990 s reaching about $35 \%$ of the underlying risk based upon the total foreign stock portfolios. This reduction comes from the pattern found in Figure 9 that the covariance between the two sets of foreign stocks becomes negative at the same time that the variance of foreign stocks are declining. By the mid-1990s, this pattern reverses as the two sets of portfolios become much more highly correlated.

The minimum variance portfolio with foreign stocks indices alone follow a similar pattern, but without the upswing in diversification benefit in 1992. Foreign stocks become less risky, but there is not a set of foreign assets with low correlation such as the foreign stocks inside the US to allow the hedge component. On the other hand, the diversification potential does not drop off as dramatically as when US listed foreign stocks can be held. Rather, it rises slightly and stays at about $15 \%$.

This difference underlies the significantly different sizes of foreign portfolio holdings in the two cases. When there is only one source of holding foreign assets, Figure 3 showed that the general decline in systematic risk in the foreign portfolio makes the US investor put more weight in the foreign portfolio over time. However, when there are two sources of foreign investment, the attractiveness of this investment depends critically on the co-movement between these two portfolios. As long as the correlation is small and negative, the US investor would like to hold both portfolios. On the other hand, if the correlation increases over time, as it did after 1994, allocation of portfolio into one of the portfolios will increase risk in the foreign portfolio allocation overall, thereby increasing the allocation at home.

\section{(3b) "Home-Grown Foreign Diversification"}

The results above show that the risk reduction properties of foreign assets have declined over time. This relationship is especially pronounced when foreign stocks inside and outside the US are part of the investment opportunity set.

Errunza et al (1999) have proposed using "Home Grown" foreign assets as a substitute for investing directly in foreign equity markets. Indeed, the results above suggest that the foreign equities that trade in the US move very closely with their local markets. Therefore, I now consider the two asset allocation model as in Section 1 but substitute foreign stocks listed in the US for the portfolio of foreign markets. That is, I consider an investor choosing an allocation in two possible assets with return vector: $\mathbf{r}_{\mathbf{t}} \equiv\left[r_{t}^{s}, r_{t}^{w}\right]^{\prime}$ where the processes are the same as estimated above. 
Figures 11 report the results of repeating the portfolio simulations excluding the foreign market allocation. Comparing these results to the counterparts using foreign indices only in Figures 5 demonstrates a similar pattern, but with much greater time variation. For example, the pronounced increase in variance in foreign stock inside the US following the crash of 1987 creates a more significant decline in foreign allocation. Similarly, there is more variation in the estimates in the late 1990s and early 2000s, and the standard errors show much greater sampling error. The mean allocation at the end of the sample is roughly the same as the beginning and is comparable to the allocation in Figure 5a at the end of the sample. However, the sampling error shows that the allocation could be as low as 0.3 or as high as 0.9 . Figure $11 \mathrm{~b}$ also shows the effects upon the tangency portfolio implied by the means of countries. Once again, the degree of variability is substantially greater than the foreign indices alone.

Returning to the variance reduction properties of these portfolios, Figure 10b shows that during the period following 1994 through 2003, a portfolio of foreign stocks outside the US, using foreign market indices, dominates a portfolio of foreign stocks inside the US, using cross-listed stocks. By 2003, however, the diversification properties are essentially the same for both portfolios.

Overall, then, the foreign stocks listed within the US have similar diversification patterns as foreign markets indices particularly following 1994. The primary differences between the foreign stocks inside and outside the US are two-fold. First, the portfolio of foreign cross-listed stocks in the US has a greater residual systematic risk than the portfolio of foreign market indices. Second, the sampling uncertainty for the beta coefficients from the cross-listed stocks is greater than that of the foreign market portfolio. As a result, the confidence intervals around the appropriate allocation into a portfolio of crosslisted stocks are many times larger than those of the portfolio of foreign market indices.

\section{Conclusion}

In this paper, I have looked at the data on foreign returns from a US investor's point of view to consider the impact of changing covariances among international returns on the opportunities for diversification. I examined the foreign markets first to consider the usual argument that domestic residents hold a suboptimally low portfolio allocation in foreign stock indices. I have found that the covariances among country stock markets have indeed shifted over time for a majority of the countries. However, in contrast to the common perception that markets have become more integrated over time, the covariance between foreign markets and the US market have increased only slightly from the beginning to the end over the last twenty years. Moreover the standard deviation of the foreign portfolio has declined over this time.

To consider the economic significance of these parameter changes, I looked at a simple portfolio decision model in which a US investor could choose between US and foreign market 
portfolios. With two different assumptions about the estimate of foreign means, I found that the optimal allocation in foreign markets has actually increased over time. This may seem counterintuitive given that the higher degree of integration increases the correlation across markets. On the other hand, the falling variance of foreign portfolios increases the allocation into foreign markets. Overall, this second effect dominates the integration effect so that allocation into foreign markets remains high.

These results work against a resolution to the home bias puzzle due to greater integration. I therefore looked at whether foreign stocks that list in the United States can explain the lack of foreign investment. Errunza et al (1999) have argued that these stocks can explain the lack of investment in foreign markets directly. I extended the model from above to examine the behavior of foreign stocks listed in the United States. Perhaps surprisingly, I found that the estimates of covariation with the US market have increased over time, even after conditioning on the general increase in covariation between US and foreign markets.

Using these parameter estimates to evaluate a simple three-asset model, I found that while the allocation in the foreign markets do not decline much over time, the allocation into US listed foreign stocks do decline, particularly in the 1990s. These results suggest that the diversification properties of domestic-listed foreign stocks are inferior to investing in foreign markets directly. I then evaluated the two asset model using the cross-listed foreign stocks instead of foreign market indices. I found that the mean of allocation into foreign stocks do not decline over time, but the confidence intervals increase substantially.

A more important determinant of economic importance is whether these allocations in fact can reduce the variability of the portfolio. For this purpose, I compared the risk reduction from three possible foreign portfolios - foreign market indices, foreign cross-listed stocks, and both groups. Here I found that the greatest gains in diversification improvement since 1994 have been in foreign market indices over foreign cross-listed stocks or a combination of both groups. Of course, these results are just a way to demonstrate the effects of the parameters. An unconstrained efficient portfolio decision based upon the universe of foreign stocks would undoubtedly allow a larger reduction in risk. Nevertheless, the analysis here points to some general trends in the foreign portfolio diversification potentials. These trends could be summarized with the following results. First, international equity markets have become more highly correlated. Second, foreign stocks inside the US have come more correlated with the US over time. As a consequence of these trends, the attainable diversification from foreign diversification is declining whether the investor holds foreign stocks inside or outside the US. 
TABLE 1: Foreign Country Market Breaks

$$
\mathrm{r}_{\mathrm{t}}^{\ell}=I\left(T_{\tau}\right)\left[\alpha^{\ell}+\beta^{\ell} \mathrm{r}^{\mathrm{w}}+\mathrm{u}_{\ell, \mathrm{t}}\right], \quad \text { for } \ell=1, \ldots, \mathrm{L}, \quad \tau=1, \ldots, 4
$$

Panel A: Distribution of Break Categories across Marginal Significance Levels

\begin{tabular}{|cc|ccc|}
\cline { 3 - 5 } MSL & $\begin{array}{c}\text { Proportion of } \\
\text { Total Countries } \\
\text { Rejecting } \\
\text { Ho: No Breaks }\end{array}$ & \multicolumn{3}{|c|}{ Proportional \# of Breaks } \\
\hline $\mathbf{1 0 \%}$ & 0.722 & 0.692 & 0.231 & 0.077 \\
\hline $\mathbf{5 \%}$ & 0.639 & 0.739 & 0.261 & 0.043 \\
\hline $\mathbf{2 . 5 \%}$ & 0.639 & 0.783 & 0.217 & 0.043 \\
\hline
\end{tabular}

Panel B: Summary Statistics of Country Break Estimates

\begin{tabular}{|c|c|c|c|c|c|}
\hline \multirow{2}{*}{ Statistic $^{\text {30 }}$} & \multicolumn{2}{|c|}{ Full Sample by Break } & $\begin{array}{c}\text { Single Break } \\
\text { Only }\end{array}$ & \multicolumn{2}{c|}{ Double Break Only } \\
\cline { 2 - 6 } & Break 1 & Break 2 & Break & Break 1 & Break 2 \\
\hline Mean Break & 1992.11 & 1997.11 & 1993.05 & 1991.03 & 1997.11 \\
$\begin{array}{c}\text { Mean StErr } \\
\text { (in months) }\end{array}$ & 10 & 5 & 12 & 6 & 5 \\
\hline
\end{tabular}

${ }^{30}$ Estimates based upon $5 \%$ MSL case. Results for $2.5 \%$ and $10 \%$ are almost identical. 
TABLE 2: Foreign Country Market Breaks: Estimates of Beta $\mathrm{r}_{\mathrm{t}}^{\ell}=I\left(T_{\tau}\right)\left[\alpha^{\ell}+\beta^{\ell} \mathrm{r}_{\mathrm{t}}^{\mathrm{w}}+\mathrm{u}_{\ell, \mathrm{t}}\right]$,

\begin{tabular}{|c|c|c|c|c|}
\hline Portfolio & $\boldsymbol{\beta}^{\boldsymbol{\ell}}$ Estimate & $\begin{array}{c}\text { Period 1 } \\
(\boldsymbol{\tau}=\mathbf{1})\end{array}$ & $\begin{array}{c}\text { Period 2 } \\
(\boldsymbol{\tau}=\mathbf{2})\end{array}$ & $\begin{array}{c}\text { Period 3 } \\
(\boldsymbol{\tau}=\mathbf{3})\end{array}$ \\
\hline \multicolumn{5}{|c|}{ Panel A: Market Weighted Total and by Quartile } \\
\hline Market & Mean & $\mathbf{0 . 3 8 6}$ & $\mathbf{0 . 5 7 2}$ & $\mathbf{0 . 5 8 8}$ \\
Weighted & Std Err Mean & 0.050 & 0.050 & 0.048 \\
& Std Dev Beta & 0.003 & 0.003 & 0.003 \\
\hline \multirow{3}{*}{$\mathbf{1}^{\text {st }}$ Quartile } & Mean & $\mathbf{0 . 4 0 0}$ & $\mathbf{0 . 4 8 6}$ & $\mathbf{0 . 3 2 7}$ \\
& Std Err Mean & 0.045 & 0.039 & 0.037 \\
& Std Dev Beta & 0.034 & 0.042 & 0.028 \\
\hline \multirow{3}{*}{ 2nd Quartile } & Mean & $\mathbf{0 . 3 6 8}$ & $\mathbf{0 . 5 8 3}$ & $\mathbf{0 . 5 6 1}$ \\
& Std Err Mean & 0.044 & 0.051 & 0.051 \\
& Std Dev Beta & 0.052 & 0.037 & 0.039 \\
\hline \multirow{3}{*}{$\mathbf{3}^{\text {rd } \text { Quartile }}$} & Mean & $\mathbf{0 . 4 3 6}$ & $\mathbf{0 . 7 3 5}$ & $\mathbf{0 . 6 9 4}$ \\
& Std Err Mean & 0.083 & 0.088 & 0.076 \\
& Std Dev Beta & 0.037 & 0.044 & 0.038 \\
\hline \multirow{3}{*}{ Top Quart } & Mean & $\mathbf{0 . 4 0 0}$ & $\mathbf{0 . 5 6 8}$ & $\mathbf{0 . 6 0 6}$ \\
& Std Err Mean & 0.062 & 0.056 & 0.056 \\
& Std Dev Beta & 0.043 & 0.046 & 0.044 \\
\hline \multicolumn{5}{|c|}{ Panel B: Market Weighted Developed Vs. Emerging } \\
\hline Market & Mean & 0.372 & 0.533 & 0.574 \\
Weighted & Std Err Mean & 0.040 & 0.041 & 0.041 \\
Developed & Std Dev Beta & 0.031 & 0.037 & 0.038 \\
\hline Market & Mean & 0.458 & 0.761 & 0.655 \\
Weighted & Std Err Mean & 0.104 & 0.093 & 0.085 \\
Emerging & Std Dev Beta & 0.012 & 0.021 & 0.016 \\
\hline \multicolumn{5}{|c|}{}
\end{tabular}

\begin{tabular}{|c|c|c|c|c|}
\multicolumn{5}{|c|}{ Panel C: Market Weighted by Region } \\
\hline \multirow{2}{*}{ Equally } & Mean & $\mathbf{0 . 3 6 2}$ & $\mathbf{0 . 5 8 9}$ & $\mathbf{0 . 5 3 2}$ \\
Weighted & Std Err Mean & 0.092 & 0.078 & 0.071 \\
& Std Dev Beta & 0.003 & 0.003 & 0.003 \\
\hline \multirow{4}{*}{ Europe } & Mean & $\mathbf{0 . 3 2 8}$ & $\mathbf{0 . 6 0 5}$ & $\mathbf{0 . 5 8 1}$ \\
& Std Err Mean & 0.057 & 0.058 & 0.049 \\
& Std Dev Beta & 0.024 & 0.027 & 0.028 \\
\hline \multirow{4}{*}{ Asia } & Mean & $\mathbf{0 . 3 8 6}$ & $\mathbf{0 . 5 8 6}$ & $\mathbf{0 . 5 2 1}$ \\
& Std Err Mean & 0.093 & 0.096 & 0.095 \\
& Std Dev Beta & 0.020 & 0.299 & 0.299 \\
\hline \multirow{3}{*}{ Oceania } & Mean & $\mathbf{0 . 4 3 5}$ & $\mathbf{0 . 3 1 7}$ & $\mathbf{0 . 3 1 7}$ \\
& Std Err Mean & 0.043 & 0.053 & 0.053 \\
& Std Dev Beta & 0.112 & 0.116 & 0.116 \\
\hline \multirow{2}{*}{ Latin } & Mean & $\mathbf{0 . 5 3 3}$ & $\mathbf{0 . 6 2 6}$ & $\mathbf{0 . 4 5 9}$ \\
America & Std Err Mean & 0.149 & 0.100 & 0.087 \\
& Std Dev Beta & 0.004 & 0.009 & 0.004 \\
\hline Africa \& & Mean & $\mathbf{0 . 0 6 4}$ & $\mathbf{0 . 7 3 3}$ & $\mathbf{0 . 7 3 3}$ \\
Middle & Std Err Mean & 0.172 & 0.088 & 0.088 \\
East & Std Dev Beta & 0.003 & 0.003 & 0.003 \\
\hline
\end{tabular}


TABLE 3: Foreign Market Breaks and Restrictions on Foreign Firm Pricing

$$
\begin{aligned}
r_{t}^{\ell} & =I\left(T_{\tau}\right)\left[\alpha_{\tau}^{\ell}+\beta_{\tau}^{\ell} r_{t}^{w}+u_{t, \tau}^{\ell}\right], \quad \quad \text { for } \ell=1, \ldots, \mathrm{L}, \quad \tau=1, \ldots, \mathrm{m}+1 \\
r_{t}^{i \ell} & =\alpha^{i \ell}+\beta^{i \ell} r_{t}^{\ell}+\beta^{i w} r_{t}^{w}+e_{t}^{i \ell} \\
& =\alpha^{i \ell}+\beta^{i \ell} I\left(T_{\tau}\right) \alpha_{\tau}^{\ell}+\left(\beta^{i w}+\beta^{i \ell} I\left(T_{\tau}\right) \beta_{\tau}^{\ell}\right) r_{t}^{w}+\beta^{i \ell} I\left(T_{\tau}\right) u_{t, \tau}^{\ell}+e_{t}^{i \ell}
\end{aligned}
$$

\begin{tabular}{|c|c|c|c|c|}
\hline \multicolumn{5}{|c|}{ Panel A: Firms Decomposed by Country Break Category } \\
\hline Statistic & $\begin{array}{c}\text { No Breaks } \\
\mathbf{m}=\mathbf{0}\end{array}$ & $\begin{array}{c}\text { One Break } \\
\mathbf{m}=1\end{array}$ & $\begin{array}{c}\text { Two } \\
\text { Breaks } \\
\text { m=2 }\end{array}$ & All \\
\hline $\begin{array}{l}\text { Proportion of Firms } \\
\text { No of Firms }\end{array}$ & $\begin{array}{c}0.402 \\
130\end{array}$ & $\begin{array}{c}0.415 \\
134\end{array}$ & $\begin{array}{c}0.183 \\
59\end{array}$ & $\begin{array}{c}1.000 \\
324\end{array}$ \\
\hline \multicolumn{5}{|c|}{ Panel B. Proportion of Firms rejecting Zero Parameter Restrictions } \\
\hline Null Hypothesis & No Breaks & One Break & $\begin{array}{c}\text { Two } \\
\text { Breaks }\end{array}$ & All \\
\hline Ho: $\alpha^{i \ell}=0 ; \beta^{i w}=0$ & 0.399 & 0.459 & 0.200 & 0.401 \\
\hline Ho $: \alpha^{i \ell}=0$ & 0.040 & 0.092 & 0.000 & 0.054 \\
\hline Ho: $\beta^{i w}=0$ & 0.457 & 0.495 & 0.267 & 0.452 \\
\hline Ho $: I\left(T_{\tau}\right) \alpha^{i \ell}=0$ & 0.058 & 0.050 & 0.007 & 0.032 \\
\hline Ho: $I\left(T_{\tau}\right) \beta^{i w}=0$ & 0.669 & 0.928 & 0.210 & 0.420 \\
\hline \multicolumn{5}{|c|}{$\begin{array}{c}\text { Panel C: Proportion of Firms rejecting Constant Parameters } \\
\text { across Country Breaks }\end{array}$} \\
\hline Null Hypothesis & $\delta^{i \ell} \equiv \alpha^{i \ell}$ & $\delta^{i \ell} \equiv \beta^{i \ell}$ & $\delta^{i \ell} \equiv \beta^{i w}$ & $\begin{array}{c}\delta^{i \ell} \equiv \\
\left\{\alpha^{i \ell}, \beta^{i \ell}, \beta^{i w}\right\}\end{array}$ \\
\hline $\begin{array}{c}\text { Ho: } \\
I\left(T_{j}\right) \delta^{i \ell}=I\left(T_{k}\right) \delta^{i \ell}, \\
j \neq k, \forall j, k\end{array}$ & 0.060 & 0.163 & 0.132 & 0.397 \\
\hline
\end{tabular}




\begin{tabular}{|c|c|c|c|c|c|}
\hline & $\begin{array}{r}\text { P } \\
\text { Entry = ? }\end{array}$ & $\begin{array}{l}\text { umber of } \\
\text { uding Can }\end{array}$ & $\begin{array}{l}\text { n Stock Ob } \\
\text { n firms, Sec }\end{array}$ & $\begin{array}{l}\text { s } \\
y=F u l l\end{array}$ & \\
\hline Category & Statistic & Total & \multicolumn{2}{|c|}{ By Subperiods in Local Market Stock Return } & $\begin{array}{l}\text { k Return } \\
\tau=3\end{array}$ \\
\hline $\begin{array}{c}\text { No of Firms } \\
\text { per Time } \\
\text { (Cross-Section) }\end{array}$ & Count & $\begin{array}{l}312 \\
363\end{array}$ & $\begin{array}{l}291 \\
304\end{array}$ & $\begin{array}{l}139 \\
190\end{array}$ & $\begin{array}{l}30 \\
30\end{array}$ \\
\hline \multirow{4}{*}{$\begin{array}{c}\text { No of } \\
\text { Observations } \\
\text { in } \mathbf{I}(\mathbf{T} \boldsymbol{\tau}) \text { per } \\
\text { Firm } \\
\text { (Time Series) }\end{array}$} & Mean & $\begin{array}{l}772 \\
800\end{array}$ & $\begin{array}{l}576 \\
558\end{array}$ & $\begin{array}{l}461 \\
586\end{array}$ & $\begin{array}{l}294 \\
294\end{array}$ \\
\hline & Median & $\begin{array}{l}564 \\
634\end{array}$ & $\begin{array}{l}406 \\
388\end{array}$ & $\begin{array}{l}361 \\
505\end{array}$ & $\begin{array}{l}266 \\
266\end{array}$ \\
\hline & Min & $\begin{array}{l}62 \\
62\end{array}$ & $\begin{array}{l}62 \\
62\end{array}$ & $\begin{array}{l}75 \\
75\end{array}$ & $\begin{array}{l}266 \\
266\end{array}$ \\
\hline & Max & $\begin{array}{l}1625 \\
1670\end{array}$ & $\begin{array}{l}1625 \\
1625\end{array}$ & $\begin{array}{l}1255 \\
1437\end{array}$ & $\begin{array}{l}346 \\
346\end{array}$ \\
\hline $\begin{array}{l}\text { Total No. of } \\
\text { Firm,Country } \\
\text { Observations } \\
\text { (Time Series } \\
\text { and Cross } \\
\text { Section) } \\
\end{array}$ & Count & $\begin{array}{l}481,792 \\
580,478\end{array}$ & 167,640 & 222,652 & 17,632 \\
\hline
\end{tabular}


TABLE 4: Foreign Company Stock Breaks Conditional on Local Market Breaks

$$
\begin{array}{ll}
\mathrm{r}_{\mathrm{t}}^{\ell}=\mathrm{I}\left(\mathrm{T}_{\tau}\right)\left[\alpha_{\tau}^{\ell}+\beta_{\tau}^{\ell} \mathrm{r}_{t}^{\mathrm{w}}+\mathrm{u}_{\tau, \mathrm{t}}^{\ell}\right] ; & \text { for } \ell=1, \ldots, \mathrm{L}, \quad \tau=1, \ldots, 4 \\
\mathrm{r}_{\mathrm{t}}^{\mathrm{i} \ell}=\Xi\left(\kappa_{\varsigma}\right)\left[\alpha_{\varsigma}^{\mathrm{i} \ell}+\beta_{\varsigma}^{i \ell} \mathrm{r}_{\mathrm{t}}^{\ell}+\beta_{\varsigma}^{i w} \mathrm{r}_{\mathrm{t}}^{\mathrm{w}}+\mathrm{e}_{\varsigma, \mathrm{t}}^{\mathrm{i} \ell}\right], & \text { for } \mathrm{i}=1, \ldots, \mathrm{N} ; \varsigma=1, \ldots, 4
\end{array}
$$

\begin{tabular}{|c|c|c|c|c|c|c|c|c|c|c|}
\hline \multicolumn{11}{|c|}{ Panel A: Summary Statistics of Breaks across Marginal Significance Levels } \\
\hline \multirow{2}{*}{ MSL } & \multirow{2}{*}{ Statistic } & \multicolumn{3}{|c|}{ Full Sample by Break } & \multirow{2}{*}{$\begin{array}{c}\text { Single } \\
\text { Break } \\
\text { Only }\end{array}$} & \multicolumn{2}{|c|}{$\begin{array}{c}\text { Double Break } \\
\text { Only }\end{array}$} & \multicolumn{3}{|c|}{ Triple Break Only } \\
\hline & & $\begin{array}{c}\text { Break } \\
1\end{array}$ & $\begin{array}{c}\text { Break } \\
2\end{array}$ & $\begin{array}{c}\text { Break } \\
\mathbf{3}\end{array}$ & & $\begin{array}{c}\text { Break } \\
1\end{array}$ & $\begin{array}{c}\text { Break } \\
\quad 2\end{array}$ & $\begin{array}{c}\text { Break } \\
1\end{array}$ & $\begin{array}{c}\text { Break } \\
2\end{array}$ & $\begin{array}{c}\text { Break } \\
\mathbf{3}\end{array}$ \\
\hline \multirow{3}{*}{$10 \%$} & $\begin{array}{l}\text { Mean } \\
\text { Break }\end{array}$ & 1996.02 & 1999.12 & 1998.05 & 1997.03 & 1993.03 & 1999.11 & 1984.01 & 1989.00 & 1998.05 \\
\hline & $\begin{array}{c}\text { Mean } \\
\text { StErr } \\
\quad \text { (in } \\
\text { months) }\end{array}$ & 8.0 & 4.7 & 7.1 & 8.3 & 7.0 & 4.8 & 6.8 & 4.4 & 7.1 \\
\hline & $\begin{array}{l}\text { No. of } \\
\text { Stocks }\end{array}$ & 164 & 35 & 4 & 129 & \multicolumn{2}{|c|}{31} & \multicolumn{3}{|c|}{4} \\
\hline \multirow{3}{*}{$5 \%$} & $\begin{array}{l}\text { Mean } \\
\text { Break }\end{array}$ & 1996.06 & 1998.11 & 1998.08 & 1997.05 & 1992.06 & 1999.06 & 1978.11 & 1985.09 & 1998.08 \\
\hline & $\begin{array}{c}\text { Mean } \\
\text { StErr } \\
\quad \text { (in } \\
\text { months) }\end{array}$ & 6.8 & 4.8 & 4.2 & 7.0 & 5.7 & 4.6 & 8.2 & 8.6 & 4.2 \\
\hline & $\begin{array}{l}\text { No. of } \\
\text { Stocks }\end{array}$ & 134 & 23 & 1 & 111 & \multicolumn{2}{|c|}{22} & \multicolumn{3}{|c|}{1} \\
\hline \multirow{3}{*}{$2.5 \%$} & $\begin{array}{l}\text { Mean } \\
\text { Break }\end{array}$ & 1996.07 & 1999.12 & NA & 1997.02 & 1991.12 & 1999.12 & NA & NA & NA \\
\hline & $\begin{array}{c}\text { Mean } \\
\text { StErr } \\
\quad \text { (in } \\
\text { months) }\end{array}$ & 5.7 & 4.7 & $N A$ & 5.8 & 5.0 & 4.7 & $N A$ & $N A$ & $N A$ \\
\hline & $\begin{array}{l}\text { No. of } \\
\text { Stocks }\end{array}$ & 111 & 13 & 0 & 98 & \multicolumn{2}{|c|}{13} & \multicolumn{3}{|c|}{0} \\
\hline
\end{tabular}


TABLE 5: Foreign Stock Breaks and Local Market Betas

\begin{tabular}{|c|c|c|c|c|c|}
\hline \multicolumn{6}{|c|}{ Panel A: Market-Weighted Portfolios } \\
\hline Portfolio & $\beta^{\text {il }}$ Estimate & $\begin{array}{c}\text { Period 1 } \\
(\varsigma=1)\end{array}$ & $\begin{array}{c}\text { Period 2 } \\
(\varsigma=2)\end{array}$ & $\begin{array}{c}\text { Period 3 } \\
(\varsigma=3)\end{array}$ & $\begin{array}{c}\text { Period } 4 \\
(\varsigma=4)\end{array}$ \\
\hline $\begin{array}{c}\text { Market } \\
\text { Weighted }\end{array}$ & $\begin{array}{c}\text { Mean } \\
\text { Std Err Mean } \\
\text { Std Dev Beta }\end{array}$ & $\begin{array}{l}1.000 \\
0.082 \\
0.001 \\
\end{array}$ & $\begin{array}{l}0.998 \\
0.093 \\
0.001\end{array}$ & $\begin{array}{l}1.043 \\
0.094 \\
0.001\end{array}$ & $\begin{array}{l}1.035 \\
0.093 \\
0.001\end{array}$ \\
\hline $\begin{array}{c}\text { Equally } \\
\text { Weighted }\end{array}$ & $\begin{array}{c}\text { Mean } \\
\text { Std Err Mean } \\
\text { Std Dev Beta }\end{array}$ & $\begin{array}{l}0.899 \\
0.103 \\
0.422\end{array}$ & $\begin{array}{l}1.043 \\
0.117 \\
0.471\end{array}$ & $\begin{array}{l}1.071 \\
0.120 \\
0.505 \\
\end{array}$ & $\begin{array}{l}1.062 \\
0.121 \\
0.493 \\
\end{array}$ \\
\hline $\begin{array}{c}\text { Bottom } \\
\text { Quartile }\end{array}$ & $\begin{array}{c}\text { Mean } \\
\text { Std Err Mean } \\
\text { Std Dev Beta }\end{array}$ & $\begin{array}{l}0.834 \\
0.125 \\
0.003\end{array}$ & $\begin{array}{l}0.985 \\
0.138 \\
0.004\end{array}$ & $\begin{array}{l}1.013 \\
0.139 \\
0.003\end{array}$ & $\begin{array}{l}1.002 \\
0.140 \\
0.003\end{array}$ \\
\hline $2^{\text {nd }}$ Quartile & $\begin{array}{c}\text { Mean } \\
\text { Std Err Mean } \\
\text { Std Dev Beta }\end{array}$ & $\begin{array}{l}0.870 \\
0.119 \\
0.002\end{array}$ & $\begin{array}{l}1.130 \\
0.135 \\
0.003\end{array}$ & $\begin{array}{l}1.147 \\
0.141 \\
0.003\end{array}$ & $\begin{array}{l}1.149 \\
0.142 \\
0.003\end{array}$ \\
\hline $3^{\text {rd }}$ Quartile & $\begin{array}{c}\text { Mean } \\
\text { Std Err Mean } \\
\text { Std Dev Beta }\end{array}$ & $\begin{array}{l}0.880 \\
0.098 \\
0.003\end{array}$ & $\begin{array}{l}0.975 \\
0.102 \\
0.003\end{array}$ & $\begin{array}{l}1.000 \\
0.106 \\
0.004\end{array}$ & $\begin{array}{l}0.991 \\
0.106 \\
0.004\end{array}$ \\
\hline Top Quart & $\begin{array}{c}\text { Mean } \\
\text { Std Err Mean } \\
\text { Std Dev Beta }\end{array}$ & $\begin{array}{l}1.031 \\
0.077 \\
0.001\end{array}$ & $\begin{array}{l}0.996 \\
0.089 \\
0.002\end{array}$ & $\begin{array}{l}1.046 \\
0.089 \\
0.002\end{array}$ & $\begin{array}{l}1.037 \\
0.088 \\
0.002\end{array}$ \\
\hline
\end{tabular}




\begin{tabular}{|c|c|c|c|c|c|}
\hline \multicolumn{6}{|c|}{ Panel B: Geographic Portfolios } \\
\hline $\begin{array}{c}\text { Portfolio } \\
\text { Equally } \\
\text { Weighted }\end{array}$ & $\beta^{\text {il }}$ Estimate & $\begin{array}{c}\text { Period 1 } \\
(\varsigma=1)\end{array}$ & $\begin{array}{c}\text { Period 2 } \\
(\varsigma=2)\end{array}$ & $\begin{array}{c}\text { Period } 3 \\
(\varsigma=3)\end{array}$ & $\begin{array}{c}\text { Period } 4 \\
(\varsigma=4)\end{array}$ \\
\hline \multirow{4}{*}{ Europe } & Mean & 0.912 & 1.028 & 1.065 & 1.062 \\
\hline & Std Err Mean & 0.101 & 0.123 & 0.127 & 0.127 \\
\hline & Std Dev Beta & 0.391 & 0.532 & 0.596 & 0.588 \\
\hline & No of Obs & 150 & 150 & 150 & 150 \\
\hline \multirow{4}{*}{ Asia } & Mean & 0.816 & 0.967 & 0.983 & 0.939 \\
\hline & Std Err Mean & 0.101 & 0.100 & 0.099 & 0.098 \\
\hline & Std Dev Beta & 0.510 & 0.540 & 0.542 & 0.487 \\
\hline & No of Obs & 62 & 62 & 62 & 62 \\
\hline \multirow{4}{*}{ Oceania } & Mean & 0.946 & 1.032 & 1.077 & 1.091 \\
\hline & Std Err Mean & 0.080 & 0.090 & 0.091 & 0.092 \\
\hline & Std Dev Beta & 0.288 & 0.371 & 0.243 & 0.233 \\
\hline & No of Obs & 12 & 12 & 12 & 12 \\
\hline \multirow{4}{*}{$\begin{array}{c}\text { Latin } \\
\text { America }\end{array}$} & Mean & 0.841 & 1.029 & 1.037 & 1.038 \\
\hline & Std Err Mean & 0.101 & 0.113 & 0.118 & 0.120 \\
\hline & Std Dev Beta & 0.495 & 0.427 & 0.429 & 0.436 \\
\hline & No of Obs & 89 & 89 & 89 & 89 \\
\hline \multirow{4}{*}{$\begin{array}{c}\text { Africa \& } \\
\text { Middle } \\
\text { East }\end{array}$} & Mean & 0.666 & 0.706 & 0.798 & 0.798 \\
\hline & Std Err Mean & 0.077 & 0.074 & 0.072 & 0.072 \\
\hline & Std Dev Beta & 0.467 & 0.496 & 0.601 & 0.601 \\
\hline & No of Obs & 9 & 9 & 9 & 9 \\
\hline \multicolumn{6}{|c|}{ Panel C: Developed and Emerging Market Portfolios } \\
\hline Portfolio & $\beta^{\text {it }}$ Estimate & $\begin{array}{c}\text { Period 1 } \\
(\varsigma=1)\end{array}$ & $\begin{array}{c}\text { Period 2 } \\
(\varsigma=2)\end{array}$ & $\begin{array}{c}\text { Period } 3 \\
(\varsigma=3)\end{array}$ & $\begin{array}{c}\text { Period } 4 \\
(\varsigma=4)\end{array}$ \\
\hline \multirow{3}{*}{$\begin{array}{c}\text { Developed } \\
\text { Markets }\end{array}$} & Mean & 0.906 & 0.946 & 0.920 & 0.918 \\
\hline & Std Err Mean & 0.072 & $\cap \cap 8)$ & $\cap \cap 83$ & $\cap \cap 82$ \\
\hline & Std Dev Beta & 0.001 & 0.001 & 0.001 & 0.001 \\
\hline \multirow{3}{*}{$\begin{array}{c}\text { Emerging } \\
\text { Markets }\end{array}$} & Mean & 0.874 & 1.072 & 1.029 & 1.029 \\
\hline & Std Err Mean & $\cap \cap 87$ & ก ก० & ก ก०२ & ก ก०२ \\
\hline & Std Dev Beta & 0.004 & 0.014 & 0.009 & 0.009 \\
\hline
\end{tabular}


TABLE 6: Foreign Stock Breaks and US Market Betas

$$
\begin{array}{ll}
\mathrm{r}_{\mathrm{t}}^{\ell}=I\left(T_{\tau}\right)\left[\alpha^{\ell}+\beta^{\ell} \mathrm{r}^{\mathrm{w}}{ }_{\mathrm{t}}+\mathrm{u}_{\ell, \mathrm{t}}\right], & \text { for } \ell=1, \ldots, \mathrm{L}, \tau=1, \ldots, 4 \\
\mathrm{r}^{\mathrm{i} \ell}=\Xi\left(\kappa_{\mathrm{c}}\right)\left[\alpha^{\mathrm{i} \ell}+\beta^{\mathrm{i} \ell} \mathrm{u}_{\ell, \mathrm{t}}+\beta^{\mathrm{iw}} \mathrm{r}^{\mathrm{w}}{ }_{\mathrm{t}}+\mathrm{e}_{\mathrm{i}, \mathrm{t}}\right], & \text { for } \mathrm{i}=1, \ldots, \mathrm{N}, \quad \varsigma=1, \ldots, 4
\end{array}
$$

\begin{tabular}{|c|c|c|c|c|c|}
\hline \multicolumn{6}{|c|}{ Panel A: Market-Weighted Portfolios } \\
\hline Portfolio & $\beta^{\text {iw }}$ Estimate & $\begin{array}{c}\text { Period } 1 \\
(\varsigma=1)\end{array}$ & $\begin{array}{c}\text { Period 2 } \\
(\varsigma=2)\end{array}$ & $\begin{array}{c}\text { Period } 3 \\
(\varsigma=3)\end{array}$ & $\begin{array}{c}\text { Period } 4 \\
(\varsigma=4)\end{array}$ \\
\hline $\begin{array}{c}\text { Market } \\
\text { Weighted }\end{array}$ & $\begin{array}{c}\text { Mean } \\
\text { Std Err Mean } \\
\text { Std Dev Beta }\end{array}$ & $\begin{array}{l}0,061 \\
0.002 \\
0001\end{array}$ & $\begin{array}{l}0.060 \\
0.003 \\
0.003 \\
\end{array}$ & $\begin{array}{l}0.081 \\
0.002 \\
0.003 \\
\end{array}$ & $\begin{array}{l}0.082 \\
0.003 \\
0.003 \\
\end{array}$ \\
\hline $\begin{array}{c}\text { Equally } \\
\text { Weighted }\end{array}$ & $\begin{array}{c}\text { Mean } \\
\text { Std Err Mean } \\
\text { Std Dev Beta }\end{array}$ & $\begin{array}{c}0.07 \\
0140 \\
0.29 \\
\end{array}$ & $\begin{array}{c}0.05 \\
0.071 \\
0.33 \\
\end{array}$ & $\begin{array}{c}0.06 \\
0.075 \\
0.34 \\
\end{array}$ & $\begin{array}{c}0.06 \\
0.074 \\
0.35 \\
\end{array}$ \\
\hline $\begin{array}{l}\text { Bottom } \\
\text { Quartile }\end{array}$ & $\begin{array}{c}\text { Mean } \\
\text { Std Err Mean } \\
\text { Std Dev Beta }\end{array}$ & $\begin{array}{l}n 007 \\
<0.001 \\
0001\end{array}$ & $\begin{array}{l}n \cap 7 n \\
<0.001 \\
0.001\end{array}$ & $\begin{array}{l}n \cap 46 \\
<0.001 \\
0.001\end{array}$ & $\begin{array}{l}n \cap 46 \\
<0.001 \\
0.001\end{array}$ \\
\hline $2^{\text {nd }}$ Quartile & $\begin{array}{c}\text { Mean } \\
\text { Std Err Mean } \\
\text { Std Dev: MW }\end{array}$ & $\begin{array}{l}0101 \\
<0.001 \\
0 \Omega 02\end{array}$ & $\begin{array}{l}n 057 \\
<0.001 \\
0.002 \\
\end{array}$ & $\begin{array}{l}0.07 n \\
0.001 \\
0.002 \\
\end{array}$ & $\begin{array}{l}n \cap 7 n \\
0.001 \\
0.002 \\
\end{array}$ \\
\hline $3^{\text {rd }}$ Quartile & $\begin{array}{c}\text { Mean } \\
\text { Std Err Mean } \\
\text { Std Dev Beta }\end{array}$ & $\begin{array}{l}0.051 \\
<0.001 \\
0001\end{array}$ & $\begin{array}{l}0 \cap 42 \\
<0.001 \\
0 \cap 02\end{array}$ & $\begin{array}{c}0103 \\
<0.001 \\
0.001 \\
\end{array}$ & $\begin{array}{c}0103 \\
<0.001 \\
0.001 \\
\end{array}$ \\
\hline Top Quart & $\begin{array}{c}\text { Mean } \\
\text { Std Err Mean } \\
\text { Std Dev Beta }\end{array}$ & $\begin{array}{c}n \cap \Delta 5 \\
<0.001 \\
0.001\end{array}$ & $\begin{array}{l}0.010 \\
<0.001 \\
0.001\end{array}$ & $\begin{array}{c}0.007 \\
<0.001 \\
0.001\end{array}$ & $\begin{array}{c}0.016 \\
<0.001 \\
0.001\end{array}$ \\
\hline
\end{tabular}




\begin{tabular}{|c|c|c|c|c|c|}
\hline \multicolumn{6}{|c|}{ Panel B: Geographic Equally Weighted Portfolios } \\
\hline Portfolio & $\beta^{\mathrm{iw}}$ Estimate & $\begin{array}{c}\text { Period 1 } \\
(\varsigma=1)\end{array}$ & $\begin{array}{c}\text { Period 2 } \\
(\varsigma=2)\end{array}$ & $\begin{array}{c}\text { Period } 3 \\
(\varsigma=3)\end{array}$ & $\begin{array}{c}\text { Period } 4 \\
(\varsigma=4)\end{array}$ \\
\hline \multirow{4}{*}{ Europe } & Mean & ก ก)ด & $\cap \cap 37$ & ก ก.5. & $\cap \cap K 1$ \\
\hline & Std Err Mean & ח & 0.137 & 0.136 & 0.136 \\
\hline & Std Dev Beta & ก 267 & 0.368 & 0.371 & 0.378 \\
\hline & No of Firms & 148 & 148 & 148 & 148 \\
\hline \multirow{4}{*}{ Asia } & Mean & ก 107 & 0.087 & 0.123 & 0.123 \\
\hline & Std Err Mean & 0188 & 0.154 & 0.154 & 0.154 \\
\hline & Std Dev Beta & ก 317 & 0.279 & 0.317 & 0.317 \\
\hline & No of Obs & 56 & 56 & 56 & 56 \\
\hline \multirow{4}{*}{ Oceania } & Mean & $\cap \cap 27$ & 0.087 & 0.066 & 0.066 \\
\hline & Std Err Mean & $\cap 090$ & 0.092 & 0.092 & 0.092 \\
\hline & Std Dev Beta & ก 278 & 0.293 & 0.298 & 0.298 \\
\hline & No of Obs & 12 & 12 & 12 & 12 \\
\hline \multirow{4}{*}{$\begin{array}{c}\text { Latin } \\
\text { America }\end{array}$} & Mean & $\cap \cap 70$ & 0.052 & 0.059 & 0.059 \\
\hline & Std Err Mean & I & 0.177 & 0.170 & 0.171 \\
\hline & Std Dev Beta & ก 280 & 0.290 & 0.290 & 0.290 \\
\hline & No of Obs & & & & \\
\hline \multirow{4}{*}{$\begin{array}{c}\text { Africa \& } \\
\text { Middle } \\
\text { East }\end{array}$} & Mean & & -0.190 & -0.383 & -0.383 \\
\hline & Std Err Mean & O 110 & 0.128 & 0.128 & 0.128 \\
\hline & Std Dev Beta & ก 311 & 0.420 & 0.336 & 0.336 \\
\hline & No of Obs & 7 & 7 & 7 & 7 \\
\hline
\end{tabular}

\begin{tabular}{|c|c|c|c|c|c|}
\hline \multicolumn{6}{|c|}{ Panel C: Developed and Emerging Market Weighted Portfolios } \\
\hline Portfolio & $\beta^{\text {iw }}$ Estimate & $\begin{array}{c}\text { Period 1 } \\
(\varsigma=1)\end{array}$ & $\begin{array}{c}\text { Period 2 } \\
(\varsigma=2)\end{array}$ & $\begin{array}{c}\text { Period } 3 \\
(\varsigma=3)\end{array}$ & $\begin{array}{c}\text { Period } 4 \\
(\varsigma=4)\end{array}$ \\
\hline $\begin{array}{c}\text { Market } \\
\text { Weighted } \\
\text { Developed }\end{array}$ & $\begin{array}{c}\text { Mean } \\
\text { Std Err Mean } \\
\text { Std Dev Beta }\end{array}$ & $\begin{array}{l}n \cap 44 \\
\cap \cap 86 \\
\cap \cap \Omega 2\end{array}$ & $\begin{array}{l}0 \cap 18 \\
0.100 \\
0 \Omega 2\end{array}$ & $\begin{array}{l}0 \cap 4 \\
0.098 \\
0 \Omega 70\end{array}$ & $\begin{array}{l}0 \cap 21 \\
0.098 \\
0 \Omega 2\end{array}$ \\
\hline $\begin{array}{c}\text { Market } \\
\text { Weighted } \\
\text { Emerging }\end{array}$ & $\begin{array}{c}\text { Mean } \\
\text { Std Err Mean } \\
\text { Std Dev Beta }\end{array}$ & $\begin{array}{l}0 \cap 68 \\
0.157 \\
0.003\end{array}$ & $\begin{array}{l}0.140 \\
0.140 \\
0 \cap \Omega 4\end{array}$ & $\begin{array}{l}0.024 \\
0.129 \\
0 \cap \Omega 4\end{array}$ & $\begin{array}{l}0 \cap 4 \\
0.130 \\
0 \cap \Omega 4\end{array}$ \\
\hline
\end{tabular}


Figure 1A: Break Point Estimates by Country

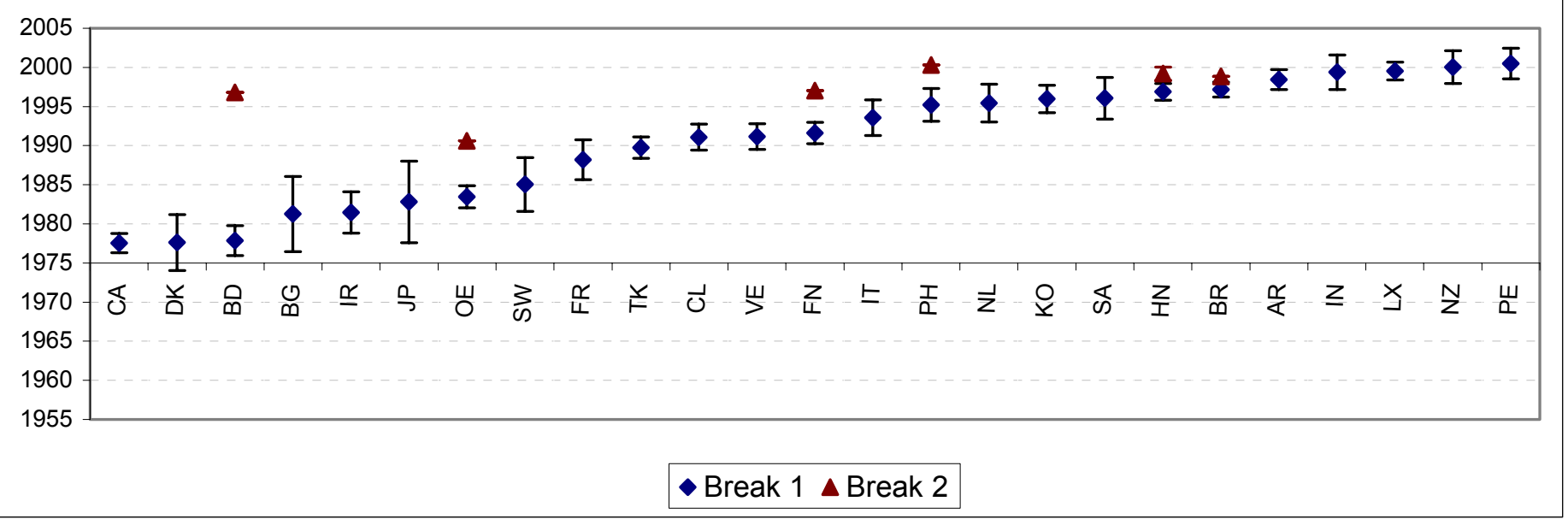



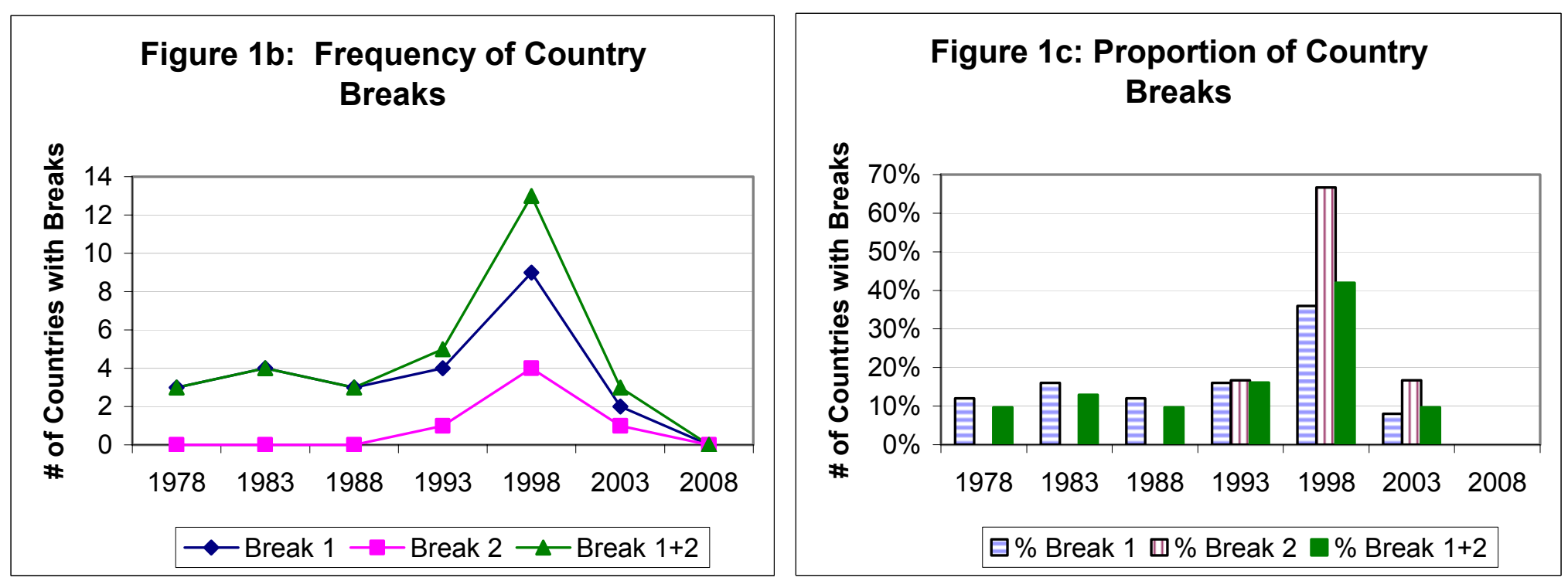
Figure 2: Market-Weighted Country Betas on US Market

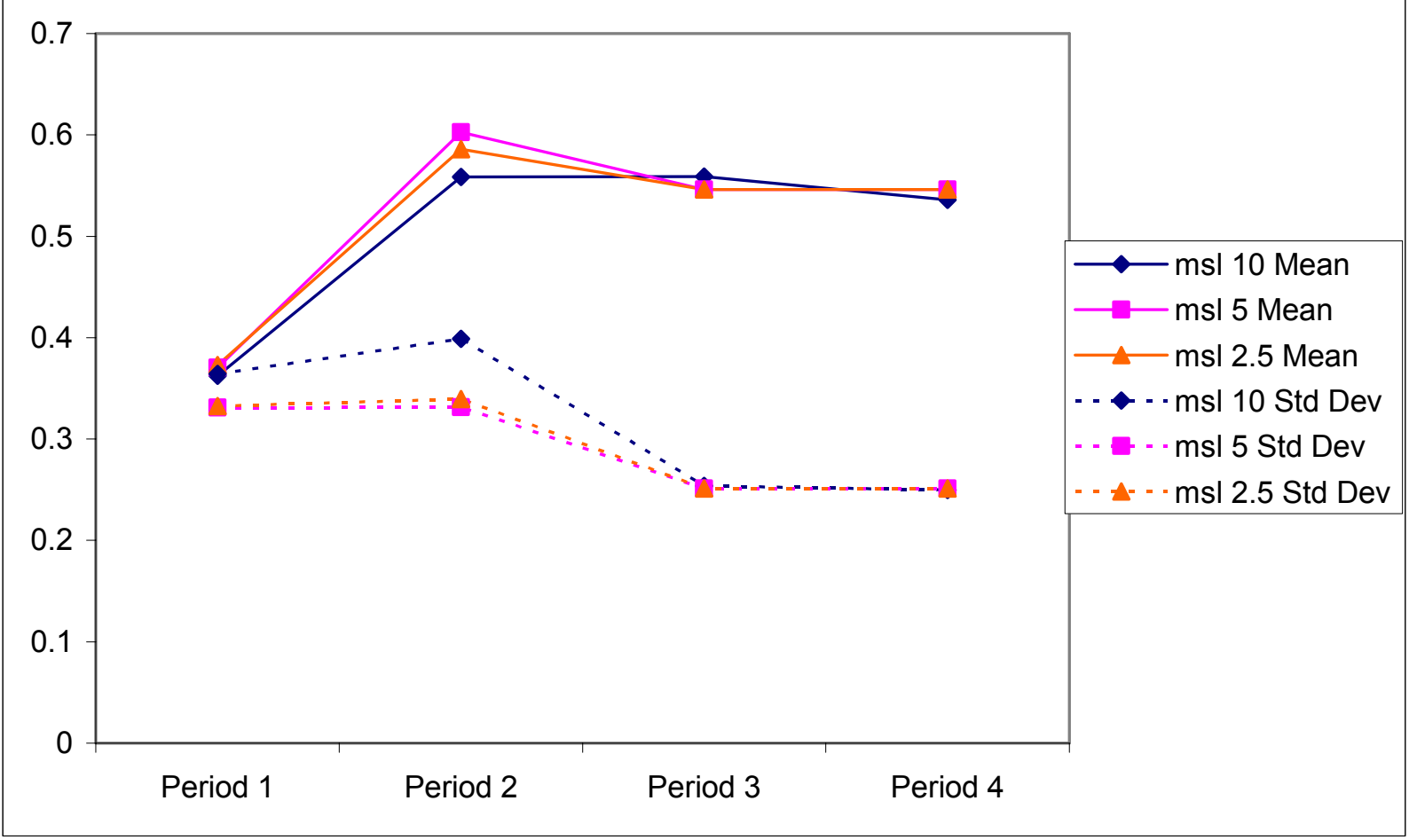


Figure 3A: Local Market Betas on US (MSL $=5 \%$ )

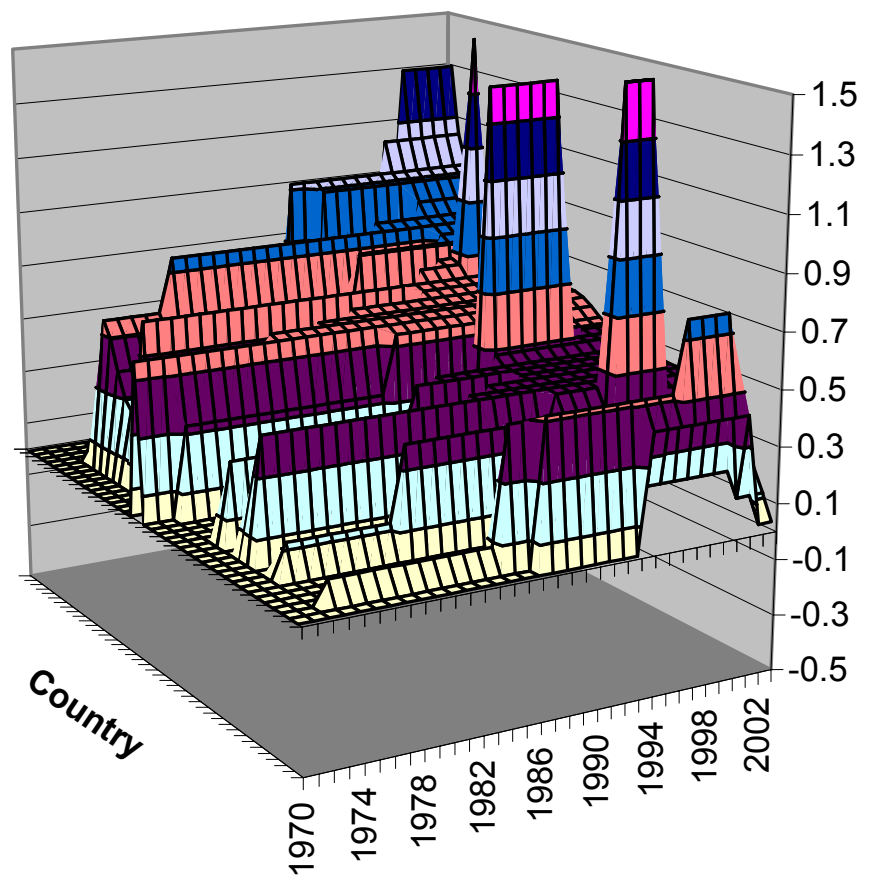

ㅁ.3-1.5

-1.1-1.3

$\square 0.9-1.1$

口0.7-0.9

$\square 0.5-0.7$

๑ 0.3-0.5

ㅁ.1-0.3

ㅁ-0.1-0.1

ㅁ-0.3--0.1

$\square-0.5--0.3$ 
Figure 3B: Local Market Betas on US (MSL 10\%)

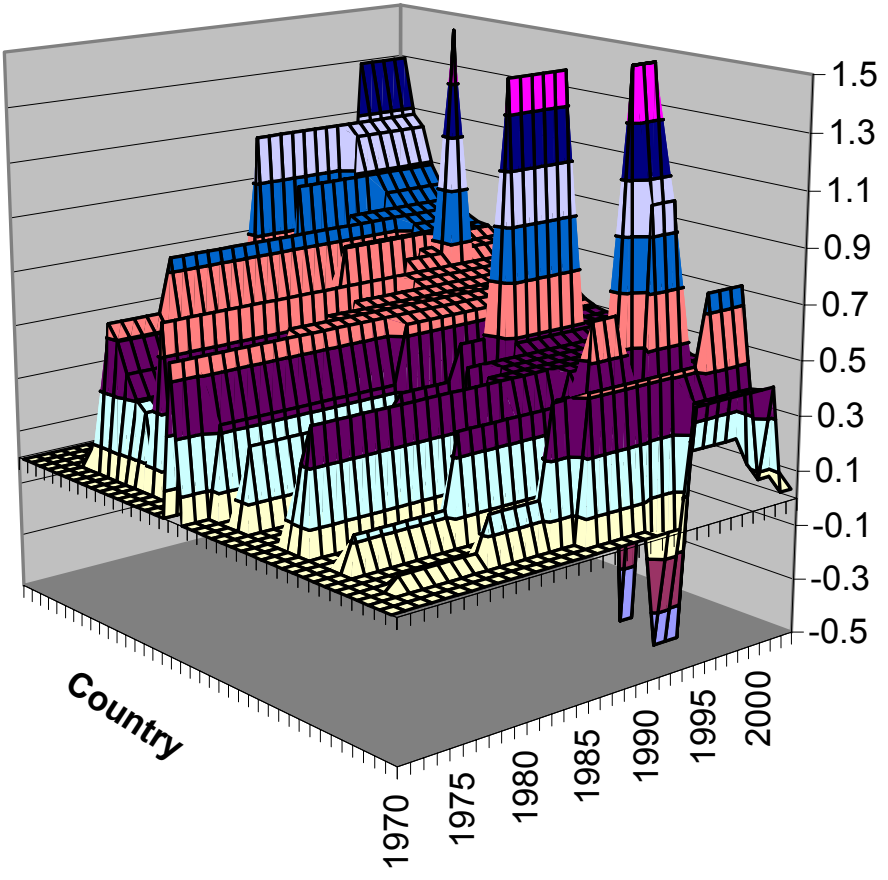




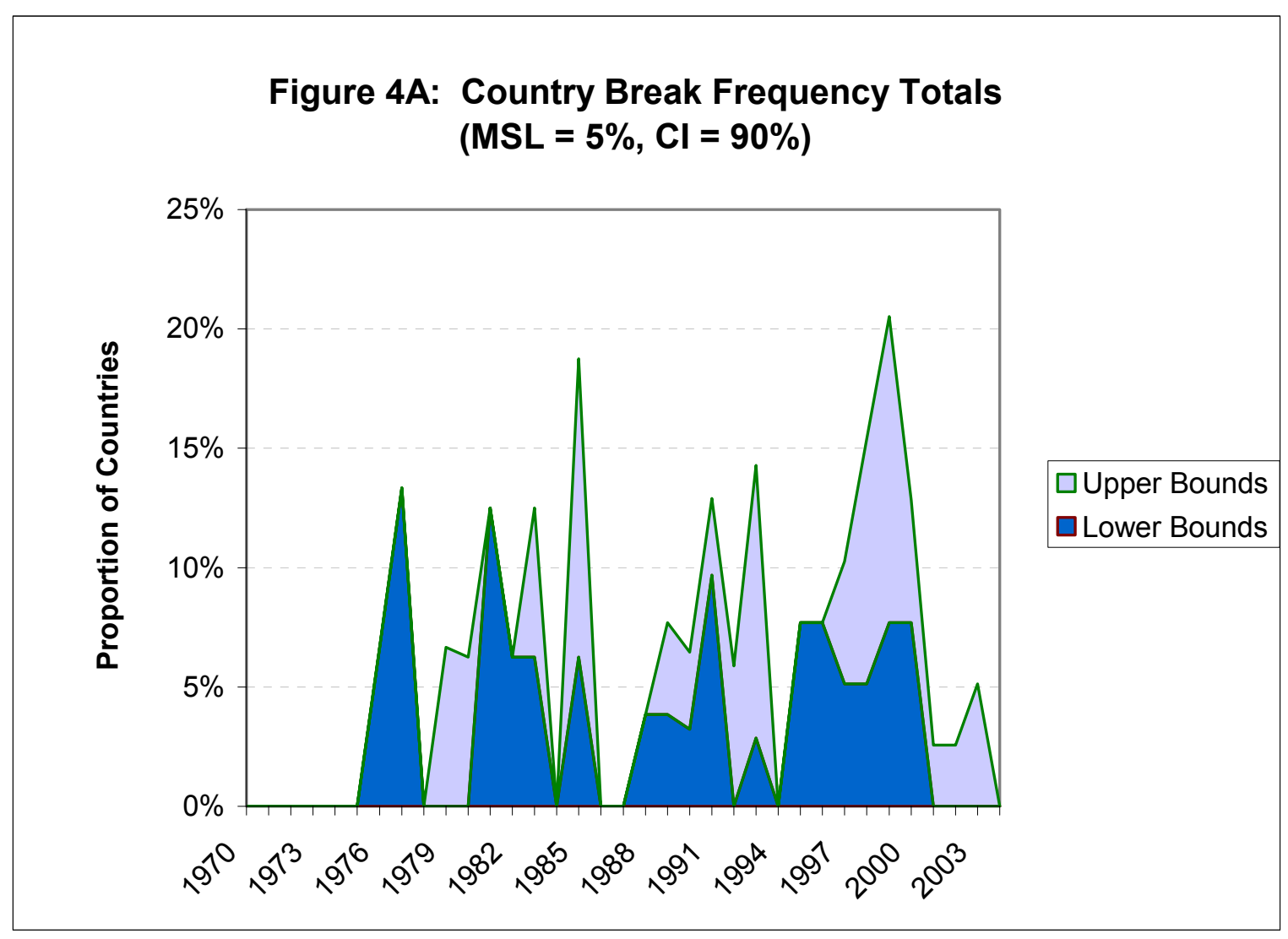




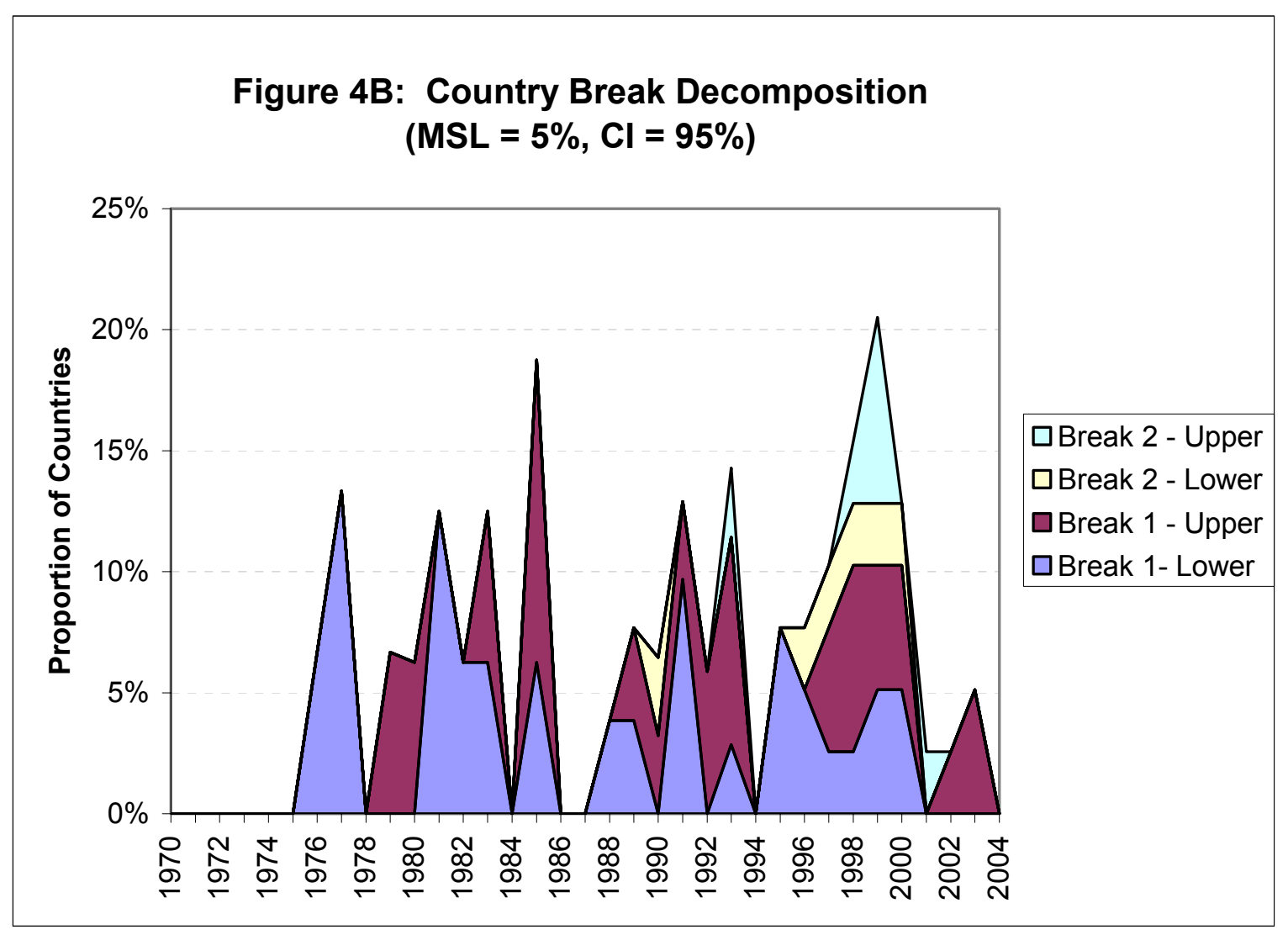




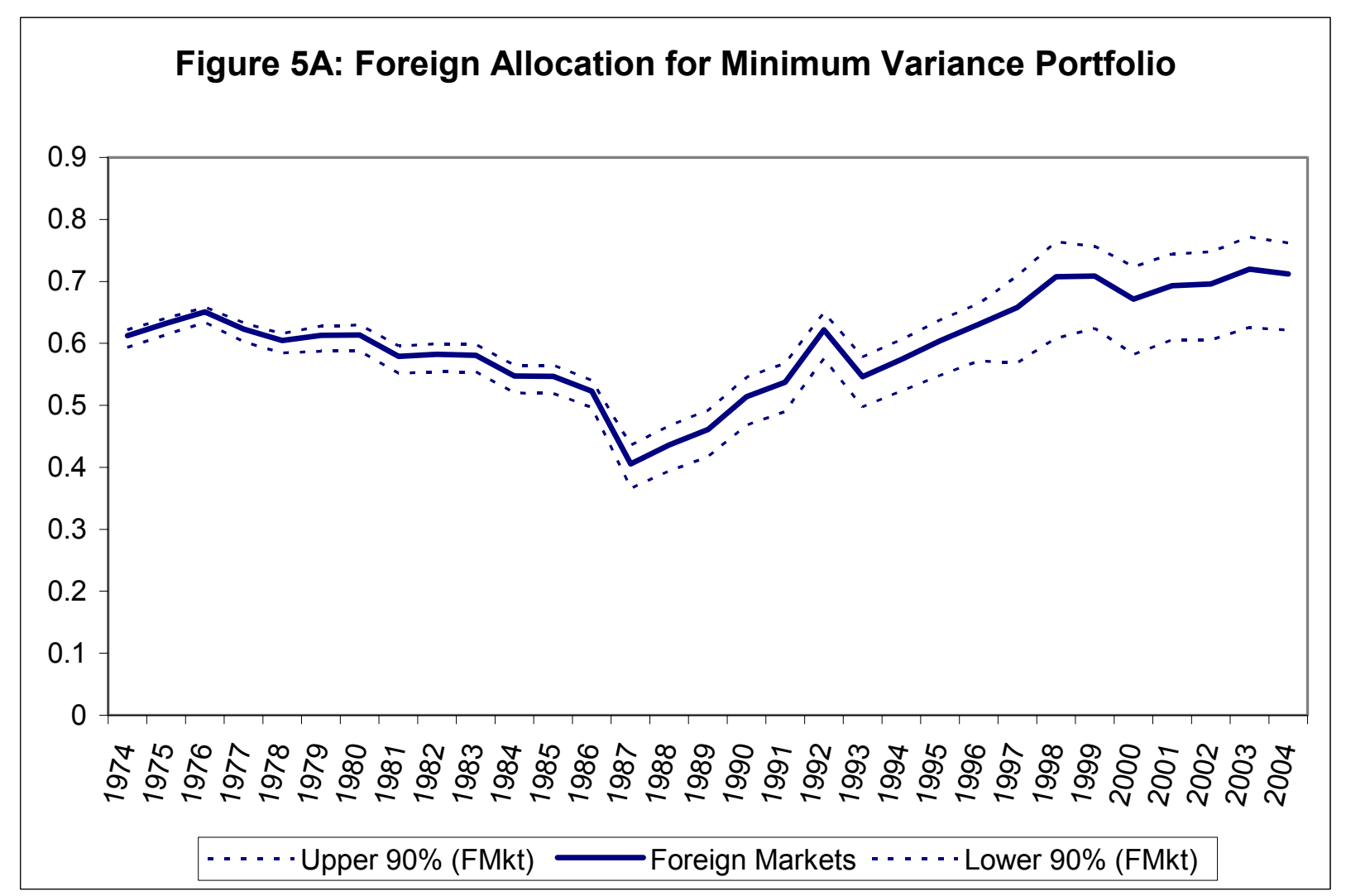




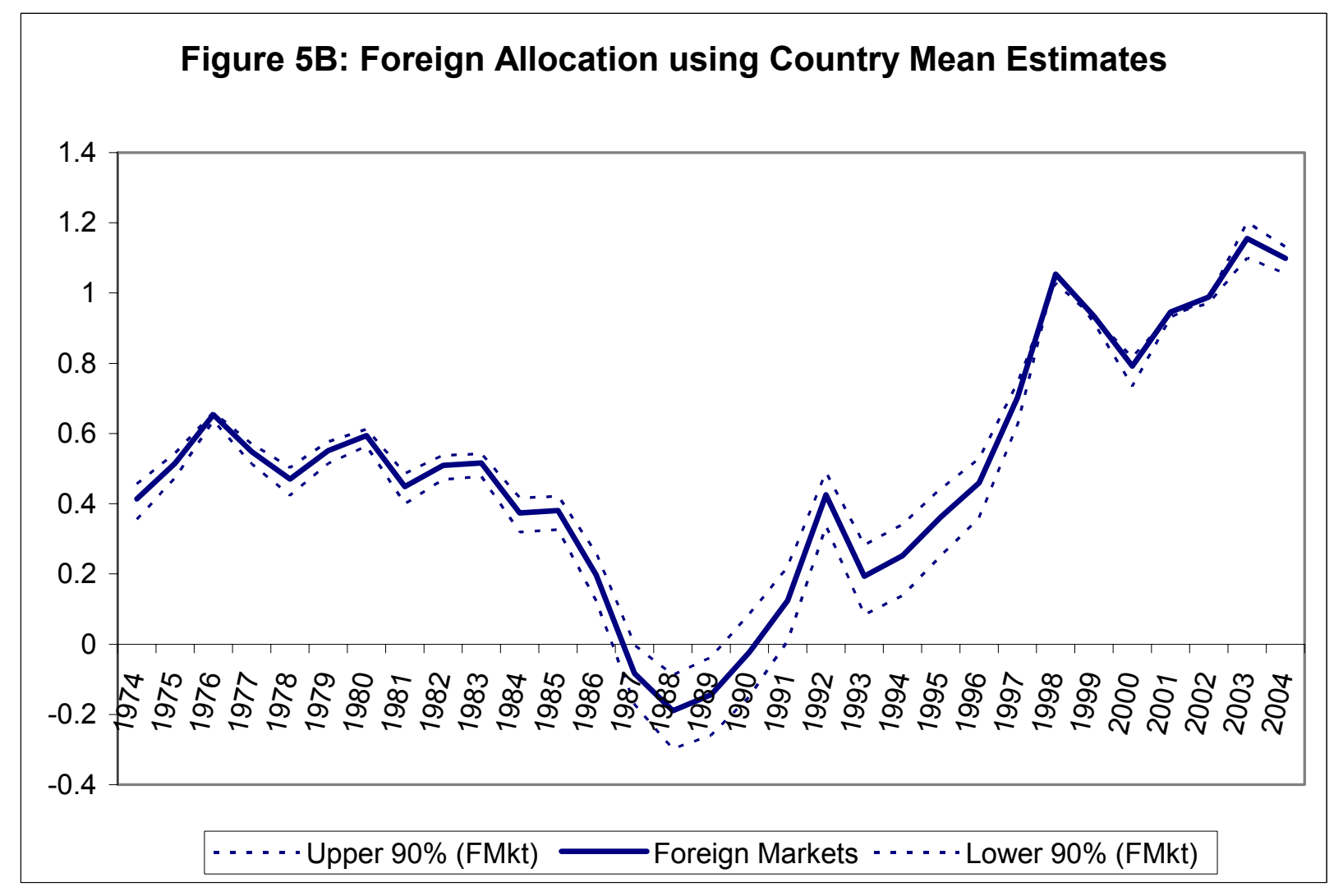




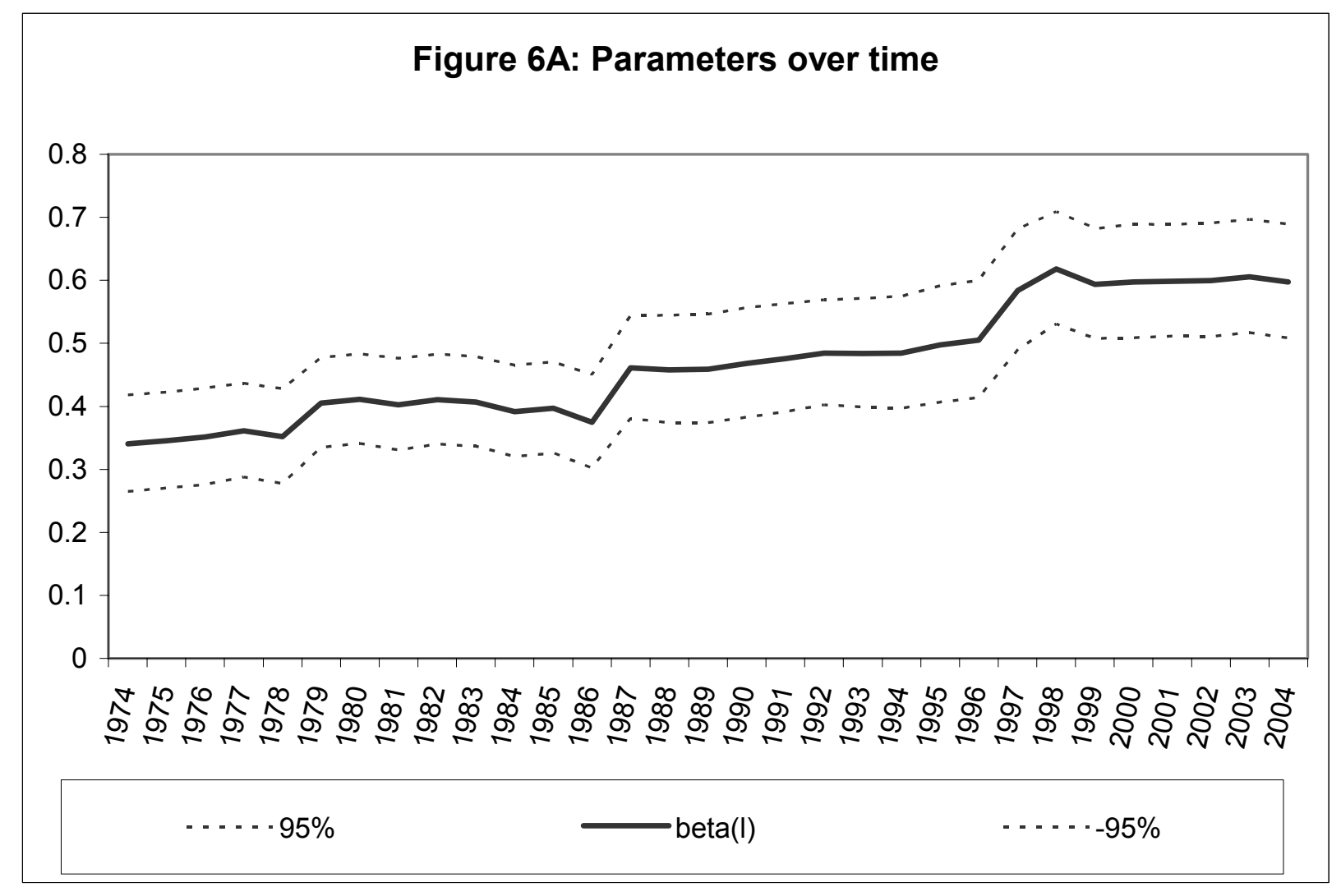




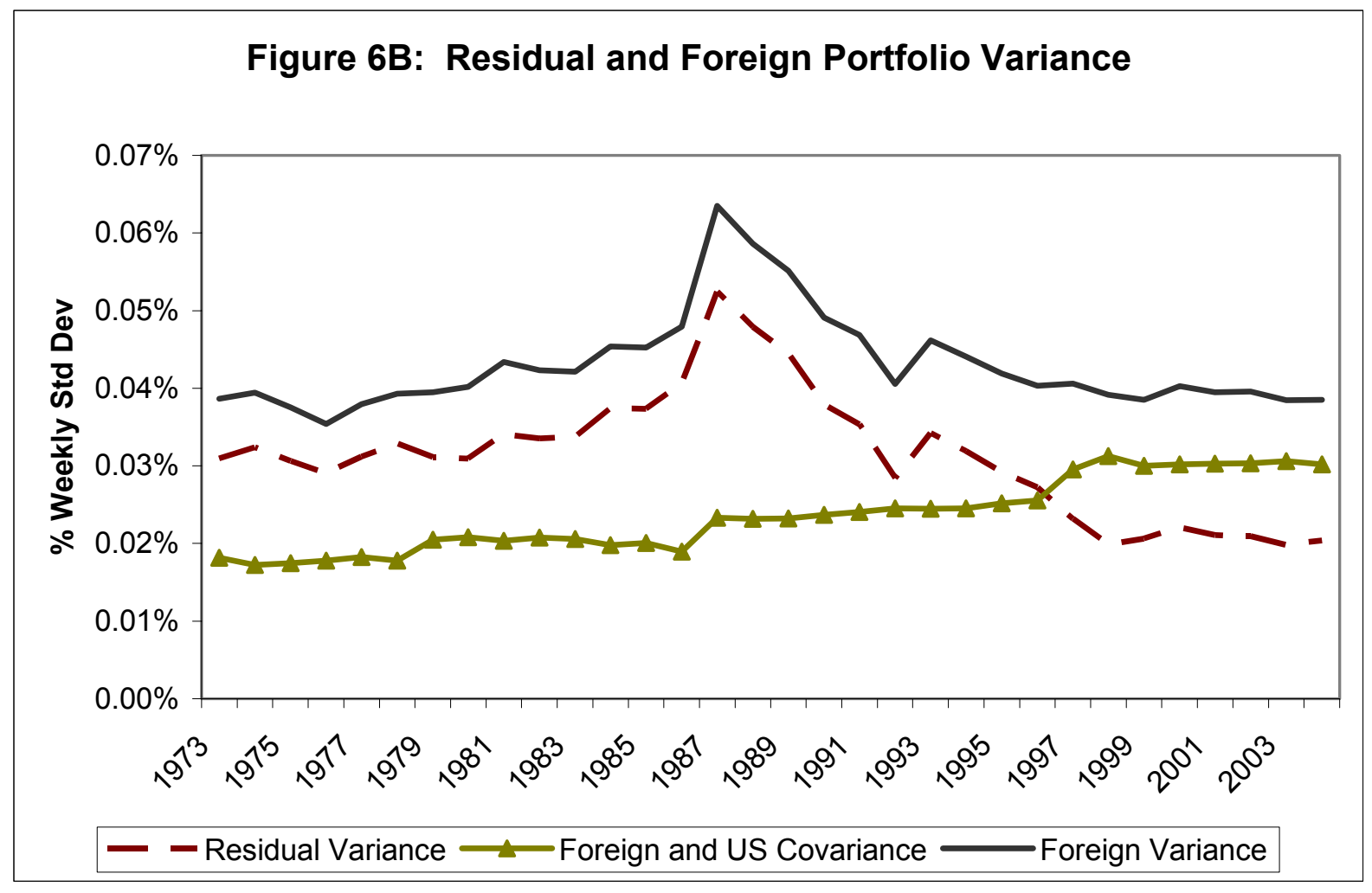




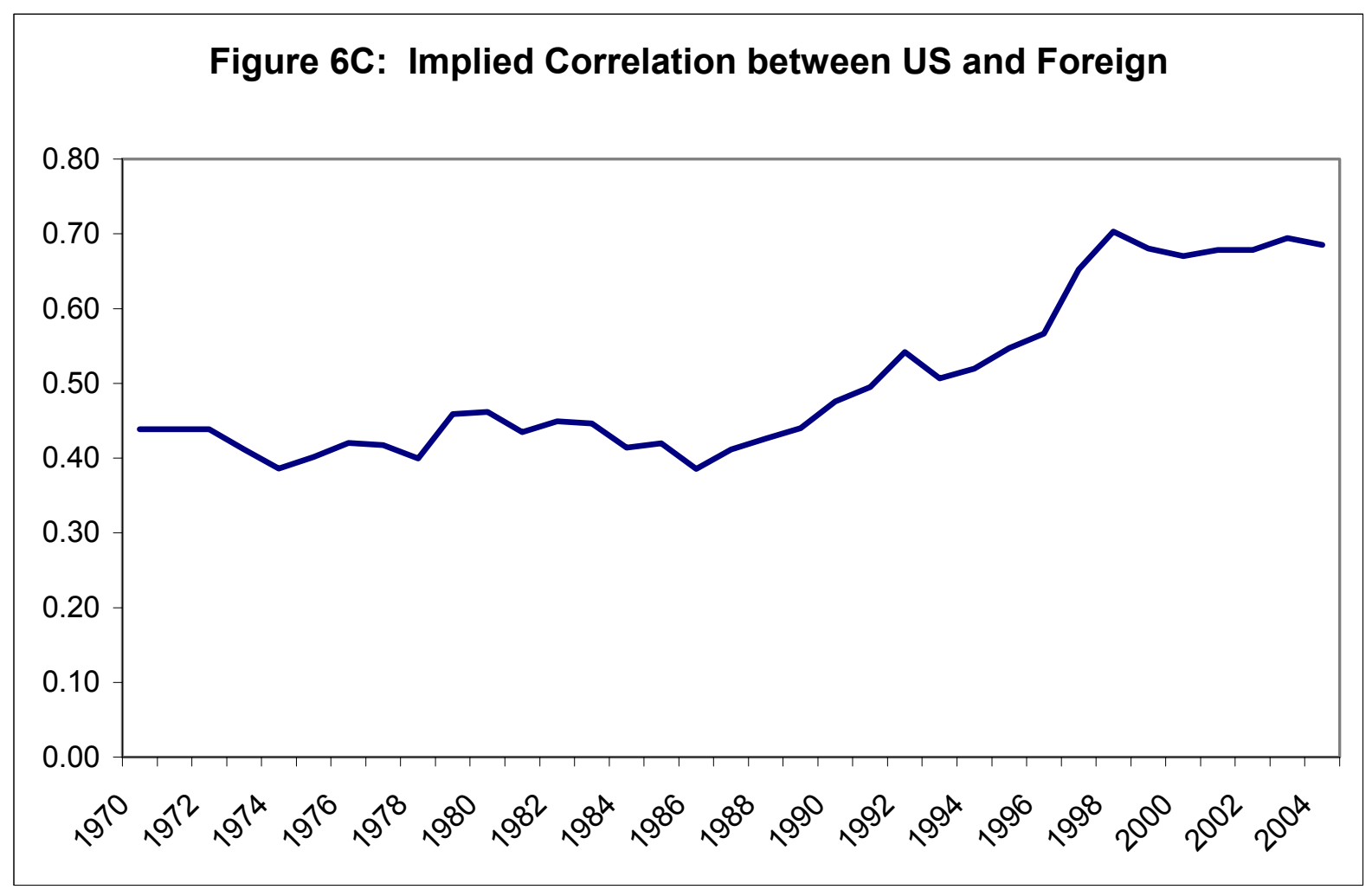




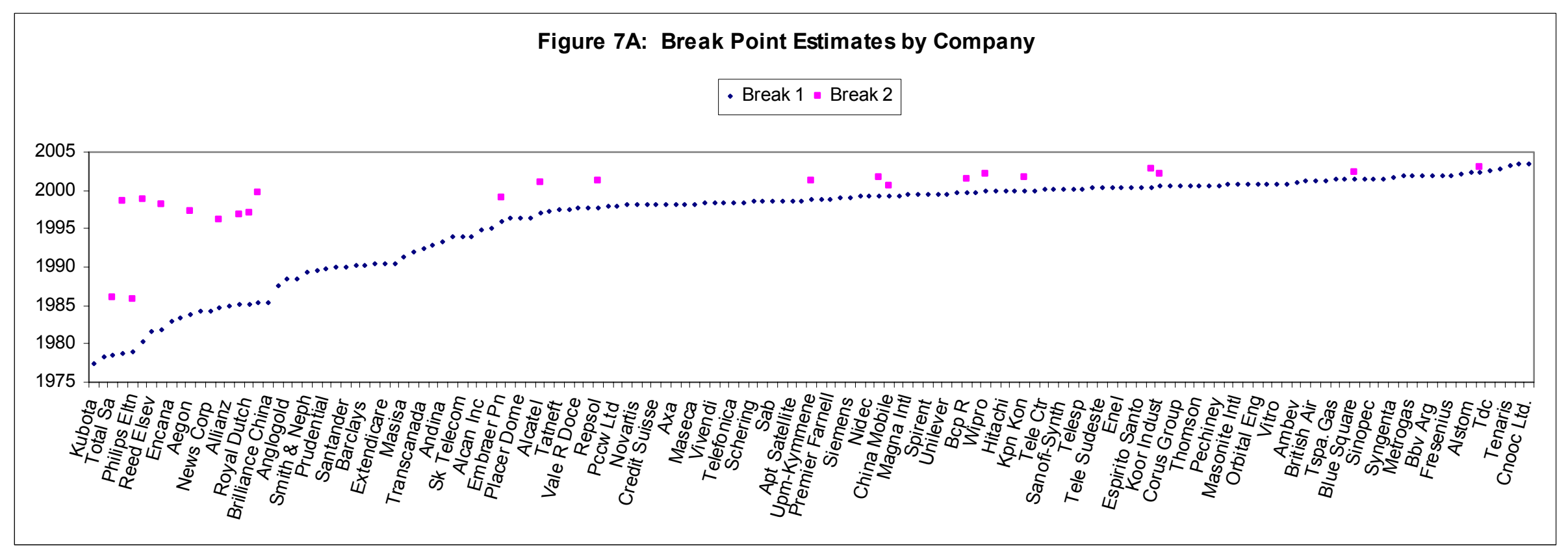




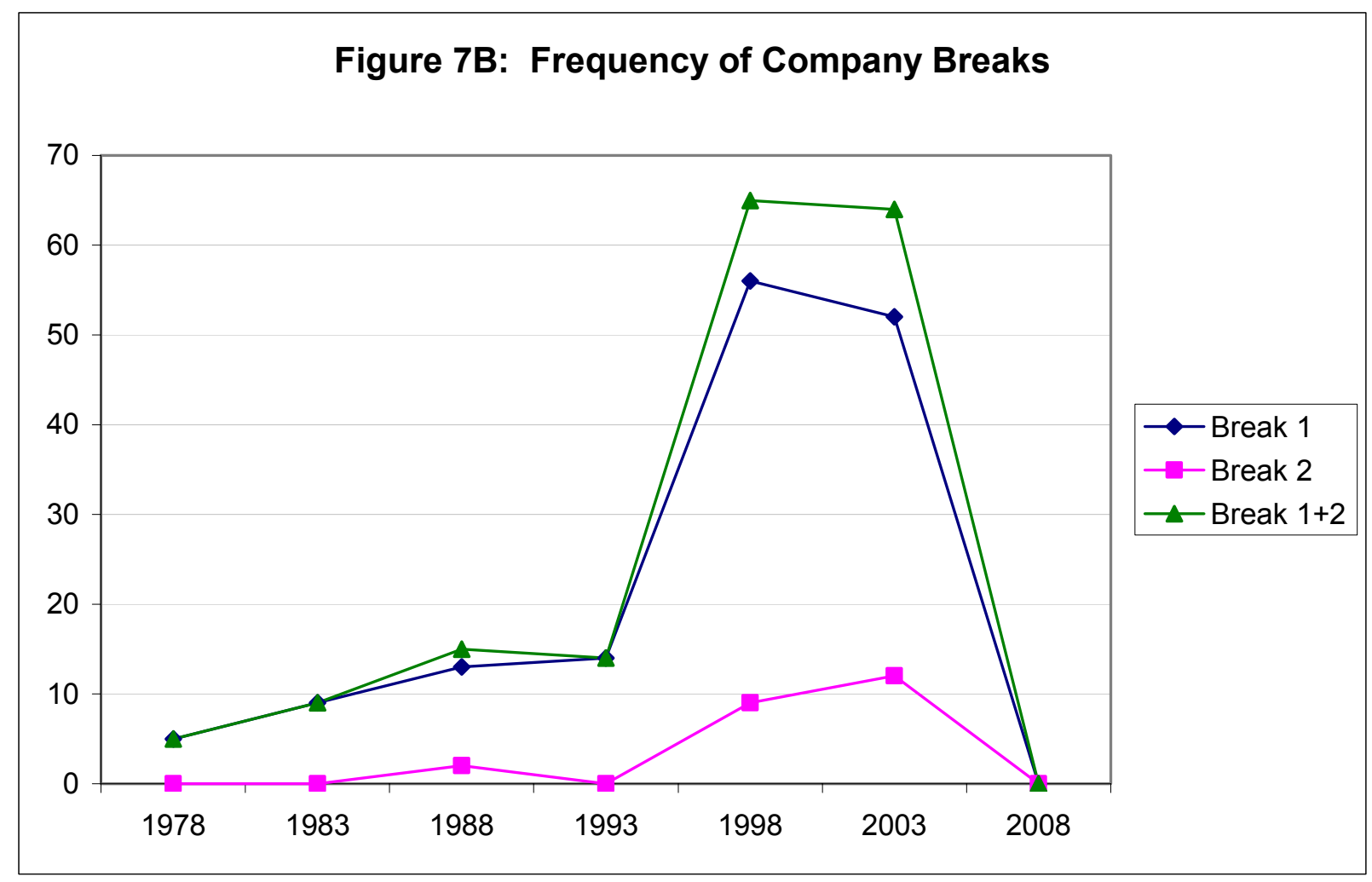

Figure 7C: Proportion of Company Breaks

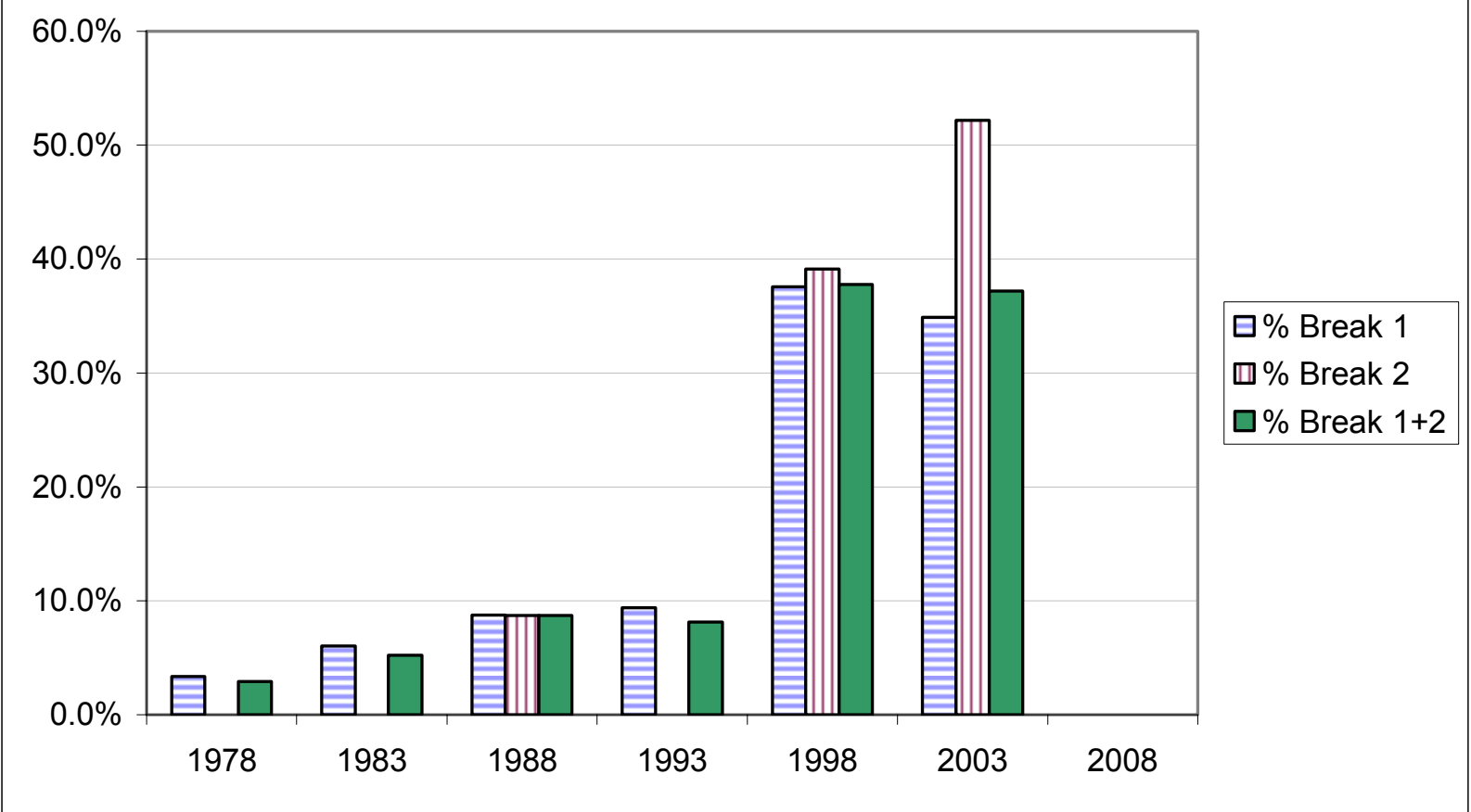




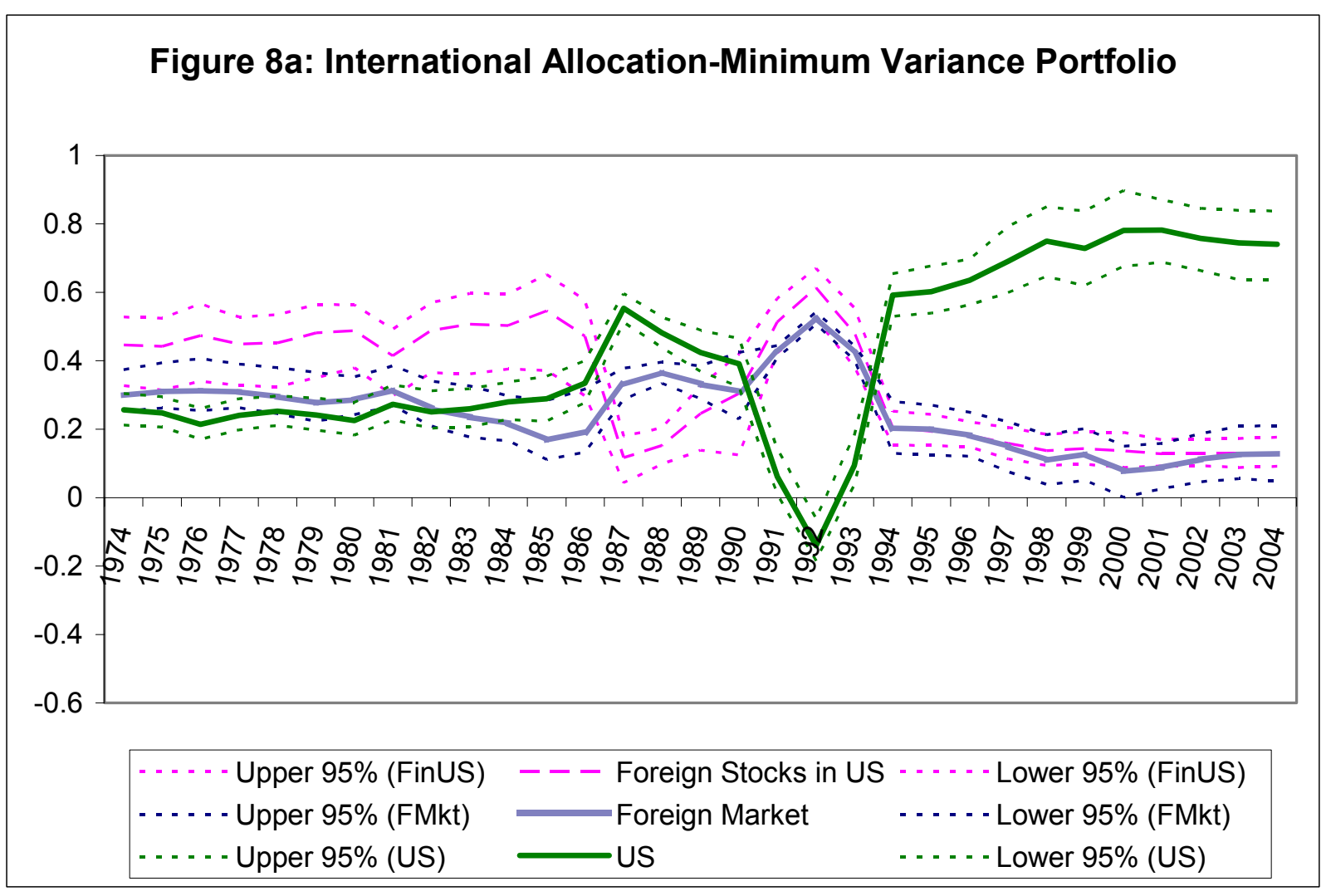




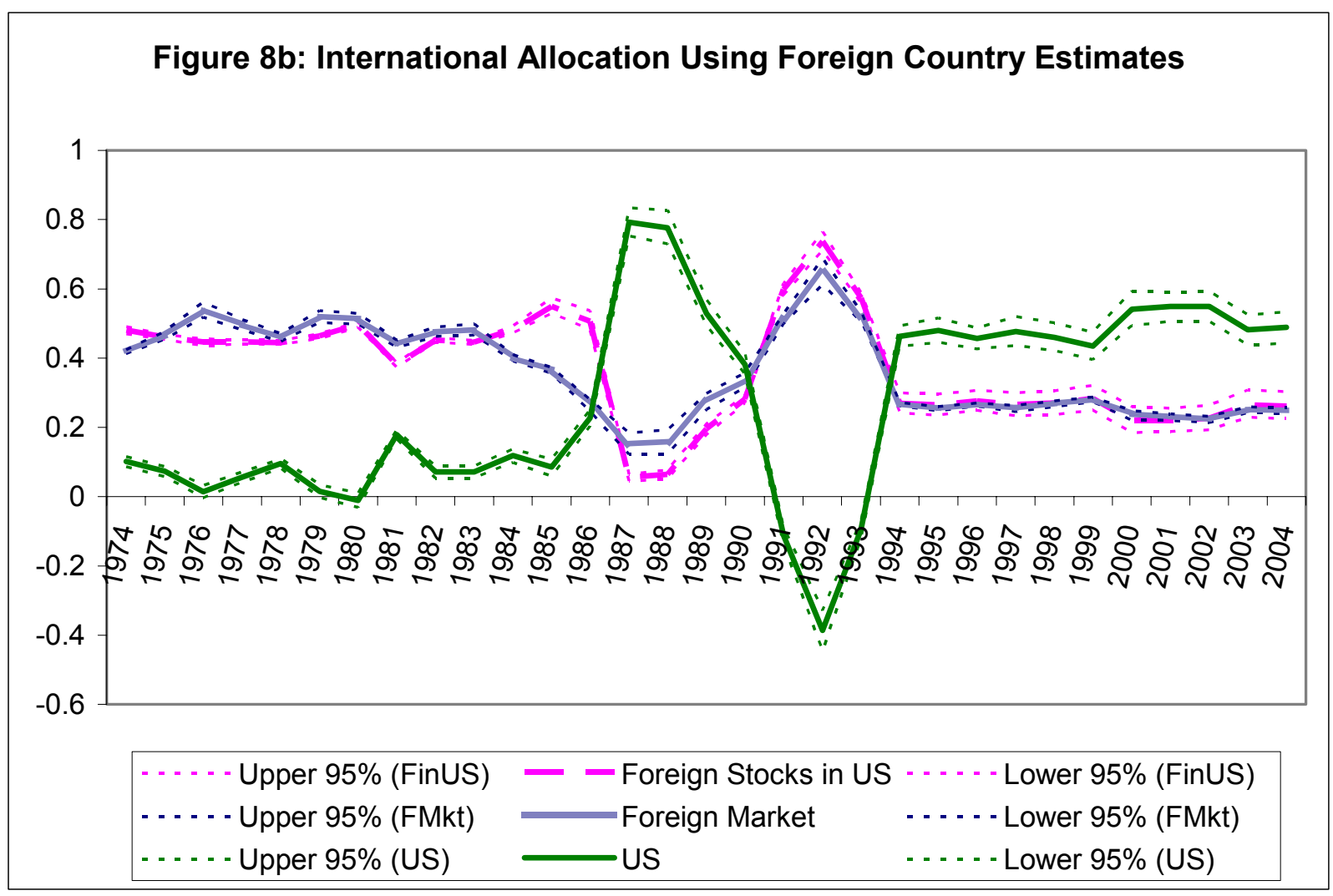


Figure 9a: Foreign Portfolio Parameters over Time

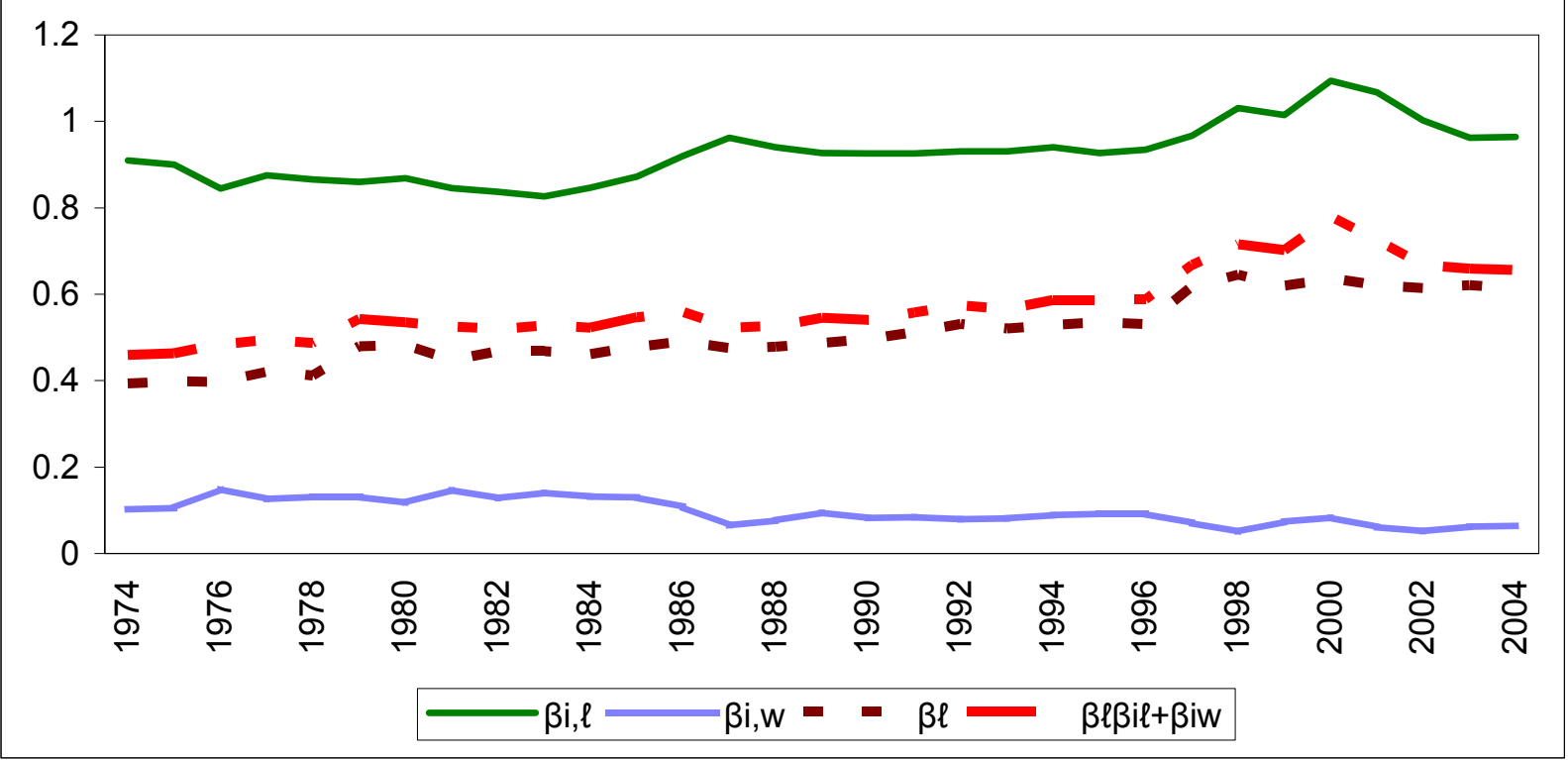

Figure 9b: Covariance Estimates Over Time

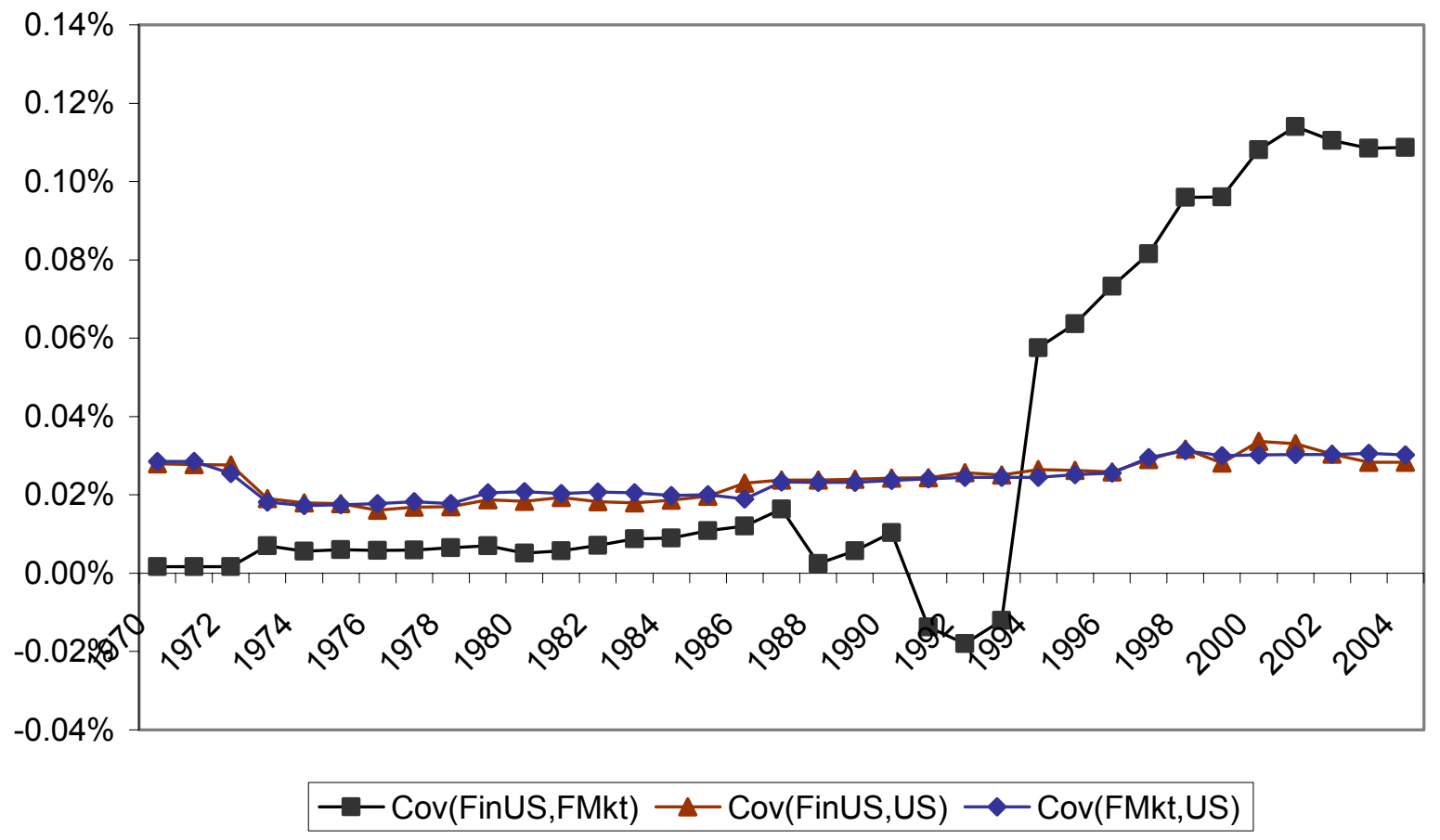




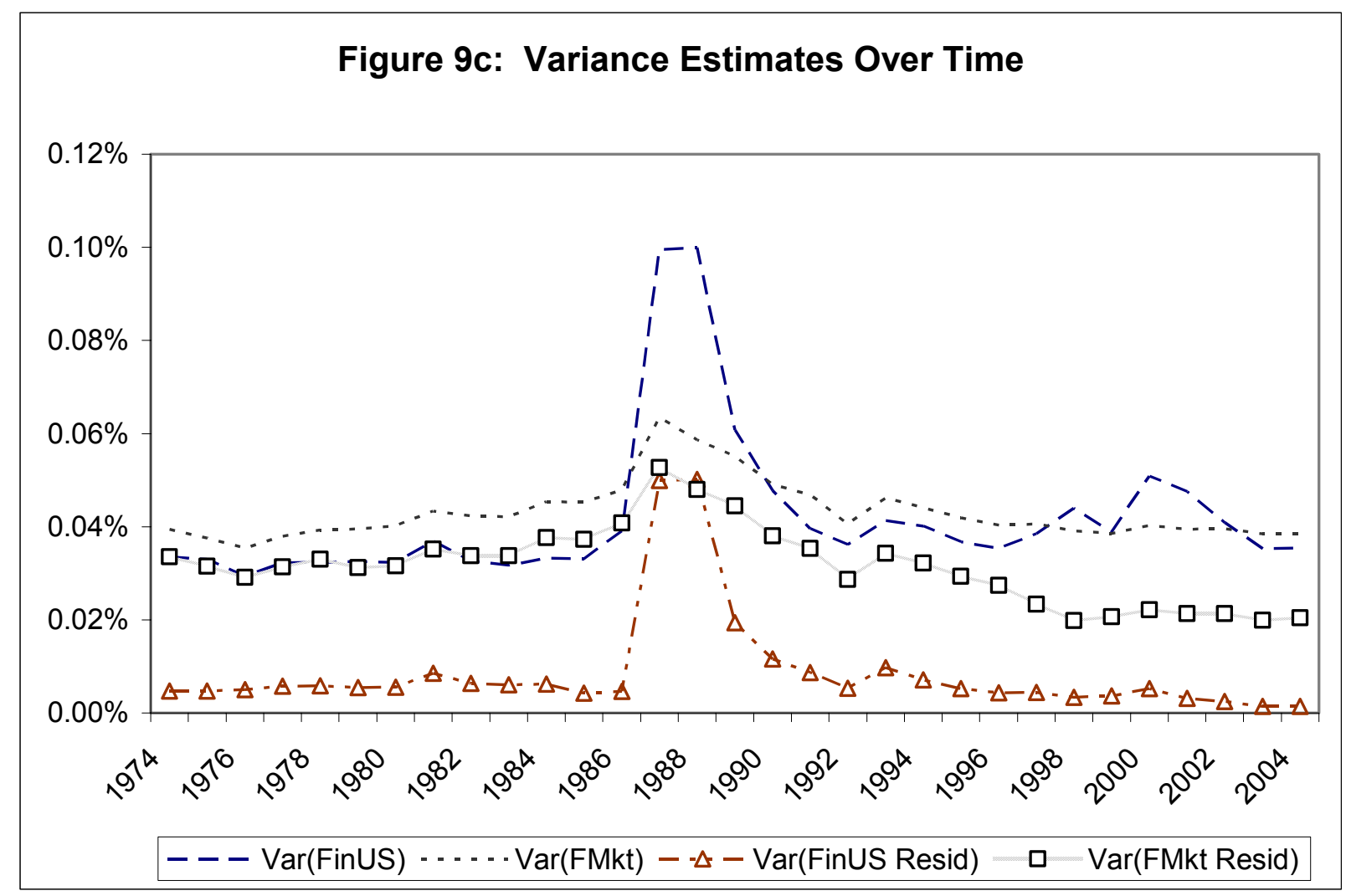



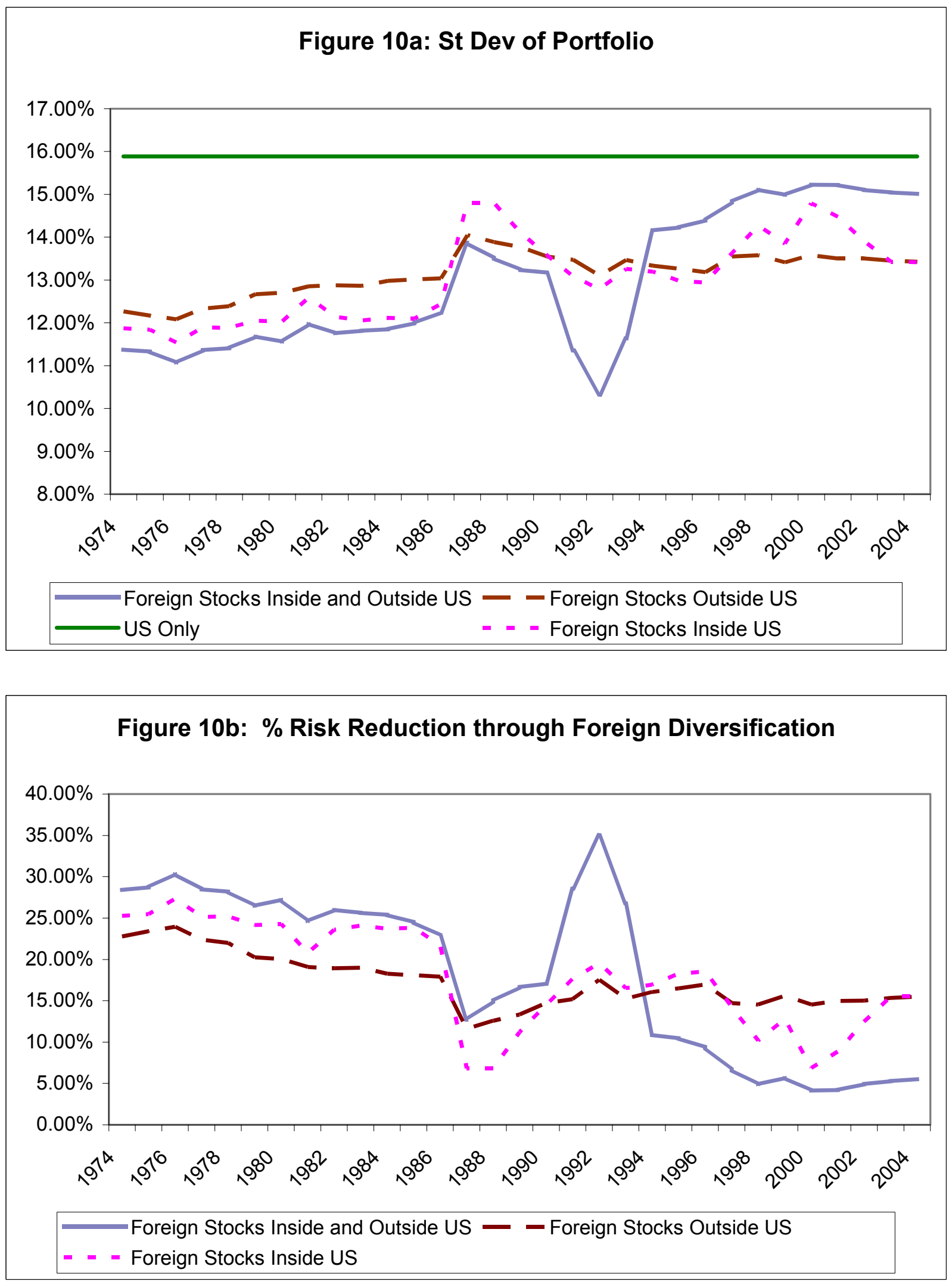

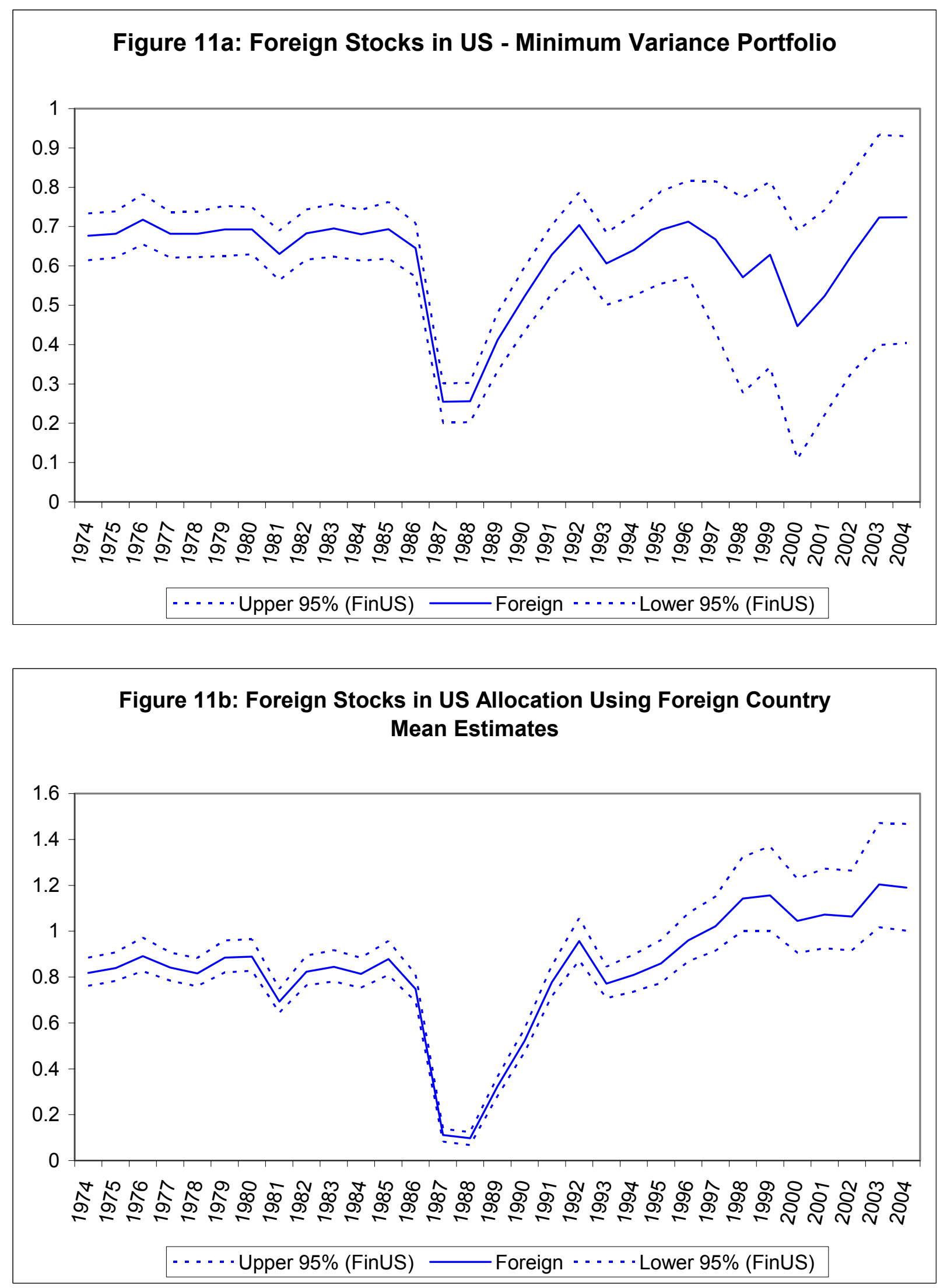


\section{Appendix 1: Data Description}

The data on stock returns were compiled from Data stream for the market return index. The country indices are Morgan Stanley Capital Weighted Indices for the countries with foreign stocks listed in the United States. Appendix Table A1 reports these countries along with their mneumonics.

The data for the individual company stock returns were collected and crosschecked from the websites of the NYSE and three ADR custodian depositaries: JP Morgan, Citibank, and Bank of New York. For these companies, the stock return data were compiled from Data Stream. Appendix Table A2 reports these companies along with their primary country allocation.

\section{Table A1: List of Foreign Countries}

\begin{tabular}{|l|c|l|c|}
\hline Country & Mneumonic & Country & Mneumonic \\
\hline Argentina & AR & Israel & IS \\
\hline Australia & AU & Italy & IT \\
\hline Austria & OE & Japan & JP \\
\hline Belgium & BG & Korea & KO \\
\hline Brazil & BR & Luxembourg & LX \\
\hline Canada & CA & Mexico & MX \\
\hline Chile & CL & Netherlands & NL \\
\hline China & CH & New Zealand & NZ \\
\hline Columbia & CB & Norway & NW \\
\hline Denmark & DK & Peru & PE \\
\hline Finland & FN & Philipines & PH \\
\hline France & FR & Portugal & PT \\
\hline Germany & BD & Russia & RS \\
\hline Ghana & GH & South Africa & SA \\
\hline Greece & GR & Spain & ES \\
\hline Hong Kong & HK & Switzerland & SW \\
\hline Hungary & HN & Taiwan & TA \\
\hline India & IN & Turkey & TK \\
\hline Indonesia & ID & United Kingdom & UK \\
\hline Ireland & IR & Venezuela & VE \\
\hline
\end{tabular}


Table A2: List of Foreign Companies

\begin{tabular}{|c|c|c|c|}
\hline Company Name & Country & Company Name & Country \\
\hline AUS.AND NZ.BANKING GP. & AU & BRASKEM PNA 1000 & $\mathrm{BR}$ \\
\hline BHP BILLITON & $A U$ & BRASIL TELEC PN 1000 & $\mathrm{BR}$ \\
\hline COLES MYER & $\mathrm{AU}$ & PETROBRAS ON & $\mathrm{BR}$ \\
\hline HARDIE JAMES & $A U$ & PETROBRAS PN & $\mathrm{BR}$ \\
\hline NATIONAL AUS.BANK & $A U$ & VCP PN 1000 & $\mathrm{BR}$ \\
\hline NEWS CORP.PREF. & $A U$ & $\begin{array}{l}\text { CIA.SANMT.BASICO DE SP. } \\
(100\end{array}$ & $\mathrm{BR}$ \\
\hline NEWS CORPORATION & $A U$ & SADIA S/A PN & $\mathrm{BR}$ \\
\hline ORBITAL ENGINE CORP. & AU & TELE CTR OES PN 1000 & $\mathrm{BR}$ \\
\hline TELSTRA CORPORATION & $A U$ & TELESP PN 1000 & $\mathrm{BR}$ \\
\hline WESTPAC BANKING & $A U$ & BRASIL T PAR PN 1000 & $\mathrm{BR}$ \\
\hline ALUMINA & $A U$ & TELE CELULAR SUL PN 1000 & $\mathrm{BR}$ \\
\hline WMC RESOURCES & $A U$ & TELEMIG PART PN 1000 & $\mathrm{BR}$ \\
\hline BBVA BANCO FRANCES & $A R$ & TELE NORTE PN 1000 & $\mathrm{BR}$ \\
\hline IRSA & AR & TELE LEST CL PN 1000 & $\mathrm{BR}$ \\
\hline METROGAS B & AR & TELE NORT CL PN 1000 & $\mathrm{BR}$ \\
\hline NORTEL INVERSORA PFD B & AR & TELE NORD CL PN 1000 & $\mathrm{BR}$ \\
\hline PEREZ COMPANC 'B' & $A R$ & TELESP CL PA PN 1000 & $\mathrm{BR}$ \\
\hline TELF.DE ARGN.'B' & $A R$ & TELE SUDESTE PN 1000 & $\mathrm{BR}$ \\
\hline TELECOM ARGN.'B' & AR & ULTRAPAR PN 1000 & $\mathrm{BR}$ \\
\hline TSPA.GAS DEL SUR B & AR & $\begin{array}{c}\text { UNIBANCO UNITS (1 PN \& } 1 \\
\text { PNB }\end{array}$ & $\mathrm{BR}$ \\
\hline YPF 'D' & $A R$ & VALE R DOCE ON EJ & $\mathrm{BR}$ \\
\hline AMERSHAM & UK & VALE R DOCE PNA EJ & $\mathrm{BR}$ \\
\hline ALLIED IRISH BANKS & IR & BRIT.SKY BCAST. & UK \\
\hline ALLIED DOMECQ & UK & BT GROUP & UK \\
\hline AMVESCAP & UK & CABLE \& WIRELESS & UK \\
\hline ASTRAZENECA & UK & BANCOLOMBIA PFCL. & $\mathrm{CB}$ \\
\hline DELHAIZE & BG & CADBURY SCHWEPPES & UK \\
\hline BARCLAYS & UK & CELLTECH GROUP & UK \\
\hline BRITISH AIRWAYS & UK & ANDINA 'B' & $\mathrm{CL}$ \\
\hline BG GROUP & UK & ANDINA 'A' & $\mathrm{CL}$ \\
\hline BRITISH ENERGY & UK & CTC 'A' & $\mathrm{CL}$ \\
\hline BANK OF IRELAND & IR & CONCHATORO & $\mathrm{CL}$ \\
\hline BHP BILLITON & UK & BANCO DE CHILE & $\mathrm{CL}$ \\
\hline BUNZL & UK & CRISTALES & $\mathrm{CL}$ \\
\hline BOC GROUP & UK & CERVEZAS & $\mathrm{CL}$ \\
\hline $\mathrm{BP}$ & UK & D\&S & $\mathrm{CL}$ \\
\hline ARACRUZ PNB & BR & ENERSIS & $\mathrm{CL}$ \\
\hline AMBEV ON 1000 & $\mathrm{BR}$ & ENDESA & $\mathrm{CL}$ \\
\hline AMBEV PN 1000 & $\mathrm{BR}$ & LAN & $\mathrm{CL}$ \\
\hline COPEL PNB 1000 & $\mathrm{BR}$ & MASISA & $\mathrm{CL}$ \\
\hline CMPH.BRASL.DISTB.PN 1000 & $\mathrm{BR}$ & PROVIDA & $\mathrm{CL}$ \\
\hline BRADESCO PN 1000 & $\mathrm{BR}$ & QUINENCO & $\mathrm{CL}$ \\
\hline PERDIGAO S/A PN & BR & BSANTANDER & $\mathrm{CL}$ \\
\hline SID NACIONAL ON 1000 & BR & SQM 'A' & $\mathrm{CL}$ \\
\hline EMBRAER PN & $\mathrm{BR}$ & SQM 'B' & $\mathrm{CL}$ \\
\hline EMBRATEL PAR PN 1000 & $\mathrm{BR}$ & CORUS GROUP & UK \\
\hline GERDAU PN & BR & ALTANA & $\mathrm{BD}$ \\
\hline CEMIG PN 1000 & $\mathrm{BR}$ & ALLIANZ & $\mathrm{BD}$ \\
\hline BNC.ITAU HLDG.FINCA.PN 1000 & $\mathrm{BR}$ & BASF & $\mathrm{BD}$ \\
\hline
\end{tabular}


Table A2: List of Foreign Companies (cont.)

\begin{tabular}{|c|c|c|c|}
\hline Company Name & Country & Company Name & Country \\
\hline BAYER & $\mathrm{BD}$ & GALLAHER GROUP & UK \\
\hline DEUTSCHE TELEKOM & $\mathrm{BD}$ & GLAXOSMITHKLINE & UK \\
\hline E ON & $\mathrm{BD}$ & ABN AMRO HOLDING & $\mathrm{NL}$ \\
\hline EPCOS & $\mathrm{BD}$ & AEGON & $\mathrm{NL}$ \\
\hline FRESENIUS MED.CARE & $\mathrm{BD}$ & AHOLD KON. & $\mathrm{NL}$ \\
\hline FRESENIUS MED.CARE PREF. & $\mathrm{BD}$ & CHICAGO BRIDGE \& IRON & NL \\
\hline INFINEON TECHNOLOGIES & $\mathrm{BD}$ & REED ELSEVIER (AMS) & $\mathrm{NL}$ \\
\hline PFEIFFER VACUUM TECH. & $\mathrm{BD}$ & ING GROEP CERTS. & $\mathrm{NL}$ \\
\hline SAP & $\mathrm{BD}$ & ISPAT INTERNATIONAL & $\mathrm{NL}$ \\
\hline SCHERING & $\mathrm{BD}$ & KLM & $\mathrm{NL}$ \\
\hline SGL CARBON & $\mathrm{BD}$ & BUHRMANN & $\mathrm{NL}$ \\
\hline SIEMENS & $\mathrm{BD}$ & KPN KON & $\mathrm{NL}$ \\
\hline DIAGEO & UK & NEW SKIES SATTELITES & NL \\
\hline NOVO NORDISK B & DK & PHILIPS ELTN.KON & NL \\
\hline TDC & DK & ROYAL DUTCH PTL. & $\mathrm{NL}$ \\
\hline ELAN & IR & TPG NV & NL \\
\hline BBV ARGENTARIA & ES & UNILEVER CERTS. & $\mathrm{NL}$ \\
\hline ENDESA & ES & MOOLEN (VAN DER) & $\mathrm{NL}$ \\
\hline REPSOL YPF & ES & MATAV & $\mathrm{HN}$ \\
\hline SANTANDER CTL.HISPANO & ES & HANSON & UK \\
\hline TELEFONICA & ES & HSBC HDG. (ORD \$0.50) & UK \\
\hline TELEFONICA MOVILES & ES & BENETTON & IT \\
\hline ENODIS & UK & DUCATI MOTOR HOLDING & IT \\
\hline ALSTOM & $\mathrm{FR}$ & ENEL & IT \\
\hline DANONE & $\mathrm{FR}$ & ENI & IT \\
\hline ALCATEL & $\mathrm{FR}$ & FIAT & $\mathrm{IT}$ \\
\hline EQUANT (PAR) & $\mathrm{FR}$ & FIAT PV & IT \\
\hline VIVENDI UNIVERSAL & $\mathrm{FR}$ & FIAT RNC & IT \\
\hline FRANCE TELECOM & FR & LUXOTTICA & IT \\
\hline COMPAGNIE GL GEOPHYSIQUE & FR & SAN PAOLO IMI & $\mathrm{IT}$ \\
\hline SUEZ & FR & TENARIS & IT \\
\hline LAFARGE & $\mathrm{FR}$ & INDOSAT & ID \\
\hline AXA & $\mathrm{FR}$ & TELKOM & ID \\
\hline PECHINEY & $\mathrm{FR}$ & ICTL.HTLS.GP. & UK \\
\hline PUBLICIS GROUPE & $\mathrm{FR}$ & IMPERIAL TOBACCO GP. & UK \\
\hline RHODIA & $\mathrm{FR}$ & DR REDDYS LABS. & IN \\
\hline AVENTIS & FR & HDFC BANK & IN \\
\hline SCOR & FR & ICICI BANK & IN \\
\hline SODEXHO ALLIANCE & $\mathrm{FR}$ & MAHANAGAR TEL.NIGAM & IN \\
\hline STMICROELECTRONICS (PAR) & $\mathrm{FR}$ & SATYAM CMP.SVS. & IN \\
\hline SANOFI-SYNTHELABO & $\mathrm{FR}$ & SILVERLINE TECHS.LTD. & IN \\
\hline TOTAL SA & $\mathrm{FR}$ & VIDESH SANCHAR NIGAM & IN \\
\hline TECHNIP & $\mathrm{FR}$ & WIPRO & IN \\
\hline THOMSON & $\mathrm{FR}$ & INTERNATIONAL POWER & UK \\
\hline VEOLIA ENVIRONNEMENT & $\mathrm{FR}$ & BLUE SQUARE ISR & IS \\
\hline COCA-COLA HLC.BT. & GR & KOOR INDUSTRIES LTD & IS \\
\hline NAT.BK.OF GREECE & GR & ADVANTEST & $\mathrm{JP}$ \\
\hline OTE-HELLENIC TELC. & GR & CANON & $\mathrm{JP}$ \\
\hline ASHANTI GOLDFIELDS & $\mathrm{GH}$ & HITACHI & $\mathrm{JP}$ \\
\hline
\end{tabular}


Table A2: List of Foreign Companies (cont.)

\begin{tabular}{|c|c|c|c|}
\hline Company Name & Country & Company Name & Country \\
\hline HONDA MOTOR & $\mathrm{JP}$ & BACHOCO UBL & $\mathrm{MX}$ \\
\hline KONAMI & JP & CERAMIC ULD & $\mathrm{MX}$ \\
\hline KUBOTA & $\mathrm{JP}$ & CEL 'V' & $\mathrm{MX}$ \\
\hline MATSUSHITA ELEC.INDL. & JP & CEMEX CPO & $\mathrm{MX}$ \\
\hline MITSUB.TOK.FINL.GP. & $J P$ & COMERCI UBC & $\mathrm{MX}$ \\
\hline NIDEC & $\mathrm{JP}$ & DESC 'C' & $\mathrm{MX}$ \\
\hline NISSIN & $\mathrm{JP}$ & ELEKTRA & $\mathrm{MX}$ \\
\hline NOMURA HDG. & JP & FEMSA.UBD & $\mathrm{MX}$ \\
\hline NIPPON TELG. \& TEL. & $\mathrm{JP}$ & CODUSA & $\mathrm{MX}$ \\
\hline ORIX & $\mathrm{JP}$ & GRUMA 'B' & $\mathrm{MX}$ \\
\hline PIONEER & $\mathrm{JP}$ & ICA & $\mathrm{MX}$ \\
\hline SONY & JP & IMSA UBC & $\mathrm{MX}$ \\
\hline TDK & $\mathrm{JP}$ & COCA-COLA FEMSA 'L' & $\mathrm{MX}$ \\
\hline NTT DOCOMO INC & $\mathrm{JP}$ & SAVIA 'A' & $\mathrm{MX}$ \\
\hline TOYOTA MOTOR & $\mathrm{JP}$ & TMM 'A' & $\mathrm{MX}$ \\
\hline ALUM.CORP.OF CHINA 'H' & $\mathrm{CH}$ & MASECA 'B' & $\mathrm{MX}$ \\
\hline APT SATELLITE HDG. & $\mathrm{HK}$ & RCENTRO 'A' & $\mathrm{MX}$ \\
\hline ASIA SATELLITE TELECOM & $\mathrm{HK}$ & $S A B$ & $\mathrm{MX}$ \\
\hline SINOPEC BEJ YANHUA 'H' & $\mathrm{CH}$ & TLEVISA 'CPO' & $\mathrm{MX}$ \\
\hline BRILLIANCE CHINA AUTV.HLDG. & $\mathrm{HK}$ & TELMEX 'L' & $\mathrm{MX}$ \\
\hline CHINA EASTERN AIRL. 'H' & $\mathrm{CH}$ & TVAZTCA CPO & $\mathrm{MX}$ \\
\hline SINOPEC CORP. 'H' & $\mathrm{CH}$ & VITRO 'A' & $\mathrm{MX}$ \\
\hline CHINA MOBILE (HK) LTD. & $\mathrm{HK}$ & NORSK HYDRO & NW \\
\hline CNOOC LTD. & $\mathrm{HK}$ & SMEDVIG A & NW \\
\hline CHINA STHN.AIRL. 'H' & $\mathrm{CH}$ & SMEDVIG B & NW \\
\hline CHINA TELECOM 'H' & $\mathrm{CH}$ & STATOIL & NW \\
\hline GUANGSHEN RAILWAY 'H' & $\mathrm{CH}$ & NATIONAL GRID TRANSCO & UK \\
\hline HUANENG PWR.INTL. 'H' & $\mathrm{CH}$ & \begin{tabular}{|c|} 
HEAD NV \\
\end{tabular} & $\mathrm{OE}$ \\
\hline JILIN CHEMICAL IND. 'H' & $\mathrm{CH}$ & TELEKOM AUSTRIA & $\mathrm{OE}$ \\
\hline PETROCHINA CO. 'H' & $\mathrm{CH}$ & MMO2 & UK \\
\hline SINOPEC SHAI.PETROCHEM. 'H' & $\mathrm{CH}$ & BCP R & PT \\
\hline PCCW LIMITED & HK & ELCTDAD.DE PORTL. & PT \\
\hline CHINA UNICOM & $\mathrm{HK}$ & PT TELECOM SGPS & PT \\
\hline YANZHOU COAL MINING 'H' & $\mathrm{CH}$ & BUENAVENTURA CAP & $\mathrm{PE}$ \\
\hline KOREA ELECTRIC POWER & $\mathrm{KO}$ & TELF.DEL PERU 'B' & $\mathrm{PE}$ \\
\hline KOOKMIN BK. & KO & PREMIER FARNELL & UK \\
\hline KT CORPORATION & KO & PHILP.LONG DSN.TEL. & $\mathrm{PH}$ \\
\hline POSco & KO & PHILP.LONG DSN.TEL. & $\mathrm{PH}$ \\
\hline SK TELECOM & KO & PRUDENTIAL & UK \\
\hline LLOYDS TSB GP. & UK & PEARSON & UK \\
\hline ESPIRITO SANTO & $L X$ & ANGLOGOLD & SA \\
\hline QUINSA PREF & $L X$ & GOLD FIELDS & SA \\
\hline STORA ENSO R & $\mathrm{FN}$ & HARMONY GOLD MINING & SA \\
\hline METSO & FN & SAPPI & SA \\
\hline NOKIA & $\mathrm{FN}$ & SASOL & SA \\
\hline UPM-KYMMENE & $\mathrm{FN}$ & TELKOM & SA \\
\hline MITCHELLS \& BUTLERS & UK & REED ELSEVIER & UK \\
\hline AMX 'L' & $\mathrm{MX}$ & RIO TINTO & UK \\
\hline ASUR & $\mathrm{MX}$ & ROSTELECOM & RS \\
\hline
\end{tabular}




\section{Table A2: List of Foreign Companies (cont.)}

\begin{tabular}{|c|c|c|c|}
\hline Company Name & $\begin{array}{c}\text { Country } \\
\text { Mneumonic }\end{array}$ & Company Name & $\begin{array}{c}\text { Country } \\
\text { Mneumonic }\end{array}$ \\
\hline TATNEFT & RS & KINROSS GOLD CORPORATION & CA \\
\hline VIMPELCOM & RS & ENERPLUS RESOURCES FUND & $\mathrm{CA}$ \\
\hline ROYAL \& SUN ALL.IN. & UK & CGI GROUP INC & $\mathrm{CA}$ \\
\hline ABB LTD. $R$ & SW & SHAW COMMUNICATIONS INC & $\mathrm{CA}$ \\
\hline ADECCO R & SW & PRECISION DRILLING CORPORATION & CA \\
\hline CENTERPULSE & SW & $\begin{array}{l}\text { POTASH CORPORATION OF SASKATCHEWAN } \\
\text { INC. }\end{array}$ & $\mathrm{CA}$ \\
\hline CONVERIUM HOLDING R & SW & PETRO-CANADA & $\mathrm{CA}$ \\
\hline CIBA SPLTY.CHEMS. R & SW & CAMECO CORPORATION & $\mathrm{CA}$ \\
\hline CREDIT SUISSE R & SW & CHC HELICOPTER CORPORATION & $\mathrm{CA}$ \\
\hline NOVARTIS R & SW & CANWEST GLOBAL COMMUNICATIONS CORP. & $\mathrm{CA}$ \\
\hline SWISSCOM R & SW & $\begin{array}{c}\text { PETROKAZAKHSTAN INCORPORATED } \\
\text { (Hurricane) }\end{array}$ & $\mathrm{CA}$ \\
\hline SERONO 'B' & SW & RITCHIE BROS AUCTIONEERS INC. & $\mathrm{CA}$ \\
\hline SYNGENTA & SW & GILDAN ACTIVEWEAR INC. & $\mathrm{CA}$ \\
\hline SHELL TRANSPORT \& TRDG. & UK & NOVA CHEMICALS CORPORATION & $\mathrm{CA}$ \\
\hline SMITH \& NEPHEW & UK & CELESTICA INCORPORATED & $\mathrm{CA}$ \\
\hline SPIRENT & UK & TELUS CORPORATION & CA \\
\hline SCOTTISH POWER & UK & $\begin{array}{l}\text { MASONITE INTERNATIONAL CORPORATION } \\
\text { (Premdor) }\end{array}$ & CA \\
\hline TURKCELL & TK & ROGERS COMMUNICATIONS INC & $\mathrm{CA}$ \\
\hline TOMKINS & UK & TRANSALTA CORPORATION & $\mathrm{CA}$ \\
\hline AU OPTRONICS & TA & MERIDIAN GOLD INC & $\mathrm{CA}$ \\
\hline ADVD. SEMICON. ENGNR. & TA & CANADIAN NATIONAL RAILWAY COMPANY & $\mathrm{CA}$ \\
\hline CHUNGHWA TELECOM & TA & ENBRIDGE INC & $\mathrm{CA}$ \\
\hline TAIWAN SEMICON.MNFG. & TA & NORANDA INC & $\mathrm{CA}$ \\
\hline UNITED MICRO ELTN. & TA & TRANSCANADA CORPORATION & $\mathrm{CA}$ \\
\hline UNILEVER (UK) & UK & ABITIBI-CONSOLIDATED INC. & $\mathrm{CA}$ \\
\hline UNITED UTILITIES & UK & DOMTAR INC. & $\mathrm{CA}$ \\
\hline CANTV & VE & BCE INC & $\mathrm{CA}$ \\
\hline VODAFONE GROUP & UK & ALCAN INC & $\mathrm{CA}$ \\
\hline WOLSELEY & UK & PLACER DOME INC. & $\mathrm{CA}$ \\
\hline FLETCHER CHAL.FOR.PREF. & NZ & NORTHGATE MINERALS CORPORATION & $\mathrm{CA}$ \\
\hline FLETCH.CHAL.FORESTS & $\mathrm{NZ}$ & ENCANA CORPORATION & $\mathrm{CA}$ \\
\hline $\begin{array}{l}\text { ROYAL GROUP TECHNOLOGIES } \\
\text { LIMITED }\end{array}$ & $\mathrm{CA}$ & IPSCO INC & $\mathrm{CA}$ \\
\hline BIOVAIL CORPORATION & $\mathrm{CA}$ & NEXEN INC. & $\mathrm{CA}$ \\
\hline CORUS ENTERTAINMENT INC & $\mathrm{CA}$ & FOUR SEASONS HOTELS INC & $\mathrm{CA}$ \\
\hline SUNCOR ENERGY INCORPORATED & $\mathrm{CA}$ & NORTEL NETWORKS CORPORATION & $\mathrm{CA}$ \\
\hline QUEBECOR WORLD INCORPORATED & $\mathrm{CA}$ & GOLDCORP INC. & $\mathrm{CA}$ \\
\hline $\begin{array}{c}\text { INTERTAPE POLYMER GROUP } \\
\text { INCORPORATED }\end{array}$ & $\mathrm{CA}$ & TALISMAN ENERGY INC & $\mathrm{CA}$ \\
\hline AGRIUM INCORPORATED & $\mathrm{CA}$ & BARRICK GOLD CORPORATION & $\mathrm{CA}$ \\
\hline
\end{tabular}




\section{Table A2: List of Foreign Companies (cont.)}

\begin{tabular}{|c|c|}
\hline Company Name & Country Mneumonic \\
\hline EXTENDICARE INC & CA \\
\hline CANADIAN NATURAL RESOURCES LTD & CA \\
\hline INCO & CA \\
\hline ZARLINK SEMICONDUCTOR INC (Mitel) & CA \\
\hline MAGNA INTERNATIONAL INC & CA \\
\hline MDS INCORPORATED & CA \\
\hline CANADIAN PACIFIC RAILWAY LIMITED & CA \\
\hline FORDING CANADIAN COAL TRUST & CA \\
\hline CP SHIPS LIMITED & CA \\
\hline FAIRMONT HOTELS \& RESORT INCORPORATED & CA \\
\hline PENGROWTH ENERGY TRUST &
\end{tabular}




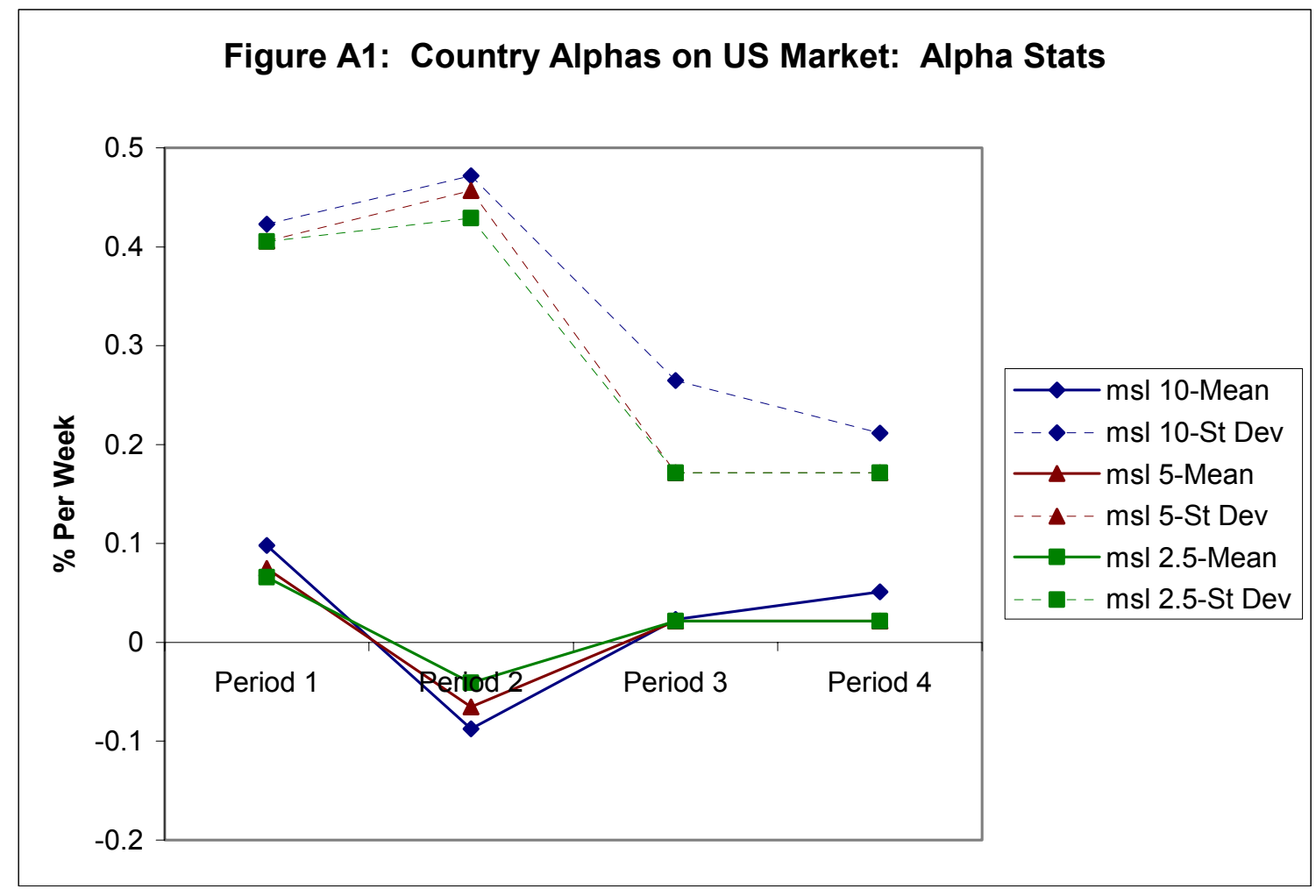




\section{Appendix 2: Parameter Estimate - Implied Portfolio Model}

The estimates of the model were used to evaluate the decision for a representative US investor who is deciding on how much to allocate into foreign stock portfolios.

Under the assumptions of i.i.d., an investor who maximizes expected returns subject to variance will choose to hold the tangency portfolio given by equation (12) in the text:

$$
\varpi=V^{-1} E(\mathbf{r}) / i \mathrm{~V}^{-1} E(\mathbf{r})
$$

where $\mathrm{V}$ is the variance-covariance matrix of returns and $\mathbf{r}$ is the column vector of portfolio returns.

Since I want to examine the pattern implied with parameters changing over time, I examine the conditional version given as:

$\varpi_{t}=V_{t}^{-1} E_{t}\left(\mathbf{r}_{\mathrm{t}+1}\right) / \iota^{\prime} V_{t}^{-1} E_{t}\left(\mathbf{r}_{\mathrm{t}+1}\right)$

Where $t$ subscripts refer to the information set at time $t$. Thus, $E_{t}\left(\mathbf{r}_{\mathrm{t}+1}\right)$ is the conditional expectation at time $t$ of the return vector realization at $t+1$ and $\mathrm{V}_{\mathrm{t}}$ is the variancecovariance matrix of returns

This appendix describes the details of construction of these moments in the following cases: (a) the two-asset model in Section 1, (b) the three asset model in Section 2, and (c) the Monte Carlo simulation that provides the confidence intervals for the model.

\section{(a) Two Asset Model}

For the two asset model, the investor chooses between a market-weighted portfolio of foreign market indices and the US market. In this case,

$\mathbf{r}_{t} \equiv\left[r_{t}^{F}, r_{t}^{w}\right] \equiv\left[\mathbf{X}_{t}{ }^{\prime} \mathbf{r}_{t}^{\ell}, r_{t}^{w}\right]$

Where $\mathbf{r}_{t}^{\ell}$ is an $\mathrm{L} \mathrm{x} 1$ vector of the foreign market index returns at time $\mathrm{t}, \mathbf{X}_{t}$ is an $\mathrm{L} \times 1$ vector of the market weights of the stock market indices in the foreign market portfolio at 
time t. Note that the returns for each component of $r_{t}^{\ell}$ are given by the process in equation (3) of the text:

$\mathrm{r}_{\mathrm{t}}^{\ell}=I\left(T_{\tau}\right)\left[\alpha^{\ell}+\beta^{\ell} \mathrm{r}^{\mathrm{w}}{ }_{\mathrm{t}}+\mathrm{u}^{\ell}, \mathrm{t}\right], \quad$ for $\ell=1, \ldots, \mathrm{L}, \quad \tau=1, \ldots, \mathrm{m}+1$

where $I\left(T_{\tau}\right)$ is an indicator function that time is within a set of time intervals $T_{\tau}$ for $\tau=1$, $\ldots, \mathrm{m}+1$. For notational convenience, I hereafter redefine the parameter vector generally

as: $\delta_{t}=\left\{\delta_{\tau} \mid t=I^{-1}\left(T_{\tau}\right) ; \tau=1, \ldots, m+1\right\}$

Thus, $\delta_{t}$ represents the mapping of the set of parameters within their time subsets $T_{\tau}$ into the time domain $\mathrm{t}$.

Then the means and variances of the portfolio vector are given by:

$E\left(\mathbf{r}_{t}\right)=\left[\mathbf{X}_{t}{ }^{\prime}\left(\boldsymbol{\alpha}_{t}^{\ell}+\boldsymbol{\beta}_{t}^{\ell} E\left(r_{t}^{w}\right)\right), E\left(r_{t}^{w}\right)\right]^{\prime}$

And

$\mathbf{V}_{t}=\left(\begin{array}{cc}\sigma_{w}^{2} \mathbf{X}_{t}{ }^{\prime} \boldsymbol{\beta}_{t}^{\ell} \boldsymbol{\beta}_{t}^{\ell}{ }^{\prime} \mathbf{X}_{t}+\mathbf{X}_{t}{ }^{\prime} \mathbf{U}_{t} \mathbf{X}_{t} & \sigma_{w}^{2} \mathbf{X}_{t}{ }^{\prime} \boldsymbol{\beta}_{t}^{\ell} \\ \sigma_{w}^{2} \mathbf{X}_{t}^{\prime} \boldsymbol{\beta}_{t}^{\ell} & \sigma_{w}^{2}\end{array}\right)$

Where $\alpha_{t}^{\ell}$ and $\beta_{t}^{\ell}$ are the $\mathrm{L}$ x 1 vector of parameters $\alpha_{t}^{\ell}$ and $\beta_{t}^{\ell}$, respectively, for $\ell=1, \ldots$,

$\mathrm{L} ; \quad \mathbf{U}_{t} \equiv E_{t}\left(\mathbf{u}_{t} \mathbf{u}_{t}{ }^{\prime}\right)$ for $\mathbf{u}_{t} \equiv\left[\mathrm{u}_{\mathrm{t}}^{1}, \ldots, \mathrm{u}_{\mathrm{t}}^{\mathrm{L}}\right]^{\prime}$, the cross-country variance-covariance matrix;

and $\sigma_{w}^{2} \equiv E\left(u_{t}^{w 2}\right) .^{31}$ Note that in the off-diagonal terms, we have used the fact that:

$E\left(\mathbf{u}_{t} u_{t}^{w}\right)=0$ by construction in estimating equation (3).

I then use the estimates from the model for each year to calculate the means in (A4) and the variances in (A5) to form the tangency portfolio in (A1). The portfolios are created for each year at the end of the year for the following year. The results are plotted in Figures 5 and 6 in the text.

These results are repeated for the minimum variance case where $\mathrm{E}\left(\mathrm{r}^{\mathrm{w}}\right)=\mathrm{E}\left(\mathrm{r}^{\mathrm{F}}\right)$.

(b) Three Asset Model

\footnotetext{
${ }^{31}$ The calibration model assumes that the residuals to the processes are conditionally homoskedastic in the time domain, though not in the cross-section. Therefore, the calibration model treats the portfolio variance as changing over time in response to the evolution of the parameters $\delta_{t}$ and $\mathrm{X}_{\mathrm{t}}$. However, these assumptions are not imposed on the estimation results described in the text.
} 
For the three asset model, the investor chooses between a market-weighted portfolio of foreign stocks traded in the US, the portfolio of foreign market indices, and the US market. In this case, I redefine the return vector to be:

$\mathbf{r}_{t} \equiv\left[r_{t}^{S}, r_{t}^{F}, r_{t}^{w}\right] \equiv\left[\mathbf{Z}_{\mathbf{t}}{ }^{\prime} \mathbf{r}_{\mathbf{t}}^{\mathbf{i}}, \mathbf{X}_{t}{ }^{\prime} \mathbf{r}_{t}^{\ell}, r_{t}^{w}\right]$

Where $\mathbf{r}_{t}^{i}$ is an $\mathrm{N} \mathrm{x} 1$ vector of foreign stock returns for companies listed in the US at time $t, \mathbf{Z}_{\mathbf{t}}$ is an $\mathrm{N} \times 1$ vector of the market weights of the foreign stocks in the foreign stock portfolio at time t.

Note that the returns for each component of $\mathrm{r}_{\mathrm{t}}^{\mathrm{i}, \ell}$ are given by the process in equation (14) of the text:

$$
\begin{aligned}
\mathrm{r}_{\mathrm{t}}^{\mathrm{i} \ell} & =\Xi\left(\kappa_{\varsigma}\right)\left[\alpha_{\varsigma}^{\mathrm{i} \ell}+\beta_{\varsigma}^{i \ell} \mathrm{r}_{\mathrm{t}}^{\ell}+\beta_{\varsigma}^{i w} \mathrm{r}_{\mathrm{t}}^{\mathrm{w}}+\mathrm{e}_{\varsigma, \mathrm{t}}^{\mathrm{i} \ell}\right], \quad \text { for } \mathrm{i}=1, \ldots, \mathrm{N} ; \varsigma=1, \ldots, \mathrm{n}^{\mathrm{i}}+1 \\
& =\mathrm{a}_{t}^{i \ell}+b_{t}^{i \ell} \mathrm{r}_{t}^{\mathrm{w}}+\varepsilon_{\mathrm{t}}^{i \ell}
\end{aligned}
$$

where

$$
\begin{aligned}
& \mathrm{a}_{t}^{i \ell} \equiv \alpha^{\mathrm{i} \ell}+\beta^{\mathrm{i} \ell} \alpha_{\tau}^{\ell} \\
& b_{t}^{i \ell} \equiv \beta^{\mathrm{i} \ell} \beta_{\tau}^{\ell}+\beta^{\mathrm{iw}} \\
& \varepsilon_{\mathrm{t}}^{i \ell} \equiv \beta^{\mathrm{i} \ell} \mathrm{u}_{\tau, \mathrm{t}}^{\ell}+\mathrm{e}_{\mathrm{t}}^{\mathrm{i} \ell}
\end{aligned}
$$

And where $\Xi\left(\kappa_{s}\right)$ is an indicator function for the event that time $t$ is within a set of time intervals $\kappa_{\varsigma}$ for $\varsigma=1, \ldots, n+1$. I now redefine the parameter vector to map the set of parameter vectors in both time subsets $T_{\tau}$ and $\kappa_{\zeta}$ into parameters in each date $t$. Thus, $\delta_{t}$ represents the mapping of parameters for countries within their time subsets $T_{\tau}$ into the time domain $\mathrm{t}$ and for stocks within their time subsets $\kappa_{\varsigma}$.

Then the mean of the portfolio vector is given by:

$$
E\left(\mathbf{r}_{t}\right)=\left[\mathbf{Z}_{t}^{\prime}\left(\boldsymbol{\alpha}_{t}^{i}+\mathbf{b}_{\mathbf{t}}^{\mathbf{w}} E\left(r_{t}^{w}\right)\right), \mathbf{X}_{t}^{\prime}\left(\boldsymbol{\alpha}_{t}^{\ell}+\boldsymbol{\beta}_{t}^{\ell} E\left(r_{t}^{w}\right)\right), E\left(r_{t}^{w}\right)\right]^{\prime}
$$

Where $\boldsymbol{\alpha}_{t}^{i}$ and $\mathbf{b}_{t}^{w}$ are the $\mathrm{N} \times 1$ vectors of parameters with typical component, $\mathrm{a}_{t}^{i \ell}$, and $b_{t}^{i \ell}$, respectively, for $i=1, \ldots, N$. Then the variance of the three-asset version of the model can be written: 


$$
\mathbf{V}_{t}=\left(\begin{array}{ccc}
\sigma_{w}^{2} \mathbf{Z}_{t}^{\prime} \mathbf{b}_{t}^{w} \mathbf{b}_{t}^{w} ' \mathbf{Z}_{t}+\mathbf{Z}_{t}^{\prime} \boldsymbol{\beta}_{t}^{i} \mathbf{U}_{t} \boldsymbol{\beta}_{t}^{i} \mathbf{Z}_{t}+\mathbf{Z}_{t}{ }^{\prime} \Omega \mathbf{Z}_{t} & \sigma_{w}^{2} \mathbf{Z}_{t}^{\prime} \mathbf{b}_{t}^{w} \boldsymbol{\beta}_{t}^{\ell} \mathbf{X}_{t}+\mathbf{Z}_{t}^{\prime} \boldsymbol{\beta}_{t}^{i} \mathbf{U}_{t} \mathbf{X}_{t} & \sigma_{w}^{2} \mathbf{Z}_{t}^{\prime} \mathbf{b}_{t}^{w} \\
\sigma_{w}^{2} \mathbf{Z}_{t}^{\prime} \mathbf{b}_{t}^{w} \boldsymbol{\beta}_{t}^{\ell} \mathbf{X}_{t}+\mathbf{Z}_{t}^{\prime} \boldsymbol{\beta}_{t}^{i} \mathbf{U}_{t} \mathbf{X}_{t} & \sigma_{w}^{2} \mathbf{X}_{t}^{\prime} \boldsymbol{\beta}_{t}^{\prime} \boldsymbol{\beta}_{t}^{\ell} \mathbf{X}_{t}+\mathbf{X}_{t}^{\prime} \mathbf{U}_{t} \mathbf{X}_{t} & \sigma_{w}^{2} \mathbf{X}_{t}^{\prime} \boldsymbol{\beta}_{t}^{\ell} \\
\sigma_{w}^{2} \mathbf{Z}_{t}^{\prime} \mathbf{b}_{t}^{w} & \sigma_{w}^{2} \mathbf{X}_{t}^{\prime} \boldsymbol{\beta}_{t}^{\ell} & \sigma_{w}^{2}
\end{array}\right)
$$

Where $\Omega \equiv E\left(\mathbf{e}_{\mathbf{t}} \mathbf{e}_{\mathbf{t}}{ }^{\prime}\right)$ for $\mathbf{e}_{t} \equiv\left[\mathrm{e}_{\mathrm{t}}^{1, \ell}, \ldots, \mathrm{e}_{\mathrm{t}}^{\mathrm{N}, \ell}\right]^{\prime}$ and where I have used the fact that $E\left(\mathbf{e}_{\mathbf{t}} t_{t}^{w}\right)=0$ by construction in estimation of equation (14). Note that the lower right-hand corner submatrix of (A5') is the same as the covariance matrix in the two asset model given in (A5).

I then use the estimates from the model for each year to calculate the expected return vector in (A4') and the conditional variances in (A5') to form the tangency portfolio in (A1). The portfolios are created for each year at the end of the year for the following year. The results are plotted in Figures 8, 9 and 10 in the text.

\section{(c) Monte Carlo Simulations to Generate Confidence Intervals}

To examine the confidence intervals of the calibration model, I used the model above together with the distributions of the parameters. In particular, I used the distribution from the joint distribution of the parameters given by the variation in the conditional mean vector in (A4') and in the conditional variance matrix in (A5'). The simulation was conducted for each year in the following steps:

Step 1: For each year, I form the market weights, $\mathbf{Z}_{\mathbf{t}}$ and $\mathbf{X}_{t}$, and form the implied mean and variance-covariance matrix.

Step 2: I then use this mean and variance-covariance of the parameter estimates to generate a realization of the parameter vector: $\left\{\boldsymbol{\alpha}_{t}^{i}, \boldsymbol{\beta}_{t}^{w}, \alpha_{t}^{i, \ell}, \beta_{t}^{i, w}, \beta^{\mathrm{i} \ell}{ }_{\mathrm{t}}\right\}$.

Step 3: Given these generated parameters, I reconstruct the conditional means and variances in (A4') and (A5') and then form the implied tangency portfolio.

Step 4: Steps 1 to 3 are repeated 10,000 times. The 5\% and 95\% ordinates from the frequency distribution are retrieved and saved.

These steps are repeated for each year from 1970 to 2004. 


\section{References}

Adler, Michael; Dumas, Bernard, "International Portfolio Choice and Corporation Finance: A Synthesis," Journal of Finance, 38:3, June 1983, pp. 925-84.

Backus, David K.; Patrick J. Kehoe, and Finn E. Kydland, "International Real Business Cycles," Journal of Political Economy, 100:4, 1991, pp. 745-75.

Baele, Lieven, "Volatility Spillover Effects in European Equity Markets," Journal of Financial and Quantitative Analysis, 40:2, June 2005, pp. 373-401.

Bai, Jushan; Perron, Pierre, "Estimating and Testing Linear Models with Multiple Structural Changes," Econometrica, 66:1, January 1998, pp. 47-78.

Bai, Jushan; Perron, Pierre, "Computation and Analysis of Multiple Structural Change Models," Journal of Applied Econometrics, 18:1, Jan.-Feb. 2003a, pp. 1-22.

Bai, Jushan; Perron, Pierre, "Critical Values for Multiple Structural Change Tests," Econometrics Journal, 6:1, 2003b, pp. 72-78.

Baruch, Shmuel; Saar, Gideon. "Asset Returns and the Listing Choice of Firms," Review of Financial Studies, forthcoming.

Baxter, Marianne; Crucini, Mario J. "Business Cycles and the Asset Structure of Foreign Trade," International Economic Review, 36:4, November 1995, pp. 821-54.

Bekaert, Geert; Harvey, Campbell R; "Time-Varying World Market Integration," Journal of Finance, 50:2, June 1995, pp. 403-44.

Bekaert, Geert; Harvey, Campbell R, "Emerging Equity Market Volatility," Journal of Financial Economics, 43:1, January 1997, pp. 29-77.

Bekaert, Geert; Harvey, Campbell R, "Foreign Speculators and Emerging Equity Markets," Journal of Finance, 55:2, April 2000, pp. 565-613.

Bekaert, Geert; Harvey, Campbell R; Lumsdaine, Robin L., "Dating the Integration of World Equity Markets," Journal of Financial Economics, 65:2, August 2002, pp. 203-47.

Bekaert, Geert; Hodrick, Robert J., "Characterizing Predictable Components in Excess Returns on Equity and Foreign Exchange Markets," Journal of Finance, 47:2, June 1992, pp. 467-509.

Bekaert, G; Hodrick, R., and Zhang, L., "International Stock Return Comovements," NBER Working Paper \#311906, December 2005. 
Bonser-Neal, Catherine; Brauer, Greggory; Neal, Robert; Wheatley, Simon;

"International Investment Restrictions and Closed-End Country Fund Prices," Journal of Finance, 45:2, June 1990, pp. 523-47.

Brooks, Robin; Del Negro, Marco. "Country versus Region Effects in International Stock Returns.” Journal of Portfolio Management, 2005, 31:4, pp. 67-72.

Campbell, John Y; Lo, Andrew W; MacKinlay, A Craig. The econometrics of financial markets, Princeton: Princeton University Press, 1997.

Carrieri, Francesca; Errunza, Vihang; Sarkissian, Sergei. "The Dynamics of Geographic versus Sectoral Diversification: Is there a Link to the Real Economy?" Weiss Center Working Paper \#06-04, March 2006.

Chari, Anusha; Henry, Peter Blair. "Risk Sharing and Asset Prices: Evidence from a Natural Experiment," Journal of Finance, 59:3, June 2004, pp. 1295-1324.

Cole, Harold L; Obstfeld, Maurice. "Commodity Trade and International Risk Sharing: How Much Do Financial Markets Matter?” Journal of Monetary Economics, 28:1, August 1991, pp. 3-24.

Doidge, Craig; Karolyi, G. Andrew; Stulz, Rene' M. "Why Are Foreign Firms Listed In the U.S. Worth More?" Journal of Financial Economics, 2004, 71:2, pp.205-238.

Doidge, Craig; Karolyi, G. Andrew; Stulz, Rene' M. "The Valuation Premium for NonUS Stocks Listed in U.S. Markets,” NYSE Working Paper \#05-01, September 2005.

Dumas, Bernard; Solnik, Bruno, “The World Price of Foreign Exchange Risk," Journal of Finance, 50:2, June 1995, pp. 445-79.

Errunza, Vihung; K. Hogan and M.W. Hung, "Can the Gains from International Diversification be Achieved Without Trading Abroad?" Journal of Finance, 1999, 54, pp. 2075-2107.

Ferson, Wayne E; Harvey, Campbell R. "The Risk and Predictability of International Equity Returns," Review of Financial Studies, 6:3, 1993, pp. 527-66.

Foerster, Stephen; and G. Andrew Karolyi; "The Effects of Market Segmentation and Investor Recognition on Asset Prices: Evidence from Foreign Stocks Listing in the U.S.," Journal of Finance 54, 1999, pp. 981-1014.

French, Kenneth R; Poterba, James M. "Investor Diversification and International Equity Markets," American Economic Review, 81:2, May 1991, pp. 222-26. 
Gehrig, Thomas, "An Information Based Explanation of the Domestic Bias in International Equity Investment," Scandinavian Journal of Economics, 95:1, 1993, pp. 97-109.

Henry, Peter Blair; "Stock Market Liberalization, Economic Reform, and Emerging Market Equity Prices," Journal of Finance, 55:2, April 2000, pp. 529-64.

Henry, Peter Blair, "Capital-Account Liberalization, the Cost of Capital, and Economic Growth," American Economic Review, 93:2, May 2003, pp. 91-96.

Karolyi, G Andrew, "The World of Cross-Listings and Cross-Listings of the World: Challenging Conventional Wisdom," Review of Finance, 10:1, 2006, pp. 99-152.

Lewis, Karen K. "Trying to Explain Home Bias in Equities and Consumption," Journal of Economic Literature, June 1999, 37:2, pp. 571-608.

Lewis, Karen K.; Gangadhar Darbha, "International Equity Cross-Listings and Financial Integration," Wharton School Working Paper, 2004.

Obstfeld, Maurice, "Risk-Taking, Global Diversification, and Growth," American Economic Review, 84:5, December 1994, pp. 1310-29.

Pastor, Lubos, "Portfolio Selection and Asset Pricing Models," Journal of Finance, 55:1, February 2000, pp. 179-223.

Pesenti, Paolo; van Wincoop, Eric. "Can Nontradables Generate Substantial Home Bias?” Journal of Money, Credit, and Banking, 34:1, February 2002, pp. 25-50.

Stock, James H. "Unit Roots, Structural Breaks and Trends," Handbook of econometrics 4, 1994, pp. 2739-2841.

Stockman, Alan C; Tesar, Linda L. "Tastes and Technology in a Two-Country Model of the Business Cycle: Explaining International Comovements," American Economic Review, 85:1, March 1995, pp. 168-85.

Tesar, Linda L; Werner, Ingrid M, "Home Bias and High Turnover," Journal of International Money and Finance, 14:4, August 1995, pp. 467-92.

Vassalou, Maria, "Exchange Rate and Foreign Inflation Risk Premiums in Global Equity Returns," Journal of International Money and Finance, 19:3, June 2000, pp. 433-70.

White, Halbert, "Heteroskedasticity-Consistent Covariance Matrix Estimator and a Direct Test for Heteroskedasticity," Econometrica, 48:4, May 1980, pp. 817-38. 